\title{
DER SCHWEIZERISCHE MITTELSCHULATLAS
}

\author{
Von EdUARD IMHOF
}

Mit 6 Abbildungen, 7 Figuren und 4 mehrfarbigen Karten

\section{Einleitung}

Im Sommer 1898 beschloß die kurz zuvor gegründete Konferenz der kantonalen Erziehungsdirektorèn die Herausgabe eines schweizerischen Atlasses für Mittelschulen. Zwölf Jahre später lag das Werk vor. Seither erfuhr es wiederholte Umarbeiturgen. Im Sommer 1948, also 50 Jahre nach seiner Gründung, erschien der Atlas als Jubiläumsausgabe in erweiterter und stark erneuerter Form.

Der Mittelschulatlas ist ein schweizerisches Gemeinschaftswerk. Sämtliche Kantone und vor allem der Bund unterstützten das Unternehmen wiederholt durch kräftige finanzielle Beiträge. Dank solcher Hilfe war es möglich, den Atlas in der vorliegenden Reichhaltigkeit und in je einer deutschen, französischen und italienischen Ausgabe herauszubringen und den Verkaufspreis in erträglichen Grenzen zu halten. Durch die Ausgaben in den drei Hauptlandessprachen kommt der nationale Charakter des Unternehmens deutlich zum Ausdruck. Die schweizerische Haltung zeigt sich auch im Inhaltsplan und in der Art oder Form mancher Karten. Im Laufe der Entwicklung hat eine Reihe bekannter Pädagogen, Geographen und Kartographen aus allen Teilen der Schweiz ihr Bestes gegeben, um das Werk zu fördern.

Der Atlas bildet seit Jahrzehnten eine unentbehrliche Grundlage für den Geographieunterricht an unsern Mittelschulen. Er ist in seinen Wandlungen ein Spiegel der Entwicklungen dieses Unterrichtes, aber auch der wissenschaftlichen Fortschritte und politischer, wirtschaftlicher und anderer Veränderungen auf der Erdoberfläche.

Die Bedeutung des Atlasses reicht über diejenige eines Lehrmittels hinaus. Wie es schon seine Gründer gewünscht hatten, ist er zu einem Volksbuche geworden. Bis heute haben über 170000 Exemplare die Druckerpresse verlassen. Viele seiner Karten fanden überdies Aufnahme in Volks- und Sekundarschulatlanten. Dank seinen schweizerischen Spezialkarten ${ }^{1}$ ist der Mittelschulatlas ein Vorläufer eines geographischen Nationalatlasses unseres Landes، Grund und Boden, Klima, Wirtschaft, Bevölkerungsstruktur usw. finden sich darin leicht vergleichbar zusammengestellt. Viele dieser und seiner übrigen Darstellungen sind inhaltlich neue, erstmalige Originalkartierungen. Der Atlas dient somit nicht nur der Schule, sondern darüber hinaus der Allgemeinheit und insbesondere auch der Wissenschaft.

Ein Werk von der Art des Mittelschulatlasses interessiert überdies von kartographischen Gesichtspunkten aus. Die Mannigfaltigkeit der Gebiete, Inhalte und Maßstäbe stellt dem Kartographen die verschiedenartigsten Aufgaben. Schulatlanten zeigen

1 Wir verstehen unter Spezialkarten solche mit einem speziellen Inhalt, wie Geologie, Klima, Vegetation, Wirtschaft, Volksdichte, Sprachen, Religionen usw., also Karten, die in der deutschen Fachliteratur meist als Sonderkarten oder als angewandte Karten bezeichnet werden. Bisher wurde in Deutschland der Ausdruck Spezialkarte für eine allgemeine Karte großen Maßstabes, also für eine Detailkarte, verwendet. Diese irreführende Verwendung des Ausdruckes Spezialkarte fand sich auch in den Erläuterungstexten der frühexen Ausgaben des Schweizerischen Mittelschulatlasses.

Mit Recht lehnt HetrNer (Lit. Nr. 16) die Bezeichnung "angewandte Karte» als unrichtig ab. Er bedient sich der allzu umständlichen Benennung "physiogeographische und anthropogeographische Karten", gibt aber zu, daß auch jede gewöhnliche Karte physiogeographisch und anthropogeographisch sei. - 
nicht nur die Entwicklung der Schulkartographie, sondern weitgehend diejenige der Kartographie überhaupt; denn zeichnerisch und technisch bestehen zwischen Schulkarten und andern Karten keine grundsätzlichen Unterschiede, sondern höchstens solche ihres Generalisierungsgrades.

Zwanzigjährige Betreuung des Mittelschulatlasses wurde für mich zu einer Quelle kartographischer Erkenntnisse und Erfahrungen. Einige derselben sollen im folgenden festgehalten und den Benützern des Werkes wie auch Karten- oder Atlasbearbeitern vermittelt werden. Nicht zuletzt möchte ich damit einer späteren Weiterentwicklung des Werkes dienen.

Drei von meinen Mitarbeitern an der jüngsten Atlasumformung, die Herren Dr. M. Schüepp, Prof. Dr. E. Schmid und Dr. J. Höslr, kommen anschließend mit eigenen Aufsätzen zum Wort. Es sei ihnen für diese Bereicherung der vorliegenden Atlasmonographie bestens gedankt. In diesen Dank sei auch Herr Prof. G. Frei eingeschlossen, der die Reihe der Aufsätze mit einer Darlegung der administrativen und finanziellen Entwicklung des Atlasunternehmens abschließt. Sein Beitrag erlaubt es mir, meine geschichtlichen Notizen im wesentlichen auf methodische und kartentechnische Dinge zu beschränken. Der Atlasdelegation der Konferenz der kantonalen Erziehungsdirektoren und voran ihrem derzeitigen Präsidenten, Herrn Regierungsrat Dr. R. BRINER in Zürich, sei bestens gedankt für die finanzielle Unterstützung der vorliegenden Veröffentlichung. - Unser Dank gebührt auch der Direktion des Art. Institut Orell Füßli in Zürich, die durch großes Entgegenkommen die Ausstattung des vorliegenden Heftes mit Kartenbeispielen ermöglichte. Nicht zuletzt sei den Herren Prof. Dr. H. Gutersohn und R. BArThel, dem Chef der kartographischen Abteilung des Art. Institut Orell Füßli, gedankt für ihre, der vorliegenden Publikation geliehene Unterstützung. 


\section{TEIL: INHALTLICHE ENTWICKLUNG}

\section{A. VORLÄUFER}

Die Schulkartographie reicht in ihren Anfängen weit über ein Jahrhundert zurück. Im Jahre 1814 gab Justus Perthes' Ge og raphische Anstalt zu Gotha eine gekürzte Schülerausgabe von StiELERs Handatlas heraus. Dieser wohl älteste Schulatlas erfuhr in wenigen Jahrzehnten zahlreiche Neuauflagen. Er enthielt rund 30 kleine in Kupfer gestochene Karten mit handkolorierten politischen Grenzbändern und ist ein Zeuge der außerordentlich gepflegten Graphik jener Zeit. Wir erwähnen ihn hier, weil er der geistige Vater des ältesten in der Schweiz erstellten Schulatlasses war. Das Land Pestalozzis wollte, im Bestreben, vereinfachte Karten für den Unterricht bereitzustellen, nicht zurückstehen. Der geschäftstüchtige Zürcher Kartograph HeINRICH Keller publizierte neben Schulkarten verschiedener Gebiete 1843 einen «Schulatlas über die ganze Erde». Seine 20 Blätter zeichnen sich durch Klarheit und Einfachheit aus. Inhaltsplan und graphische Form verraten jedoch unverkennbar das deutsche Vorbild. Statt der Verkleinerungsverhältnisse (wie z. B. 1 : 4000000) finden wir auf den Blättern Meßstäbchen für geographische und englische Meilen und Reise- oder Wegstunden. Die Schweiz gelangt in keiner eigenen Karte zur Darstellung, sondern ist zusammen mit Süddeutschland nur etwa im Maßstab $1: 4000000$ wiedergegeben. Die Gebirge sind in primitiver Form durch raupenartige Schraffenreihen dargestellt. Das Innere von Afrika und Australien erscheint nahezu leer.

Kellers Atlas erreichte keine lange Lebensdauer. Er hielt nicht Schritt mit den methodischen Entwicklungen, die über das nur Topographische hinaus einer naturwissenschaftlichen Vertiefung der geographischen Betrachtung zustrebten. Bald erwuchsen ihm im Ausland verschiedene Konkurrenten. Unter diesen stand an erster Stelle wiederum ein Werk von Justus Perthes, der 1848 erschienene deutsche Schulatlas von EMII voN SYDOw. Er brachte die physischen Elemente gegenüber den politischen zu stärkerer Geltung, wurde in Hunderttausenden von Exemplaren verbreitet und fand auch Eingang in schweizerische Schulen.

Kurz zuvor, im Jahre 1842, hatte der weitsichtige Geograph und Mathematiker Dr. JAKoB MELCHIOR ZIEGLeR (1801-1883) zusammen mit dem Lithographen JoHANN UlRICH WURSTER (1814-1880) die Lithographische Anstalt Wurster \& Cie. in Winterthur gegründet. Ziegler stand in freundschaftlichem Gedankenaustausch mit Karl Ritter, Alexander von Humboldt und A. Petermann. Bald nach der Gründung der Anstalt erwiesen sich zwei ihrer Lehrlinge und Mitarbeiter, JoHANNES RANDEGGER (1830-1900) und RUDOLF LEUZINGER (1830-1896), als außerordentlich begabte, schöpferische Kartographen. So errang sich die Kartographie in Winterthur bald internationales Ansehen. Es war gegeben, dort auch die Schulkartographie zu pflegen, dies um so eher, als Ziegler einst Lehrer gewesen war. Im Jahre 1851 erschien als erstes Schulkartenwerk der Winterthurer Anstalt ZrEgLens «A tlas über alle Teile der Erde» in 24 Blättern. Unter der Kartenproduktion der folgenden Zeit befanden sich mehrere Schulkarten, so auch eine Wandkarte der Schweiz $1: 200000$ aus dem Jahre 1858. Der oben genannte Atlas wurde 1857 in einer auf 29 Blätter erweiterten zweiten Auflage herausgegeben, konnte sich dann aber nicht mehr halten. Resigniert, doch nicht entmutigt, schrieb Ziegler:

«Der Konkurrenz vermag man weder Halt noch Rücksichten zuzumuten, weil sie sich steigern kann, gleich dem Selbsterhaltungstrieb eines Verzweifelten. Deshalb, wer sich selbst nicht zu beherrschen weiß, wer in Anstrengung nachläßt, im Fortschritte innehält und wäre er ein Simson, dem schneidet Delilah die Haare ab und überliefert ihn den Philistern.» (Lit. Nr. 6.) 
Es war das Verdienst der Erziehungsdirektion des Kantons Zürich, als erste Behörde in unserem Lande sich um die Schaffung eines schweizerischen Schulatlasses bemüht $z u$ haben. Durch die Übernahme des Verlages ermöglichte sie de Erstellung eines neuen, den methodischen Entwicklungen angepaßten Kartenwerkes. Ein erfahrener Pädagoge, der weit herum geschätzte Küsnachter Seminardirektor H. WETTSTEIN, besorgte die Inhaltsplanung, die Winterthurer Anstalt unter der Leitung von J. RANDEGGER die zeichnerische und reproduktionstechnische Ausführung. Der neue Atlas erschien erstmals im Jahre 1872, wurde als obligatorisches Lehrmittel in der Oberstufe der zürcherischen Volksschule eingeführt und fand auch Eingang in viele kantonale und außerkantonale Sekundar- und Mittelschulen. Er bedeutete für den Geographieunterricht in der Schweiz eine methodische Neuheit. WETTSTEIN schrieb in der Einleitung zu seinem Werke:

"Jeder naturkundliche Unterricht, also auch der geographische (die Geographie galt damals als ein Zweig der Naturwissenschaften), hat von der Anschauung auszugehen. Nun ist das Objekt der Geographie die ganze Erde, ja, in weiterem Sinn das ganze Universum, und der direkten Beobachtung steht nur ein minimaler Teil des ganzen Materials zur Verfügung. Es muß sich daher beim geographischen Unterricht namentlich darum handeln, diesen unmittelbar zugänglichen Stoff von beschränktem Umfang so zu benützen, daß im Kopf des Lernenden richtige Vorstellungen von dem sich bilden, was er nicht selbst gesehen hat. Daraus folgt als Grundgesetz der Methode: Der geographische Unterricht muß vergleichend sein. - Nur dann, wenn der Schüler das Fremde als Modifikation der heimischen Natur aufzufassen vermag, wenn ihm die Übergangsstufen klar werden, die das scheinbar absolut Gegensätzliche vermitteln, nur dann verschwinden die falschen, weil übertriebenen Vorstellungen von tropischer Glut und polarer Kälte, von steriler Wüste und üppigem Reichtum, von Lebensfülle und Öde, von Barbarei und Zivilisation u. dgl. - Hieraus ergibt sich folgender Gang des Unterrichts: Man beginnt mit dem unmittelbar Zugänglichen, mit dem Wohnort, geht dann über zu einem schwieriger zu überblickenden und schwerer zugänglichen Ganzen, sei es ein geographisch begrenztes Gebiet, ein Tal, eine Bergkette u. dgl., oder ein politisch abgesonderter Landesteil, ein Bezirk. Dann betrachtet man den Kanton, hierauf die Schweiz, den Erdteil Europa, die übrigen Erdteile und schließt mit der mathematischen und physikalischen Geographie. - Wollte man nun aber diesen Unterrichtsstoff auf die verschiedenen Schuljahre verteilen, in der Art, daß im ersten derselben, in welchem überhaupt die realistischen Fächer begonnen werden, mit dem ersten Abschnitt angefangen und im letzten mit dem letzten aufgehört würde, so beginge man einen schweren Fehler. Man beginnt den geographischen Unterricht mit dem 4. Schuljahr (dem 10. Altersjahr). Da ist aber der Schüler noch viel zu jung und zu arm an geistiger Kraft, an Kenntnissen und an Lebenserfahrung, als daß man auch nur das beschränkteste geographische Gebiet eingehend, gründlich, nach allen Beziehungen ihm zum Verständnis bringen könnte. Anderseits aber ist auch kein nur annähernd richtiges Verständnis der beschränktesten Gegend denkbar, wenn nicht das Ganze, das nach allen Richtungen das einzelne bedingt und beeinflußt, wenigstens in seinen Hauptlinien zum geistigen Eigentum geworden ist. Daraus ergibt sich die Notwendigkeit, den geographischen Unterricht nach Stufen einzuteilen und auf jeder Stufe das gesamte Gebiet der Betrachtung zu unterziehen, aber in einer Art, wie sie dem betreffenden Alter angemessen ist.»

Mit diesen Worten wies WerrsteIN dem Geographieunterricht in der Schweiz neue Wege. Sein Atlas enthielt neben allgemeinen Úbersichtskarten zwei neuartige Blätter zur Einführung in Kartenlehre und Heimatkunde, mehrere Spezialkarten der Schweiz und einige kleine Detailkarten. Die Anzahl der Karten und für die meisten derselben auch die Form ließen jedoch $: z u$ wünscheñ übrig. Spätere Auflagen wurden verbessert und durch Übersichtskarten europäischer Länder und Spezialkarten der Erde bereichert. 
Doch blieb vielen Karten eine gewisse Ausdruckslosigkeit, und es blieb die ungeschickte Karten-Reihenfolge, die mit Erdübersichten einsetzte und mit Erd- und Himmelskarten endigte. Die Umformungen waren zu wenig durchgreifend, um mit. ausländischen Entwicklungen Schritt halten zu können.

Im Ausland kam seit den achtziger und neunziger Jahren eine wahre Flut neuer Schulatlanten heraus. Es ist nicht möglich, sie alle zu nennen oder gar zu charakterisieren. Die Karten mancher dieser Atlanten zeichneten sich durch Inhaltsbeschränkung, durch kräftige Zeichnung und reichere Farben aus. Vor allem in Deutschland entwikkelte sich ein eigentlicher Schulkartentypus, und es trat eine Scheidung in Unter-und Oberstufenatlanten ein. Zu den letzteren zählte der schon genannte, von Justus Perthes herausgegebene und ständig weiterentwickelte "Methodische Schulatlas von SyDOw-WAGNER». Er war jedoch, im Gegensatz zu seinem Titel, eher ein kleiner Handatlas; denn er enthielt vorwiegend fein gezeichnete, inhaltsreiche Länderkarten. Als Oberstufenatlas wurde er überflügelt durch den 1883 erstmals erschienenen Schulatlas für höhere Lehranstalten von Diercke und GaEbler. Dieses Lehrmittel erlangte bald auch für schweizerische Mittelschulen große Bedeutung. Es sei daher im folgenden etwas näher betrachtet.

Methodischer Bearbeiter war Seminardirektor und Schulrat C. Diercke (1842 bis 1913) in Stade und Osnabrück. Kartenzeichnung und Druckplattenerstellung erfolgten durch E. Gaebler in Leipzig und G. Westermanns Offizin in Braunschweig. Diese besorgte auch den Druck und übernahm die Herausgabe. Der Atlas zeichnete sich aus durch außerordentlichen Reichtum an Karten, durch deren geschickte Auswahl und durch einfache, markante Darstellung. Er enthielt große, klare Übersichtskarten der europäischen Länder, der Erdteile und der Erde, ferner zahlreiche Nebenkarten. Im Laufe der Jahre stieg die Anzahl der Detailkarten auf 160, diejenige der Spezialkarten auf 100. Die letzteren brachten mehr als bisherige Schulatlanten neben den physiogeographischen auch anthropogeographische Elemente zur Geltung. Topographische und physische Geographie allein genügten nicht mehr. Die Länderkunde und damit eine vergleichende Betrachtung natur- und kulturgeographischer Erscheinungen wurden zum Hauptziel des Geographieunterrichts. An Fülle und Vielseitigkeit des Inhalts übertraf der "Diercke» auch seine beiden bedeutendsten Rivalen, den "SydowWagner» und den jüngeren und formschönen "Atlas für Mittel- und Oberklassen höherer Lehranstalten" von R. LehManN und W. Petzold (hergestellt und herausgegeben durch die Geographische Anstalt von Velhagen und Klasing in Leipzig, erste Auflage 1897).

Im "Diercke» nahm aus verständlichen Gründen die Landeskunde von Deutschland einen breiten Raum ein, während diejenige der Schweiz zu kurz kommen mußte. Trotz dieses Mangels vermochte er den Wettsteinatlas als Lehrmittel für unsere Mittelschulen zu verdrängen. Der letztere wurde 1895 in fünfter Auflage zum letztenmal herausgegeben. Seinen 31 veralteten Blättern stand die im selben Jahre erschienene, auf 148 Seiten erweiterte 31. Ausgabe des deutschen Atlasses gegenüber. Eine genügende Erneuerung und Erweiterung des Winterthurer Erzeugnisses aber war auf privatwirtschaftlicher Basis nicht mehr möglich; denn hiezu erwies sich sein Absatzgebiet als zu klein. So wurde auch der dritte schweizerische Schulatlas schließlich ein Opfer ausländischer Konkurrenz. Der Diercke-Atlas fand trotz seines betont reichsdeutschen Gehaltes in der Zeit von etwa 1890 bis 1910 allgemeinen Eingang in die Mittelschulen der deutschsprachigen Schweiz.

Noch schlimmer stand es in der West- und Südschweiz. Die französischen und italienischen Schulatlanten waren, ähnlich wie der Sydow-Wagner-Atlas, kleine Handatlanten mit einer Fülle allgemeiner Länderkarten und einer Überfülle von Ortsnamen. Die Geographie unseres Landes fand darin so gut wie keine Berücksichtigung. Für die Schulen der französischsprechenden Schweiz standen freilich die Lehrbücher von 
W. Rosier zur Verfügung. Diese enthielten wohl einige Karten und Kartenskizzen, konnten aber einen Atlas nicht ersetzen.

Unsere geschichtliche Skizze wäre unvollständig, wenn nicht auch ein bemerkenswerter vierter schweizerischer Schulatlas erwähnt würde. Die Topographische Anstalt Wurster, Randegger \& Co. ging 1890 in die Hände des Lithographen Jаков SснцUмpғ über. Die neue Geschäftsleitung ließ sich durch die schlechten Erfahrungen mit dem Wettsteinatlas nicht entmutigen. In den neunziger Jahren, noch vor der Gründung des Mittelschulatlasses, trat sie an die Erstellung neuer Unter- und Oberstufenatlanten heran. Diese kamen 1902 und 1903 heraus. Hier interessiert uns vor allem die Ausgabe für die Oberstufe, der "Schweizerische Schulatlas zum Gebrauch an Gymnasien, Sekundar-, Real- und Bezirksschulen, unter Mitwirkung von Dr.W. Götzinger, Prof. am kantonalen Technikum in Winterthur, bearbeitet von J. Schlumpf. Bezug beim Kantonalen Lehrmittelverlag in Zürich.» Das 72seitige Kartenwerk sollte den Wettsteinatlas ersetzen. Es stellte diesen kartentechnisch in den Schatten. Seine Länder- und Erdteilkarten besaßen beachtenswerte Ausdruckskraft. Als Oberstufen- bzw. Mittelschulatlas aber war er zu inhaltsarm, so daß es auch ihm nicht gelang, die fetteren ausländischen Konkurrenzprodukte zu verdrängen. Er erwies sich jedoch als vorzüglicher Sekundarschulatlas und leistete während der ersten zwei Jahrzehnte unseres Jahrhunderts vielen schweizerischen Schulen gute Dienste. Er verschwand erst mit dem Auftreten reicher ausgestatteter, durch Staatsbeiträge verbilligter Sekundarschulatlanten.

\section{B. DIE ERSTE AUSGABE DES MITTELSCHULATLASSES}

Im Jahre 1898 ergriff ein Geographielehrer der Zürcher Kantonsschule, Prof. Dr. August Aeppli (1859-1938), die Initiative zur Beseitigung des unerfreulichen Zustandes. Eine Lösung war nur mit Hilfe öffentlicher Mittel möglich. Es schwebte ihm eine Herausgabe eines Unter- und eines Oberstufenatlasses auf interkantonaler Grundlage vor. In diesem Sinne richtete er eine Eingabe an die Erziehungsdirektion des Kantons Zürich. Diese brachte die Angelegenheit vor die kurz zuvor ins Leben gerufene Konferenz der kantonalen Erziehungsdirektoren. Ein gesamtschweizerischer Unterstufenatlas fand dort infolge der Ablehnung durch die welschen Kantone keine Gnade. Hingegen beschloß die Konferenz die Erstellung eines reich ausgestatteten Mittelschulatlasses, der in den drei Hauptlandessprachen herausgegeben und dessen Verkaufspreis durch Zuwendungen der Kantone möglichst niedrig gehalten werden sollte. In der Folge benötigte das Unternehmen wiederholt auch sehr beträchtliche Bundesbeiträge. Die inhaltliche Planung wurde einer Redaktionskommission, die kartographische Ausführung, auf Grund eines Ausschreibens, der «Kartographia Winterthur» (ehemals Topographische Anstalt Wurster, Randegger \& Co. bzw. J. Schlumpf) übertragen.

In methodisch-geographischer Hinsicht lag die Erstellung des Atlasses in ausgezeichneten Händen. Der Redaktionskommission gehörten an Regierungsrat Dr. A. Gobat (Bern) als Präsident, Staatsschreiber Dr. A. Huber (Zürich) als Sekretär und Prof. Dr. A. Arppli als Redaktor, die Geographen Prof. Dr. E. Brǘckner (Bern) und, nach dessen Berufung nach Halle (1905), Prof. Dr. H. Walser, ferner Prof. C. Knapp (Neuenburg) und Prof. Dr. W. Rosrer (Genf), die Topographen Prof. F. Becker (Eidgenössische Technische Hochschule Zürich) und L. Held (Direktor der Eidgenössischen Landestopographie) und die Pädagogen und Seminardirektoren Dr. F. Guex (Lausanne) und Dr. E. Zollinger (Küsnacht-Zürich). Für Spezialaufgaben wurden überdies beigezogen: Ingenieur-Topograph S. SrMONETT (Bern), Seminarlehrer Dr. H. Frey (Küsnacht), Prof. Dr. C. Brandenberger (Kantonsschule Zürich) und Prof. Dr. U. SEILER (Kantonsschule Zürich). 
Umfang und Inhaltsplan lehnten sich an den «Diercke» an. Ähnlich war auch das Format. Den 148 (oder infolge von zwei Auslegeblättern eigentlich 150) Seiten des reichsdeutschen. Vorbildes entsprachen im etwas sparsameren Schweizer Atlas deren 136. Die ersten Blätter beider Atlanten enthielten in ähnlichem Sinne Darstellungen zur Einführung in die Kartenlehre. Wie im "Diercke» bestand der Grundstock des Schweizer Atlasses aus physischen und politischen Übersichtskarten der europäischen Länder, der Erdteile und der Erde. Die ersteren zeigten vor allem Bodengestalt und Gewässer, die letzteren die staatliche Gliederung, das Verkehrsnetz und eine erweiterte Auswahl von Orten. Wo es Gebiete und Maßstäbe erlaubten, wurde beides vereinigt. Um solche Hauptkarten rankten sich in reicher Fülle Spezial- und Detailkarten. Manche derselben entsprachen in Gebieten, Themen und Maßstäben, nicht aber in ihren Formen und inhaltlichen Einzelheiten, den Karten des Diercke-Atlasses.

Der schweizerische Atlas wies gegenüber dem «Diercke» aber auch stark abweichende Züge, Verbesserungen und Neuerungen auf. Seine Kartenreihenfolge war zweckmäßiger. Das Entwickeln geographischer Vorstellungen aus dem Nahen, Sichtbaren, aus der heimatlichen Umwelt, und das schrittweise Vordringen in stets fernere, größere Räume, wie es WeTtSTEIN und andere Pädagogen schon längst empfohlen hatten, gelangte in seinem Inhaltsplan erstmals zum Durchbruch. Der Einführung in die Kartenlehre folgte eine gut aufgebaute, reich ausgestattete Gruppe von Karten zur schweizerischen Landeskunde. - Eine an Schulatlanten gestellte Anforderung ist die leichte Vergleichbarkeit der Dimensionen verschiedener Gebiete, d. $h$. eine möglichste Einheitlichkeit oder Vergleichbarkeit der Maßstäbe. Dies bezieht sich nicht auf alle Karten, wohl aber auf solche ähnlicher Gattung. Die Übersichtskarten fremder Erdteile sollen unter sich denselben Maßstab besitzen, ebenso diejenigen der für uns wichtigsten europäischen Länder und, soweit als möglich, die Städtekarten usw. Diesen Anforderungen entsprachen sowohl der «Diercke» wie auch der Schweizerische Mittelschulatlas. Während aber jener die europäischen Länder in $1: 4500000$ und Europa in 1:20000000 abbildete, gelangten in letzterem die Maßstäbe 1:4000000 bzw. $1: 15000000$ zur Anwendung. Solche Vergrößerungen bedeuteten für das schweizerische Kartenwerk einen erfreulichen Gewinn. Europa im besonderen erhielt auf diese Weise denselben Maßstab wie die großen Teilgebietskarten der fremden Erdteile, was im «Diercke» nur ausnahmsweise der Fall war. - Auch die Kartenprojektionen wurden im schweizerischen Atlas da und dort zweckmäßiger gewählt. Im «Diercke» waren die Karten von Asien in Bonnescher Projektion dargestellt, im Mittelschulatlas hingegen in ebenfalls flächentreuer Azimutalprojektion. Im Jahre 1890 hatte der österreichische Kartograph Karl Peucker (Lit. Nr. 30) auf die bessere Eignung der letzteren hingewiesen, da sie für das dargestellte Gebiet kaum stärkere Verzerrungen aufweist, jedoch die charakteristische Krümmung der asiatischen Nordküste um das Nördliche Eismeer besser zum Ausdruck bringt. - Viele Schulatlanten, selbst solche unserer Zeit, stellen Erdübersichten der politischen Gliederung, der Völker, Religionen, Volksdichte usw. in der Merkatorprojektion dar, obschon dies in der kartographischen Literatur schon oft beanstandet worden ist. Grönland ist in Wirklichkeit etwa so groß wie Arabien, erscheint aber in der Merkatorkarte beinahe flächengleich wie Afrika. Die Wahl der Merkatorprojektion führt beim Schüler zur Vorstellung stark übertriebener Dimensionen von Kanada, Skandinavien und Sibirien. Der Schweizerische Mittelschulatlas vermied diese Ungeschicklichkeit und bildete die Karten der erwähnten Inhalte flächentreu ab.

Trotz seiner größeren Seitenzahl vereinigte der «Diercke» da und dort zwei verschiedenartige Inhalte in ein und derselben Karte, so z. B. Niederschläge und Vegetation oder gar, was ja heute in gewissem Sinne sehr zeitgemäß wäre, Temperaturen und Völker! Solch verwirrendes Übereinanderlagern wurde im Schweizer Atlas vermieden. Für Europa und Deutschland gab der «Diercke» nur die wenig charakteristischen 
Jahres-Isothermen, während im schweizerischen Atlas die notwendige Trennung in Januar- und Juli-Isothermen vorgenommen wurde.

Wie die Gesamtplanung, so erfolgte auch die Inhaltsbearbeitung der einzelnen Karten mit aller Sorgfalt. AEPpli und seine Mitarbeiter scheuten keine Mühe, die neusten geographischen und kartographischen Quellen ausfindig zu machen und der Winterthurer Anstalt zur Verfügung zu stellen.

Für die allgemeinen Länder- und Erdteilkarten, -Einzelgebietskarten, Städtekarten usw. dienten als Grundlagen die Handatlanten von Streler, von Sohr-Berghaus, von ANDree und von Debes, ferner die amtlichen Kartenwerke der betreffenden Staaten. Das Geländeschraffenbild der doppelseitigen Karten der Schweiz war ein von der Eidgenössischen Landestopographie zur Verfügung gestellter Umdruck der amtlichen Ubersichtskarte der Schweiz 1:1000000.

Der Inhalt der Spezialkarten wurde folgenden Werken entnommen: Berghaus: Physikalischer Atlas; Bartholomew: Meteorological Atlas; Scobel: Handelsatlas; Lehmann und Petzold: Schulatlas; Sydow-Wagner: Schulatlas; Hann: Lehrbuch der Meteorologie; Supan: Bevölkerung der Erde; Sievers: Europa und Allgemeine Länderkunde; Internationale geologische Karte von Europa; Hellmann: Regenkarte von Deutschland; Angot: Regenkarte von Westeuropa; Köppens Karte der Klimatypen. Für unser Land im besonderen bildeten die Karten des damals im Erscheinen begriffenen Geographischen Lexikons der Schweiz willkommene Grundlagen.

Die Figuren und Abbildungen der Himmelskunde entstammten fast unverändert folgenden Quellen: Lehmann und Petzold: Schulatlas; Sydow-Wagner: Schulatlas; Nasmith und Carpenter: Der Mond; Newcomb's Astronomie für jedermann; Meyers Konversationslexikon.

Die klimatologischen Karten der Schweiz wurden nach unveröffentlichtem Material der Eidgenössischen Meteorologischen Zentralanstalt in Zürich und die Verkehrskarte von Europa nach Angaben des offiziellen Verkehrsbüros Zürich zusammengestellt. Sie waren somit erstmalig publizierte Originalkartierungen. Für die übrigen Spezialkarten beschränkte sich die Bearbeitung auf eire vereinfachende Umformung nach den genannten Quellen.

Die einleitenden Erläuterungen des Atlasses entbielten u. a. eine willkommene Zusammenstellung der wichtigsten Auss pracheregeln für fremdsprachige Namen. Sie entstammte zur Hauptsache dem Handbuch der Geographie von SEYDLITz, Jubiläumsausgabe 1908, und wurde mit wenigen Änderungen auch in den späteren Atlasausgaben beibehalten. -

Es würde zu weit führen, all den unzähligen Veränderungen des Weltbildes nachzuspüren, wie sie in den Schulatlanten der verschiedenen Epochen zum Ausdruck kamen. Wir beschränken uns auf die folgenden Hinweise:

Der älteste schweizerische Schulatlas, derjenige von HeINRICH KELLER aus dem Jahre 1843, zeigte in der Schweiz nur 6 Städte mit über 10000 Einwohnern (Genf, Lausanne, Bern, Basel, Zürich, St. Gallen). Das europäische Eisenbahnnetz bestand aus einigen unzusammenhängenden Anfangsstücken. Abgesehen von der Verbindung Mülhausen-Basel, bestand in unserem Lande kein Schienenstrang. - Die erste, 1910 fertiggestellte Ausgabe des Mittelschulatlasses gibt bereits 11 schweizerische Städte mit über 10000 Einwohnern. Unter diesen waren Lausanne und Bern auf über 50000 , Genf, Basel und Zürich auf über 100000 Einwohner angewachsen. Heute registrieren wir in unserem Lande 24 Orte mit über 10000, 4 Orte mit über 50000 und 4 Orte mit über 100000 Einwohnern. Das Bahnnetz hatte, abgesehen von einigen wenigen später gebauten Strecken, schon 1910 die heutige Ausdehnung erreicht.

Aus einer Zusammenstellung der politischen Karten aller Ausgaben schweizerischer und ausländischer Schulatlanten ergibt sich ein bewegtes Bild des Werdens und Vergehens von Staaten während der letzten hundert Jahre. Stabilen Erdräumen (Westeuropa, Nord- und Südamerika) standen solche der Unruhe gegenüber (östliches und südöstliches Europa). Die erste Ausgabe des Mittelschulatlasses erinnert u. a. an das längst vergessene türkische Riesenreich, das von der Adria bis an den Persischen Golf und von Tripolis bis Jemen gereicht hatte.

In der graphischen Gestaltung war der Schweizerische Mittelschulatlas den damaligen ausländischen Schulatlanten keineswegs überlegen. Zwar enthielt er einige von Prof. F. BECKer entworfene Reliefkarten schweizerischer Landschaften: Damit 
fand diese anschauliche schweizerische Darstellungsart zum erstenmal Aufnahme in einen Schulatlas. Die Geländezeichnung dər übrigen Karten entsprach jedoch nicht durchwegs den Erwartungen. Es fehlte vielenorts an einər wünschbaren Vereinfachung der Formen und am genügenden Zusammenspiel von Schraffen und Höhenfarbstufen. Unter dem Einfluß anfechtbarer Lehren KarL Peuckers in Wien legte man die alpinen Höhenstufen in reines Rot, was allzu süßliche Effekte zur Folge hatte.

Trotz bemerkenswerter Feinheit und sorgfältiger Ausführung der gravierten Situationszeichnungen und Beschriftungen zeigten auch andere Karten oder Kartenelemente eine gewisse Unklarheit oder Ausdrucksschwäche. Sie litten an mangelhafter Generalisierung, ungeschickter Farbwahl, an fleckigen, zerfressenen Rastern und ungenügender Präzision des Druckes.

Die Ursachen solchen Versagens lagen zum Teil am Ausmaß und in der Neuartigkeit der Aufgabe. Die Winterthurer Anstalt verfügte nicht über die Erfahrungen der großen ausländischen Karteninstitute. Sie verfügte zwar über geschickte Kartographen und Kartolithographen; offenbar fehlte es aber zu jener Zeit an einer genügend befähigten Leitung. Ưberdies lag die kartographisch-methodische Entwicklung vielfarbiger Karten, vor allem der Spezialkarten, damals noch in den Anfängen, ein Umstand, der sich auch in ausländischen Kartenwerken bemerkbar machte.

Der Mangel an Erfahrung und ein unverantwortliches Unterangebot bei der Offerierung führten im Verlaufe der Arbeiten zu schweren rechtlichen und finanziellen Störungen. Ende November 1902 hatte sich die Winterthurer Anstalt verpflichtet, bis zum 1. Januar 19046000 deutsche und 3000 französische Atlanten abzuliefern. Für Karten-Originalzeichnung, Druckplattenerstellung und Druck war somit ein einziges Jahr in Aussicht genommen worden! Dies zeigt, daß man damals nicht in der Lage war, sich vom Ausmaß und von den Schwierigkeiten der Arbeit ein annähernd richtiges Bild zu machen. Solches Unvermögen hat in der Folge das Atlasunternehmen aufs schwerste gefährdet und die Anstalt an den Rand des Ruins geführt. Tạtsächlich beanspruchte die Erstellung des Werkes dann nahezu acht Jahre, und die Kosten überschritten den Voranschlag um mehr als das Anderthalbfache. - Diese Atlastragödie findet sich im Aufsatze von Prof. G. FreI eingehend geschildert. Es ist leicht einzusehen, daß sie der graphischen Qualität der Karten wenig zuträglich sein konnte.

Als dann endlich im Jahre 1910 der Atlas erschien, fand er durch Schule und Offentlichkeit eine gute Aufnahme. Der zweckmäßige, wohlabgewogene Gesamtplan und der reiche, zuverlässige Inhalt halfen ihm über manche graphische Schwäche hinweg. Der Wissensdurst der Eidgenossen war stärker als ihr um die Jahrhundertwende ohnehin brachliegendes Stilempfinden.

\section{DIE ENTWICKLUNGEN VON 1910 BIS 1928}

Im ersten Jahrzehnt seines Bestehens erfuhr der Atlas nur wenige Änderungen. Die Ausgabe des Jahres 1915 enthält neu eine ganzseitige Karte von Palästina 1:1000000. Der erforderliche Raum wurde gewonnen durch eine starke Gebietseinschränkung der Karte von China und Japan. Dies erlaubte, die bisherige Füllkarte von Jerusalem und Jericho 1:500000 durch zweckmäßigere Darstellungen von Jerusalem 1:50000 und Damaskus 1:500000 zu ersetzen. Eingehendere Atlasbetrachtung zeigt eine Reihe von Nachführungen, die an längst vergessene Vorkommnisse erinnern. So finden wir z. B. in Zürich das neue Universitätsgebäude und den erweiterten Güterbahnhof, im Berner Oberland die Jungfraubahn von der Eigerwand zum Jungfraujoch, in den Glarner Alpen den künstlich gestauten, vergrößerten Klöntalersee, in Afrika die Besitzergreifung von Lybien durch Italien usw. - Weniger glücklich waren die Nachträge in den Städtekarten von Hamburg und Berlin, wo durch eine zu weitgehende 
Detailgliederung in Verbindung mit mangelhaftem Druck Verwirrung angerichtet wurde. Dies sei erwähnt als charakteristisches Beispiel gutgemeinten, aber fehlgeleiteten kartographischen Übereifers.

Abgesehen von der durch allzu kräftige Gletscher-Höhenkurven beeinträchtigten Relief karte der Berner Alpen, wies die Ausgabe 1915 im Abstimmen und Passen der Farben da und dort einige Verbesserungen auf.

Zur Vorbereitung der nächstfolgenden Ausgabe, derjenigen des Jahres 1924 (erschienen 1925), bestellte dieErziehungsdirektorenkonferenz eine ne ue Redaktionskommission. Ihren Vorsitz führte Regierungsrat Dr. L. Merz (Bern). Sekretär und Atlasredaktor blieb Prof. Dr. A. Aeppli (Zürich). Weitere Mitglieder waren Prof. Dr. W. Rosier (bisher) und neu die Mittelschulgeographielehrer Prof. Dr. E. LetsCH (Zürich), Prof. Dr. G. Michel (Freiburg), Prof. Dr. F. Nussbaum (Bern) und, später dazugewählt, Dr. F. JENNY (Basel).

Der erste Weltkrieg hatte Staaten zerschlagen und andere vergrößert oder neu geschaffen, was im Atlas zahlreiche Nachträge und Kartenumstellungen erforderlich machte. Diese Gelegenheit sollte benützt werden, um auch die methodischen Erfahrungen auszuwerten, die sich aus zehnjährigem Gebrauch des Lehrmittels ergeben hatten. Man sammelte und prüfte die Wünsche des Vereins Schweizerischer Geographielehrer, der Schweizerischen Gesellschaft für kaufmännisches Bildungswesen und zahlreicher einzelner Geographielehrer.

Eine beträchtliche Anzahl von Karten - zusammengerechnet 24 Seiten - wurde neu in den Atlas eingefügt, andere wurden umgezeichnet oder partiell verbessert. $\mathrm{Da}$ man aber aus Kostengründen vor einer Vermehrung der Gesamtseitenzahl zurückschreckte, mußten ebenso viele bisherige Darstellungen weggelassen werden. Die wichtigsten Änderungen seien im folgenden zusammengestellt und besprochen.

a) Beispiele aus den eidgenössischen Kartenwerken. Die bisherigen Karten-Einführungsblätter (Zeichenerklärung, Geländedarstellung, Maßstabsreduktion) wurden weggelassen, um Raum zu schaffen für vier ganzseitige Beispiele aus Siegfriedatlas, Dufourkarte und Generalkarte der Schweiz (Bern 1:25000, Rhonegletscher 1:50000, Gotthardgebiet 1:100000, St.-Gallisches Rheintal 1:250000). - Ich glaube nicht, daß diese Neuerung, im ganzen gesehen, glücklich war. Das Gute wurde hier zum Feind des Bessern. Die preisgegebene Karteneinführung hatte den Darstellungen und Maßstäben der Atlaskarten entsprochen, sie war methodisch geschickt aufgebaut und in ähnlicher Form sonst nirgends zu finden. Ihre Karten zählten graphisch zu den besten des Atlasses. Man mag einwenden, die Kartenlehre gehöre in die Elementarschule. Ja, gewiß auch, doch ist sie - ebenso wie länderkundliche Dinge - auf höheren Verständnisstufen zu wiederholen und zu vertiefen. Daß dabei u. a. Beispiele der amtlichen eidgenössischen Karten behandelt werden, erachte ich als selbstverständlich. Man wird aber hiezu besser Blätter nach freier Wahl, solche des eigenen Wohngebietes usw., beiziehen; denn diese bieten den Vorteil unmittelbarer Vergleichbarkeit mit dem Gelände. Es dürfte in der Schweiz keinem Lehrer und auch keinem Mittelschüler schwerfallen, sich solche Blätter zu beschaffen.

Eine Rechtfertigung könnten die vier neu eingefügten Karten in der besonderen Wichtigkeit der dargebotenen Landschaften finden. Bern kam jedoch darin schlechter weg als früher, da u. a. die maßstäbliche Einheit mit den andern Schweizer Städten verloren ging. Auch die nordöstliche Landesecke gewann nichts durch den Abtausch der Beckerschen Reliefkarte gegen die damals schon stark veraltete amtliche Generalkarte. Auf die Karte des Rhonegletschers hätte man neben derjenigen des Aletschgletschers verzichten können. Es blieb somit als wünschenswerte Neuerung nur die Karte des Gotthardgebietes. 
Die Neuerung war aber auch aus graphischen Gründen anfechtbar. Dufour- und Generalkarte als alte, in Kupfer gestochene Schraffenkarten lassen sich im Verein mit völlig anders gearteten und anders erstellten Karten nicht befriedigend drucken. Die Beispiele im Schulatlas zeigen daher diese Karten nicht in ihrer originalen Qualität und Schönheit. Zum mindesten hätte man sich an die Farben der amtlichen Ausgaben halten müssen, statt deren schwarze Elemente dunkelbraun zu drucken.

b) Allgemeine Karten, physische und politische Übersichtskarten und Detailgebietskarten in allen Teilen des Atlasses. Manche der letzteren wurde gegen eine andere, wichtigere vertauscht. Damit gelangten einige Karten in den Atlas, die seither wohl zu dessen dauerndem Bestande zählen, so u. a. die folgenden: Obertheinische Tiefebene, Niederlande und Belgien, Scheldemündung, Atlasländer. Wieder andere erfuhren - sehr zu ihrem Vorteil - Gebietserweiterungen (Genf, Basel, Zürich, Amsterdam usw.). Weniger zweckmäßig erscheinen mir zwei Maßstabsänderungen: das halbseitige Departementskärtchen von Frankreich wurde zu einer $1 \frac{1}{2}$ seitigen politischen Karte aufgebläht, dafür aber die politische Karte von Afrika von 2 Seiten auf $2 / 3$-Seiten reduziert.

Das Höhenrot der allgemeinen und physischen Karten wich einem angenehmeren Rotbraun. Die Städtekarten erfuhren eine Bereicherung durch Höhenfarbtöne. In mancher Detailkarte wurden diese Töne der betreffenden Gegend besser angepaßt. Eine wertvolle Neuerung bedeutete die Verstärkung der wichtigsten internationalen Bahnlinien in den allgemeinen und politischen Länder- und Erdteilkarten.

c) Meteorologische und klimatologische Karten. In die Januar- und Juli-Temperaturkarten der Schweiz wurden die mittleren und absoluten Maxima und Minima ausgewählter Orte eingetragen. Die veraltete Regenkarte der Schweiz wich einer Neukonstruktion nach H. Brockmann-Jerosch. Diese brachte die engen Beziehungen zwischen Relief und Niederschlagsmenge besser zum Ausdruck. Neu aufgenommen wurden zwei Kärtchen der Luftdruckverteilung bei Föhn und nach dessen Abzug, ferner in der Gruppe europäischer Spezialkarten eine reichlich problematische Darstellung der Zugstraßen barometrischer Minima. Die Europa- und Erdkarten der Jahres-Isothermen besitzen neben denjenigen für Januar und Juli geringe Bedeutung; sie wurden daher gestrichen. Als äußerst wertvolle Neuerung finden wir im Atlas eine Erdkarte der Linien gleicher Wärmeschwankung (Isoamplituden). Die Erdkarte der Klimatypen wurde wohl unter das erträgliche Maß verkleinert.

d) Wirtschaftsgeographische Karten. In neuerer Zeit stellte man mehr als früher den Menschen, seine Lebensbedingungen, seine Ökonomie in den Mittelpunkt länderkundlicher Betrachtung. Damit gewann die Wirtschaftsgeographie an Bedeutung. Die Atlasumformung für die Ausgabe 1924 brachte daher als wesentlichsten Fortschritt eine Erneuerung und Vermehrung der Karten für diesen Wissenszweig. Ihre Bearbeitung besorgten Prof. Dr. E. Wetrer (Kantonale Handelsschule Zürich) für die europäischen Gebiete und Prof. Dr. G. Mrchel (Collège Fribourg) für die Erdteile und Erdübersichten.

Wirtschaftsgeographische Karten können entweder analysierend oder synthetisierend sein. Erstere zeigen z. B. die Verbreitungsgebiete von Bodenschätzen, Bodenanbauformen, Industrien, Produkten usw., wobei sich mehrere verschiedenartige Vorkommnisse in ein und derselben Karte vereinigen lassen. Wesentlich bleibt, $\mathrm{da} \beta \mathrm{im}$ allgemeinen jede Industrie, jedes Erzeugnis usw. eine besondere Signatur besitzt. Es ist nicht leicht, sich durch geistige Addition der Inhalte mehrerer solcher Karten Vorstellungen des wirtschaftlichen Gesamtcharakters eines Gebietes zu bilden. Die zweite Art der Darstellung strebt daher unmittelbar nach diesem letzteren Ziel. 
- Man sucht Gebiete einheitlichen wirtschaftsgeographischen Charakters auszuscheiden. Es bleibt das Verdienst der damaligen Atlasbearbeiter, vor allem von G. MrCHEL, Lösungen in diesem Sinne gesucht und in den Erdteilkarten erstmals verwirklicht zu haben. Michel setzte z. B. zu einer bestimmt abgegrenzten Karten- bzw. Farbfläche die Legendenerläuterung: Tropische Wälder und Kulturland mit Mais, Batate, Maniok, Yams, Früchte, Tabak, Agaven, Baumwolle. Oder in einem andern Falle: Pampas mit Weizen, Mais, Alfalfa, Rind und Schaf.

Neben unbestreitbaren Vorzügen weisen auch solche Karten Mängel auf. Die einzelnen Wirtschaftslandschaften werden vorwiegend durch das Aufzählen ihrer wichtigsten Produkte charakterisiert. Damit aber sind Betriebsformen, Marktverhältnisse usw. nicht erfaßt, und überdies ist ein und dasselbe Produkt, wie z. B. der Mais, in mehreren verschiedenen Typengebieten aufzuführen. Die Verbreitungszonen einzelner Vorkommnisse oder Erzeugnisse sind somit nicht unmittelbar ersichtlich; sie müssen mit Hilfe der Legenden mühsam zusammengesucht werden. Auch durch weitere Abklärung des Begriffes «Wirtschaftsgebiet» und durch Verbesserung solcher Karten wird eine vollständige und befriedigende Kombination analysierender und synthetisierender Darstellung nicht durchführbar sein. Die Ausgabe 1924 des Atlasses enthielt daher erstmals für jeden Erdteil Karten beider Gattungen. Die inhaltliche Neufassung dieser Karten und auch der Produktekarten der Erde ermöglichte den Verzicht auf einige allzu kleine und wenig brauchbare Erdübersichten von Wirtschaftsformen, Industriegebieten, Tieren und Kulturpflanzen.

Sehr schlecht erging es bei der besprochenen Atlasumformung der schweizerischen Landwirtschaft. Gewiß war das bisherige Kärtchen der Bodenkultur mangelhaft; es war vor allem zu klein. Statt es zu vergrößern, wurde es gestrichen, ohne durch eine der neuen Wirtschaftskarten Ersatz zu bieten. Zweckmäßig scheint mir an dieser Änderung lediglich das Weglassen der Waldflächen; denn deren Kartierung erwies sich in den kleinen Atlaskärtchen für schweizerisches Gebiet als nichtssagend.

e) Ubrige Spezialkarten. Die Änderungen an Volksdichte-, Völker- und anderen Spezialkarten beschränkten sich auf einige wenige lokale Verbesserungen.

f) Kartenprojektionen. Eine nicht sehr geschickte Hand zeigten die Atlasrevisoren in der Wahl einzelner Kartennetze. Die beiden neuen, ganzseitigen Produktekarten der Erde (S. 128 und 129) wurden in einer normalen, weder flächen- noch winkeltreuen Zylinderprojektion gezeichnet. Die polnahen Gebiete erscheinen darin bis zur Unkenntlichkeit verzerrt. Ungeeignet war aus schon genannten Gründen auch die Einführung der Merkatorprojektion (normale, winkeltreue Zylinderprojektion) zur Darstellung der politischen Gliederung der Erde.

Die vielen Erweiterungen zwangen zur Streichung einer entsprechenden Menge von Karten. Auch diese seien im folgenden zusammengestellt:

1. Die schon genannten Einführungsblätter in die Kartenlehre.

2. Erläuterungen der Kartenprojektionen. Über deren Nützlichkeit gingen die Ansichten stark auseinander.

3. Reliefkarten des Napf und der Appenzeller Berge. Ein bedauerlicher Eingriff, denn damit brachte man die geschickt ausgewählte Relief kartenreihe charakteristischer schweizerischer Landschaften um die beiden Mittellandbeispiele und den planmäßigen Gesamtaufbau.

4. Einige weitere, meist weniger wichtige Gebietskärtchen in allen Atlasteilen.

5. Europäisches Rußland: Bodenkultur, Bergbau und Industrie. Infolge der kleinen Maßstäbe konnten diese Karten ohnehin nicht über die Inhalte der entsprechenden Europakarten hinausgehen. 
6. Europa: Jahres-Isothermen (oben erwähnt), ebenso Hauptverkehrslinien. Diese letzteren konnten ebenfalls entbehrt werden, da in der politischen Europakarte das Hauptverkehrsnetz seit den vorgenommenen Linienverstärkungen genügend hervortritt.

7. Alle Erdteile: Geologische Karten. Diese buntgefleckten Miniaturmosaiks wurden zu Recht weggelassen. Die Erläuterungen im Atlas stellten fest: «Es hat sich gezeigt, daß in dem kleinen Maßstab einer Erdteilkarte das oberflächliche Ausstreichen der verschiedenen geologischen Formationen für den Unterricht lange nicht die Bedeutung hat wie die Darstellung der großen Einheiten durch eine tektonische Karte.» - Die geologische Karte von Europa fand daher einen Ersatz in einer vorzüglichen tektonischen Karte. Die übrigen Erdteile aber gingen leider leer aus.

8. Nordamerika, politische Karte. Diese wurde bei gleichbleibendem Maßstab von zwei Seiten auf eine beschnitten. In Anbetracht der leeren Ozeanflächen eine verständliche Operation, die jedoch das Antlitz des Patienten übel zugerichtet hat.

9. Spezialkarten der Erde. Außer den schon genannten (Jahres-Isothermen, Wirtschaftsformen, Industriegebiete, Tiere und Kulturpflanzen) wurden diejenigen der Vergletscherung, der Verkehrsarten und Verkehrssprachen weggelassen. Infolge allzukleiner Maßstäbe waren sie wenig instruktiv. Ihr wesentlichster Inhalt findet sich in andern Karten.

10. Gestirne. Den unschön angehäuften photographischen Abbildungen der Sonne, der Kometen und Sternnebel wird niemand nachtrauern. Hingegen war der Verzicht auf die Sternkarte und auf die Darstellung des Sonnensystems wohl ein Mißgriff. Gewisse Elemente der Himmelskunde zählen mit zur allgemeinen naturwissenschaftlichen Bildung, wie sie durch die Mittelschule zu vermitteln ist.

Zusammenfassend läßt sich feststellen, daß Aufbau und Inhalt der Atlasausgabe 1924 bemerkenswerte Verbesserungen und Bereicherungen, vor allem in länderkundlicher, klimatologischer und wirtschaftsgeographischer Richtung erfahren hatten. Sie wurden jedoch erkauft durch Preisgabe wertvoller Darstellungen der Kartenlehre und Himmelskunde und durch Einbrüche in den bisherigen, wohlabgewogenen und systematisch aufgebauten Gesamtplan.

Die Anstrengungen AEppLIs und seiner Mitarbeiter um die inhaltliche und methodische Verbesserung des Atlasses gelangten leider nicht in allen Karten zu voller Auswirkung. Krankten schon die bisherigen Ausgaben an graphischen Mängeln, so war dies nun in verstärktem $\mathrm{Maße}$ der Fall. Unschön abgestimmte Farben, vor allem ein zu starkes, unsauberes Gelb, zerfressene Raster, ungenaues Passen usw. beeinträchtigten die Klarheit und Lesbarkeit mancher Karte. Es sei hingewiesen auf den verschwommenen Eindruck des Solothurner Jura (S. 17), die mangelnde Präzision der Reliefschatten auf den Gletschern des Jungfraugebietes (S. 20), den unvermittelten Gegensatz krautiggrüner Alpweiden und violetter Gesteinswüsten in den Glarner Alpen (S. 21), das noch weiter verschlimmerte Linien- und Farbengewirr in Hamburg (S. 24) und Berlin (S. 25), die verworrenen Gebirgsdarstellungen einiger Länder- und Erdteilkarten, z. B. in den französischen Alpen (S. 35) und im Balkan (S. 66-67), die zerfallene Gebirgszeichnung der Planiglobenkarte (S. 134-135) usw. -

Auch einige neu erstellte Karten litten an graphischem Ungenügen. Diejenigen der Schweizer Städte im Maßstab $1: 50000$ und auch die neue politische Afrikakarte (S. 102) entstanden nicht durch generalisierende Umzeichnung, sondern auf billigstem Wege durch photographische Reduktion aus größeren Karten. Dies ist u. a. aus ihrer zersetzten, «kranken» Struktur ersichtlich. Die Geländeschraffuren neu erstellter Karten, wie z. B. diejenigen der Oberrheinischen Tiefebene (S. 33) und der Atlasländer (S. 103), zählen 
zu den kompliziertesten und manierhaftesten des Atlasses. Ungenügend generalisiert und zerfahren im Ausdruck waren auch mehrere der neuen wirtschaftsgeographischen Karten.

Die Ursachen solcher graphischen Schwächen waren dieselben, wie wir sie schon für die früheren Auflagen festgestellt hatten. Sie waren zum Teil allgemeiner Natur. Graphische und im besonderen kartographische Methodik und Technik waren kaum genügend entwickelt, um alle Schwierigkeiten zu meistern, die die vielfarbige Miniaturgliederung der Karte bot. Die graphische Stilverwilderung, wie sie um die Jahrhundertwende geherrscht hatte, war noch nicht überwunden. Aus eigener Kraft aber vermochte die Leitung der Winterthurer Anstalt nicht zu besseren Leistungen zu gelangen. Dieses Versagen führte denn auch unmittelbar nach der Fertigstellung des Atlasneudruckes zum Zusammenbruch des einst so blühenden Winterthurer Kartengewerbes.

Ende 1924 wurde die «Kartographia Winterthur» durch das Artistische Institut Orell Füßli übernommen. Damit gelangten auch die den Mittelschulatlas betreffenden Rechte und Pflichten an diese altbewährte Zürcher Offizin.

Im Jahre 1928 erschien erstmals eine in Zürich gedruckte, im übrigen aber völlig unveränderte Atlasauflage. Da sie mit Hilfe der übernommenen Druckplatten zu erstellen war, unterschied sie sich von der vorhergehenden nur durch besseres $\mathrm{Ab}$ stimmen einzelner Farben und durch sorgfältigeren Druck.

\section{DIE UMARBEITUNG $1928-1932$}

Die methodischen und graphischen Mängel der Ausgabe 1924 veranlaßten die Erziehungsdirektorenkonferenz, schon nach wenigen Jahren wiederum eine Umarbeitung des Werkes ins Auge zu fassen. Die unveränderte Zürcher Ausgabe 1928 hatte hiefür die notwendige Zeitspanne freigelegt. Die erneute Umformung erfolgte von 1928-1932.

\section{ARBEITSORGANISATION UND MITARBEITER}

Die Redaktionskommission wurde 1927 teilweise erneuert. Von den bisherigen Mitgliedern gehörten ihr weiterhin an: Regierungsrat Dr. L. Merz (Bern) als Präsident, Prof. Dr. A. Aeppli (Zürich) als Sekretär, Prof. Dr. E. Letsch (Zollikon-Zürich), Prof. Dr. G. Mrchel (Freiburg), Prof. Dr. F. Nussbaum (Bern). Neu traten hinzu: Prof. Dr. Ch. Burky (Genf) und Prof. Ed. Imhof.

Ich löste Prof. Aeppli als Redaktor ab. Überdies übertrug mir die Erziehungsdirektorenkonferenz die Erstellung der Kartenoriginale und die Überwachung der Reproduktion. Diese letztere wurde dem Art. Institut Orell FüBli in Zürich anvertraut. Die Erstellung der Originale erfolgte somit - in Abweichung vom bisherigen Vorgehen - nicht mehr durch eine kartographische Anstalt, sondern in meinem Atelier in Erlenbach-Zürich, wo zur Mithilfe dipl. Ing. H. Surer und die Kartographen A. Sulzer und A. KMENT eingestellt wurden. Die zürcherischen Mitglieder der Redaktionskommission, AEPPLI, LETSCH und ich, bildeten einen «téchnischen Ausschuß» zur Abklärung von Detailfragen. Prof. LETSCH vertrat mich als Redaktor während meiner Reise nach China im Jahre 1930.

Privatdozent Dr. J. CADisCH (damals in Basel) erstellte Inhaltsentwürfe für die neuen geologischen und tektonischen Karten der Schweiz. Dr. J. Maurer (Direktor der Eidgenössischen Meteorologischen Zentralanstalt, Zürich) revidierte einige klimatologische Karten. Sein neuer Entwurf einer Niederschlagskarte der Schweiz ersetzte die bisherige Karte von BrockmanN. Prof. Dr. R. Zeller (Bern) überprüfte die Erdteil-Völkerkarten. Ein Hauptverdienst an der Erneuerung von Spezialkarten kam wiederum Prof. Dr. G. Mrchel zu. Er lieferte Skizzen für die Vegetationskarten der Erdteile und betreute die inhaltliche Erneuerung aller wirtschaftsgeographischen Karten, mit Ausnahme der Landwirtschaftskarte der Schweiz, die nach der neuen Karte von Dr. E. Paravicini (Basel) bearbeitet wurde. 
Prof. Dr. E. Letsch und Prof. Dr. F. Nussbaum sichteten die neueren Quellen für die tektonischen Erdteilkarten und für einzelne klimatölogische und Volksdichtekarten. Weitere Mitteilungen und Nachträge stammten von Pater Dr. Placidus Hartmann in Engelberg (Gliederung der katholischen Schweiz), von Prof. Dr. Сh. Biermann (Sprachenkarten), vom Reisebü ro Kuoni in Zürich (Verkehrslinien) und von Prof. Dr. W. BRUnNer, Eidgenössische Sternwarte Zürich (Himmelskunde).

Die UUberprüfung der Kartenbeschriftungen für die französische Ausgabe wurde durch Prof. Dr. Ch. Biermann (Lausanne), diejenige für die italienische Ausgabe durch Direktor Dr. M. Jaeggli (Bellinzona) besorgt. Prof. Dr. J. J. Hess-von Wyss (Zürich) bemühte sich um die Bereinigung der Schreibweise orientalischer Namen.

Weiterhin waren uns behilflich durch Beschaffung von Quellenmaterial: Die Eidgenössische Landestopographie (Bern), die Eidgenössische Vermessungsdirektion (Bern), das Kommando des Militärflugplatzes Dübendorf, die militärgeographischen Institute von Deutschland, Italien, Jugoslawien, der Niederlande, die Hafenverwaltungen einiger im Atlas dargestellter Meerhäfen, einige schweizerische Gesandtschaften und Konsulate, die Zentralbibliothek Zürich, die Bibliotheken der Eidgenössischen Technischen Hochschule, der Universität und der Kantonsschule in Zürich.

Die wichtigsten Quellen sind im Anhang, Seite 370, zusammengestellt.

Die kartographische Gestaltung aller Karten wurde durch mich festgelegt. Auf die hiebei befolgten Gesichtspunkte und auf einige technische Fragen soll im 2. Teil der vorliegenden Abhandlung eingetreten werden.

Wesentlichen Anteil an der Erstellung des Atlasses kam auch Richard BartheL (Zürich) zu, der als Chef der kartographischen Abteilung von Orell Füßli die Reproduktionsarbeiten leitete.

Nicht zuletzt aber sei an die unbekannten Soldaten erinnert; denn ohne die tüchtige Arbeit der Kartolithographen, der Graveure, der Umdrucker und Drucker wären alle Bemühungen um die Verbesserung des Werkes fruchtlos geblieben.

\section{WEGLEITENDE POSTULATE}

Wegleitend für die Atlasumformung 1928-1932 waren folgende Postulate:

a) Verbesserung der graphischen Form und der Reproduktion

Für viele Karten auch eine über das bisherige $\mathrm{Maß}$ hinausgehende Vereinfachung.

b) Möglichste Wiederherstellung eines systematischen Aufbaues

Wie wir gesehen haben, war dieser durch die Teilumarbeitungen der Auflagen von 1915 und 1924 gestört worden.

\section{c) Erneute Anpassung an die Lehrpläne}

Es sei erinnert an die bisherigen Entwicklungen: Die ältesten Schulatlanten hatten sich auf allgemeine und politische Länder- und Erdteilkarten beschränkt. Bald traten physische Übersichtskarten hinzu. Es folgten physiogeographische und anthropogeographische und später im besonderen auch wirtschaftsgeographische Spezialkarten. Aus Ersparnisgründen beschränkten sich solche Spezialdarstellungen zunächst auf das eigene Land (Schweiz) und auf Gesamtkarten der Erde und Erdteile. Solche Beschränkung war auch diktiert durch den Mangel an Quellen. Selbst heute - und wohl noch lange Zeit - stehen die Spezialkartierungen für größte Teile der Erdoberfläche hinter der topographischen Erschließung weit zurück. Der neuere Geographieunterricht aber erstrebte immer ęntschiedener eine vergleichende Länderkunde. Hiezu benötigte man auch für Deutschland, Frankreich, Italien usw. eine Ergänzung der allgemeinen Übersichtskarten durch Spezialkarten für Klima, Vegetation, Wirtschaft, Volksdichte usw. Die entsprechenden Europakarten boten hiefür keinen ausreichenden Ersatz, ihre Maßstäbe waren zu klein, ihre Inhalte konnten den Teilgebieten nicht genügend angepaßt und infolge räumlicher Trennung nicht leicht miteinander verglichen werden. Die Einschaltung von Spezialkarten für einzelne europäische Länder führte zu umfangreicheren Atlanten. Doch selbst in diesen, z. B. in den früheren Auflagen des Schwei- 
zerischen Mittelschulatlasses, fanden sich solche nur in enger Auswahl und nur für die wichtigsten Gebiete. So drängten die Bedürfnisse des Unterrichtes folgerichtig nach ihrer Vermehrung und leicht überblickbaren Zusammenstellung. Ähnlich, jedoch in der maßstäblichen Größenordnung verschoben, lagen die Verhältnisse bei den fremden Erdteilen. Erdübersichten für Klima, Vegetation usw. genügten nicht mehr, so daß auch für die Kontinente eine Vermehrung der Spezialdarstellungen verlangt wurde. Die Atlasausgabe des Jahres 1932 sollte nun diese Postulate erfüllen.

Trotz solcher schr. weitgehender Wünsche konnte man sich auch diesmal nicht entschließen, die Seitenzahl zu erhöhen. Eine Vermehrung der Spezialkarten auf Kosten von Detailkarten aber war nur in Ausnahmefällen möglich und wünschenswert. Die neue Inhaltsplanung stellte daher an die Kunst des Disponierens. schwere, nicht überall befriedigend lösbare Aufgaben. Unter der klug vermittelnden Leitung von Regierungsrat Dr. L. Merz wurde 1927 und 1928 ein von mir vorgelegter Entwurf in zahlreichen Kommissionssitzungen durchberaten und in manchen Teilen-vervollständigt und verbessert.

\section{DIE WESENTLICHSTEN ÄNDERUNGEN DES INHALTSPLANES}

a) Kartenlehre

Mit den ersten Atlasseiten suchte man gleichzeitig drei verschiedenen Wünschen gerecht zu werden: Beibehalten von Mustern eidgenössischer Kartenwerke, Wiedereinführung schrittweise verkleinerter Karten derselben Gegend zur Einführung in die Generalisierung, Darstellung des geschichtlich wie geographisch bedeutsamen Vierwaldstätterseegebietes. In diese Maßstabsreihe wurden erstmals auch Beispiele der Grundbuch-Übersichtspläne 1:5000 und 1: 10000 eingefügt. Trotzdem konnte durch Beschränkung auf halbseitige Karten der Gesamtraum von vier auf drei Seiten vermindert werden. - Auch in den Detailkarten alpiner Geländeformen auf Seite 24 wurden Ausschnitte aus dem Topographischen Atlas der Schweiz (Siegfriedkarte) gegeben.

b) Reliefkarten schweizerischer Landschaften

Die bisherige Kartenreihe 1: 125000 wurde durch eine neue, vollständigere ersetzt. Diese zeigte auf ganz- und halbseitigen Karten 1:50000, 1: 100000 und 1:200000 charakteristische Gebiete aus Jura, Mittelland, Alpen und Südschweiz. Damit war eine der glücklichsten methodischen Neuerungen der frühesten Atlasauflagen nicht nur wieder hergestellt, sondern wesentlich verbessert.

c) Karten schweizerischer Siedelungen

Bern erhielt in Maßstab und Form eine analoge Karte wie Genf, Basel und Zürich. Neu eingefügt wurden Karten des Gebietes Vevey-Montreux und von Chur, ferner vier Beispiele ländlicher Siedelungstypen, welch letztere aus Dispositionsgründen bei Mitteleuropa eingefügt werden mußten.

\section{d) Spezialkarten der Schweiz}

Neben einer neuen geologischen Karte wurden Darstellungen des tektonischen Baues und der diluvialen Vergletscherung aufgenommen. Diesem Gewinn opferte man leider die bisherige doppelseitige geologische Karte der Alpenländer. Eine Rechtfertigung glaubte man in der geologischen Karte von Europa zu erblicken, die zur Ergänzung der tektonischen Erdteilkarte in neuer Form wieder Aufnahme fand. An Stelle einer einzigen ganzseitigen wirtschaftsgeographischen Karte traten vier neue kleinere Karten. Eine derselben war der Landwirtschaft gewidmet, wodurch eine alte Unterlassuṇgşsünde endlich gutgemacht wurdè. 
e) Übersichtskarten der europäischen Länder

Frankreich, Mitteleuropa und Donauländer waren in den letzten Ausgaben je in großen physischen und ebenso großen politischen Übersichtskarten dargestellt. Diese raumfressende und methodisch unzweckmäßige Doppelspurigkeit wurde aufgehoben und für jedes Gebiet eine allgemeine physisch-politische Karte eingeführt, womit für alle europäischen Länder Übereinstimmung in der Darstellung erreicht war. Siedelungen und Verkehrsnetz erscheinen in solchen Karten in ihren natürlichen Rahmen eingebettet, was im Sinne geographischer Beziehungslehre zu begrüßen ist. Die drei neuen Übersichtskarten fanden immerhin Ergänzungen durch je eine kleinere Karte der inneren politischen Ländergliederung. Für Frankreich stellte man somit die Darstellungsformen der ersten Atlasausgabe wieder her. Wohl zu Unrecht opferte man die große doppelseitige Karte von Osteuropa (europäisches Rußland) dem Raummangel. Man war der Meinung, die Europakarten gleichen Maßstabes könnten genügenden Ersatz bieten.

f) Europäische Neben- oder Detailkarten

Neu eingefügt wurden folgende Karten: Ländliche Siedelungstypen in Mitteleuropa (S. 39), Rheinisch-westfälisches Industriegebiet (S. 40), Rhonemündung (S. 48), Anlandung von Inseln bei Piombino-Orbetello (S. 52), Bucht von Kotor (S. 57), Antwerpen (S. 66) und verschiedene kleinere Kärtchen. Mehrere Karten wurden erweitert, besser abgegrenzt oder in größeren Maßstäben gezeichnet, so z. B. diejenigen von Wien, Brest, Seinemündung, Küste der Landes, Rom und Neapel. Genügend große Maßstäbe erhielten insbesondere auch die Karten verschiedener Hafentypen: Hamburg (offener Flußmündungs- oder Fluthafen), Antwerpen (geschlossener Dockhafen) und Genua' (natürliches, offenes Hafenbecken). Verschwunden sind anderseits folgende Karten: Industriegebiet von Lyon, Kaledonischer Kanal (in Schottland), Dänische Inseln, Polen; die beiden letzteren, weil ihre Gebiete in der neuen Mitteleuropakarte zur Darstellung gelangten.

\section{g) Spezialkarten europäischer Gebiete}

Abgesehen von zwei Sprachenkarten für Donauraum und Balkan enthielt die bisherige Ausgabe nur wirtschaftsgeographische und Volksdichtekarten und auch diese nur für Deutschland, Donauländer, Italien, Frankreich, Pyrenäenhalbinsel und Großbritannien. Im neuen Atlas traten klimatologische Karten (Isothermen und Niederschläge) hinzu. Leider war es aus Raummangel nicht möglich, analoge Kartengruppen für alle europäischen Gebiete einzuführen.

h) Ubersichtskarten von Europa

Hier beschränkten sich die Ergänzungen auf die schon erwähnte Wiedereinführung einer neu entworfenen geologischen Karte und auf ein kleines Klimakärtchen.

\section{i) Allgemeine Übersichtskarten fremder Erdteile und der Ozeane}

Für Afrika stellte man die ursprüngliche große politische Karte und damit die maßstäbliche Übereinstimmung mit den übrigen fremden Erdteilen wieder her. Abgesehen von Australien, wurde für alle Kontinente an der Trennung in physische und politische Karten festgehalten, da eine Vereinigung beider Elemente zu Überlastungen geführt hätte und weil kombinierte Darstellungen in zahlreichen größeren Teilgebietskarten zur Verfügung stehen. Wie bisher, enthalten aber auch die politischen Karten Gebirgsschraffen.

Der Atlas besaß seit Anbeginn eine Karte des Großen Ozeans. Neu aufgenommen wurden nun eine analoge Karte des Atlantischen Ozeans und zwei kleine Nebenkärtchen zur Veranschaulichung von Ebbe und Flut. 
k) Teilgebiets- und Detailkarten fremder Erdteile und der Ozeane Asien: Westasien (Anatolien, Nordarabien), Britisch-Indien, China und Japan wurden in größeren Maßstäben neu gezeichnet und die Chinakarte auf zwei Seiten erweitert. Eine Begründung hiefür màg ein Blick auf die Volksdichtekarte von Asien geben. Dieser gewaltige Kontinent ist ein Gebiet extremster Gegensätze. Leeren Räumen stehen überfüllte gegenüber. Den letzteren suchte man durch detailreichere Karten gerecht zu werden. Die neue, im Gebiet beschränkte einseitige Westasienkarte 1: 10000000 bot jedoch für die ausgeschalteten Karten (Westasien 1: 15000000 mit Atabien, Iran usw.; Palästina $1: 1000000$ ), trotz Hervorhebens der irakischen Ölgebiete, nur einen mangelhaften Ersatz. Durch Vergrößerungen der Karten von Westasien, Indien und China auf $1: 10000000$ wurde die maßstäbliche Úbereinstimmung mit den Karten 1: 15000000 von Europa und der Vereinigten Staaten gestört. Auch den Wegfall der Kärtchen von Jerusalem, Peking und Tokio mag man bedauern. So mochten sich Vor- und Nachteile der Änderungen etwa die Waage halten.

Glücklicher waren die Neuerungen für die übrigen Kontinente.

Afrika: Eine wenig instruktive Karte von Kapland usw. wurde geopfert, dafür aber Darstellungen von Biskra (Flußoase), Tunis und Kapstadt nei eingefügt und für Kairo der Maßstab von 1:500000 auf 1:200000 vergrößert.

Nordamerika erhielt folgende neuen Karten: östlicher Teil der Vereinigten Staaten 1:4000000 (also im Maßstab der europäischen Länderkarten), New York 1:200000 (Maßstab europäischer Hauptstädte), Niagarafälle 1:100000, Kalifornien $1: 4000000$. Einige bisherige Karten wurden somit in den Maßstäben oder Gebieten vergrößert, andere weniger wichtige fallengelassen.

Südamerika zählte durch Maßstabsvergrößerungen der meisten Detailkärtchen ebenfalls zu den Gewinnern.

Australien erfuhr Ergänzungen durch Kärtchen von Canberra und Sidney.

Großer Ozean: An Stelle der bisherigen vier Nebenkärtchen (Auflage 1928, S. 122-123) traten deren sechs (Auflage 1932, S. 106-107). So konnten neben der Vulkaninsel Hawaii die Saumriff-, Wallriff- und Atollinseltypen besser dargestellt und überdies ein Beispiel einer antarktischen Eisküste neu aufgenommen werden.

1) Spezialkarten fremder Erdteile

In der Ausgabe 1924 hatte man die nichtssagenden geologischen Kärtchen der fremden Erdteile entfernt, ohne hiefür einen Ersatz zu bieten. Diese Unterlassung wurde nun durch Einführung tektonischer Karten wieder gutgemacht. Überdies erhielt jeder Erdteil neben der schon vorhandenen Niederschlagskarte eine solche für Klima und für Vegetation (Australien nur die letztere). Solche Darstellungen natürlicher Verhältnisse tragen wesentlich zum Verständnis anthropogeographischer Erscheinungen bei. Auch die Karten dieser letzteren, vor allem diejenigen für Wirtschaft und Produkte, wurden neu bearbeitet und zum Teil vermehrt.

m) Erdübersichten

Ähnlich wie die Gruppe der Europa-Gesamtkarten war auch diejenige der Erdkarten schon in den früheren Ausgaben allseitig ausgebaut. Tiefgreifende Änderungen der allgemeinen Planung waren daher nicht nötig. Durch Verkleinerung und Neugestaltung der Vegetations- und Produktekarten wurde eine Seite eingespart und überdies Raum gewonnen für neue Karten der Wirtschaftsformen und Verkehrssprachen.

n) Himmelsgewölbe, Mond und Gestirne

Die Darstellungen des nördlichen Sternhimmels und des Sonnensystems - einst im Atlas vorhanden und dann daraus entfernt - wurden in ähnlicher Form wieder aufgenommen. Abgesehen von graphischen Verbesserungen, Umstellungen und Detailkorrekturen, waren keine Änderungen nötig. 


\section{o) Projektionsänderungen}

Die Erdübersicht des Kolonialbesitzes und Weltverkehrs war in der ersten Atlasausgabe in einer Planiglobenkarte, also in Kreisscheiben der westlichen und östlichen Halbkugel, dargestellt. Um die Trennung der Schiffslinien im Atlantischen Ozean zu vermeiden, ging man dann zur Merkatorkarte über. Diese ist infolge außerordentlicher Flächenverzerrungen ebenfalls ungeeignet. So wurde in der Ausgabe 1932 Hammers Projektion (eine modifizierte, normale Zylinderprojektion) gewählt. Sie ist flächentreu und zeigt ein geschlossenes Weltbild innerhalb einer Ellipse, vermeidet also die beiden Mängel der früheren Netze. Analog wurden auch die Erdübersichten der Volksdichte, Produkte, Völker usw. entworfen. Das seltsam verzerrte, ungewohnte Netz der bisherigen Produkte-Erdkarten fiel somit ebenfalls weg. Die Hammersche Projektion zeigt jedoch die westlichsten und östlichsten Kartenteile in allzu starker Verbiegung, so daß sie vielleicht später einmal durch eine noch geeignetere ersetzt werden sollte.

\section{4. ÄNDERUNGEN UND NACHFÜHRUNGEN DER KARTEN}

Es wäre sinnlos und unmöglich, hier alle Mutationen zu nennen, die sich durch die Neubearbeitung der meisten Karten ergaben. Die kartographischen Neuerungen sind im 2. Teil dieser Abhandlung dargelegt. Kurz erwähnt seien hier nur einige ge ne relle Inhaltsverbesserungen:

Landhöhen und Meerestiefen aller allgemeinen und physischen Karten wurden durch zweckmäßigere Wahl der Stufen und Farben besser zum Ausdruck gebracht. Damit erreichte man auch eine deutlichere Scheidung von Land und Wasser. Viele Karten erhielten neue Gebirgszeichnungen.

Ortspositionen, Beschriftungen usw. erfuhren durchwegs eine systematischere Abstufung. Sie wurden für alle Karten neu graviert.

Wachstumsphasen der Städte gelangten in vielen Detailkarten durch verschiedene Farbtöne zu besserer Gliederung.

In den politischen Erdteilkarten wurde die staatliche Struktur des Britischen Weltreiches und der Sowjetunion angedeutet.

Grüne Grenzbänder lösten in den allgemeinen Karten die orangefarbigen ab, da sich letztere in unangenehmer Weise mit den Gebirgsfarben vermischt hatten.

Die meisten Spezialkarten erhielten anschaulichere und mit den Inhalten besser korrespondierende Farben.

In einigen Produktekarten, besonders in den Erdübersichten, wurden ozeanische Export- und Importlinien eingetragen.

Die beiden Polarkarten (S. 126-127) erfuhren eine Bereicherung durch Darstellung der Vereisungsverhältnisse und der Forschungsgeschichte.

Ein aufmerksamer Atlasbenützer wird auch in der Ausgabe 1932 manch interessante Zeugen jüngster Entwicklungen und neuester Erderforschung finden. Hingewiesen sei auf die Änderungen politischer Grenzen im Innern von Asien, Afrika und Südamerika, die neuen Bahnlinien im zentralen Rußland (Nowo Sibirsk Alma Ata - Taschkent), in Anatolien, Mesopotamien, China, in der Mandschurei, in Alaska, Bolivien, Australien usw., die berühmte Brücke des Schweizer Ingenieurs Ammann über den Hudson (Karte von New York). In den Polarkarten finden wir die damals jüngsten Forschungsfahrten und Flüge (Nordpol: Nobile - Amundsen 1926, Nobile 1928; Südpol: Byrd 1928-1930. Die Erinnerung an Nobiles Todesfahrt 1928 ist auch in der Spitzbergenkarte [S. 67] festgehalten). Der Schweizerische Mittelschul- 
atlas, Ausgabe 1932, war das erste Kartenwerk, in welchem Chinas neu entdeckter höchster Berg, der Minya Konka, eingetragen wurde. Dieser Hinweis sei dem Verfasser gestattet, da er im'Jahre 1930 diesen ostasiatischen Siebentausender erstmalig eingemessen hatte.

\section{GESAMTAUSMASS DER ATLASUMFORMUNG}

Die neuen Dispositionen und der Wille, den Atlas graphisch zu verbessern, führten zur Neuerstellung auch solcher Karten, die in Gebieten, Inhalten und Maßstäben nicht oder nur unwesentlich zu ändern waren.

Der Atlas erschien im Jahre 1932 in je einer deutschen, französischen und italienischen Ausgabe. Er enthielt 260 neue oder umgezeichnete Karten, die, zusammengerechnet, einer Fläche von 100 Atlasseiten entsprachen. Auch für die übrigen Karten waren Beschriftungen und Flächenfarben neu entworfen und lithographiert worden. Die Neuerstellungen umfaßten somit mehr als Dreiviertel des Werkes. Dabei standen für Entwurf und Reproduktion nur dreieinhalb Jahre zur Verfügung, während seinerzeit die erstmalige Erstellung der deutschen Ausgabe allein die doppelte Zeit exfordert hatte.

Aus dem bisherigen Atlas übernommen wurde die "Situation» (lineare Lagezeichnung) von 11 Seiten, ferner die Geländeschraffur folgender, insgesamt 36 Seiten einnehmender Karten:

Schweiz (physisch und politisch), Alpenländer, Danziger Bucht, Karstlandschaft, Oberrheinische Tiefebene, Auvergne, Paris, Themsemündung, London, Liverpool-Manchester, Niederlande und Belgien, Spitzbergen, Schärenküste, Sognefjord, Finnische Seenplatte, alle Erdteile physisch und politisch, Malaiischer Archipel, Atlasländer, Nilländer, Südöstliches Australien, Neuseeland, Vereinigte Staaten und Mexiko.

Für manche dieser Karten wäre eine Neuerstellung des «Terrains» ebenfalls wünschenswert gewesen, doch hätten hiefür weder Zeit noch budgetierte Mittel ausgereicht.

Der Zuwachs an Karten ergibt sich aus folgender Tabelle:

\begin{tabular}{|c|c|c|c|c|c|c|}
\hline Inhaltsgruppen & \multicolumn{2}{|c|}{ Ausgabe 1928} & \multicolumn{2}{|c|}{ Ausgabe 1932} & \multicolumn{2}{|c|}{ Zuwachs } \\
\hline hweiz und Alp & 29 Karten & 23 Seiten & 48 Karten & $=27 \mathrm{~S}$ & 19 Karten & 1 \\
\hline ri & 91 & & $126 \mathrm{Ka}$ & & & en \\
\hline emde Erdteile & $71 \mathrm{~K}$ & 42 & $85 \mathrm{~K}$ & $=43$ & en & $=+$ \\
\hline & 23 & $=$ & $24 \mathrm{~K}$ & $=10$ & 1 Karte & $=-$ \\
\hline immelsku & 1 & $2 \mathrm{~s}$ & 18 Figure & $3 s$ & & ite \\
\hline & $\begin{array}{l}4 \text { Karten } \\
8 \text { Figuren }\end{array}$ & & $\begin{array}{l}\text { ten } \\
\text { aren }\end{array}$ & & Seitenz & inve \\
\hline
\end{tabular}

Die Anzahl der Karten stieg somit um 69 (wovon 43 Spezialkarten), ohne Erhöhen der Seitenzahl. Dies wurde ermöglicht durch Wegschneiden unwesentlicher Kartenteile und vielenorts durch Maßstabsverkleinerungen. Solche erfolgten da und dort auch in der Absicht, mehrere Karten im Interesse ihrer leichteren Vergleichbarkeit auf ein und derselben Seite anordnen zu können. Hiebei schoß man für einige Spezialkarten europäischer Länder wohl etwas übers Ziel hinaus. Den Maßstabs- und Gebietsverkleinerungen standen aber, da wo es angezeigt war, auch entsprechende Vergrößerungen gegenüber.

\section{BEURTEILUNG}

Die Atlasausgabe 1932 war nicht nur reicher an Karten, sie war systematischer, konsequenter, ausgeglichener in ihrem Aufbau. Vor allem übertraf sie die früheren Ausgaben in der graphischen Form. Sie fand, trotz der ihr immer noch anhaftenden Mängel, überall eine erfreulich gute Aufnahme. Unter verschiedenen, ähnlich lautenden 
Urteilen sei dasjenige von Emmanuel de Margerie (Président de la Section de Géographie du Comité des Travaux historiques et scientifiques, Paris) angeführt. Er schloß eine eingehende Würdigung des Atlasses (Lit. Nr. 28) mit folgenden Worten:

"Comme conclusion du présent compte rendu, je n'hésite pas à déclarer, qu'à mon sens, et sous sa forme actuelle, le Schweizerischer Mittelschulatlas constitue l'Atlas scolaire le plus remarquable qui ait encore été produit jusqu'à ce jour, non pas seulement en Suisse, mais aussi bien dans le reste de l'Europe et du Monde.»

Zwei Jahre nach Erscheinen des umgeformten Werkes kam im Verlag Benno Schwabe in Basel ein Buch von Prof. Dr. Emil Letsch heraus: "Begleitworte zur 6. Auflage (1932) des Schweizerischen Mittelschulatlasses.» Es gab geographische Erläuterungen und Ergänzungen zu den Karten und Kartengruppen und trug wesentlich zu deren Verständnis und vertiefter Auswertung bei.

\section{E. DIE AUSGABEN 1936 UND 1942}

Die Ausgaben 1936 und 1942 waren im großen ganzen unveränderte Neudrucke derjenigen von 1932. Ihre Revisionen wurden durch mich in Zusammenarbeit mit Orell Füßli besorgt, ohne daß eine Redaktionskommission in Funktion trat.

Prof. Dr. August Aeppli überlebte die Ausgabe 1936 noch um nahezu zwei Jahre. Der verdienstvolle Urheber des Atlasunternehmens verschied am 15. Januar 1938 im Alter von 79 Jahren.

In der Ausgabe 1936 wurde, abgesehen von Korrekturen und Nachträgen, die physische Karte der Schweiz durch eine neue ersetzt. Ein schattenplastisches Reliefbild, das ich kurz zuvor für den Schweizerischen Sekundarschulatlas entworfen hatte, trat an die Stelle der bisherigen, stark veralteten Geländeschraffur.

Für die Ausgabe 1942 erforderte die Angliederung von Österreich an Deutschland einige Umstellungen und Neuzeichnungen. Die «Ostmark» ließ sich nicht in unsere ganzseitige politische Deutschlandkarte einfügen. Diese letztere wurde daher in kleinerem Maßstab neu erstellt und auf einer halben Seite untergebracht. Der Raumgewinn kam den deutschen Spezialkarten zugute. Niederschläge und Januar- und JuliIsothermen wurden auf einer halbseitigen Karte vereinigt. Dadurch konnten die sechs Kärtchen für Bodenkultur, Bergbau, Industrie und Binnenschiffahrt auf eine ganze Seite ausgedehnt und von $1: 15000000$ auf $1: 12000000$ vergrößert werden.

Ursprünglich war vorgesehen, die Ausgabe 1942 auf das Jahr 1940 fertigzustellen. Das Art. Institut Orell Füßli hatte in der meiner Leitung unterstellten Fachgruppe "Vermessung, Grundbuch und Karte» der Schweizerischen Landesausstellung 1939 in Zürich eine Kartendruckerei eingerichtet. Während der halbjährigen Dauer der Ausstellung wurden dort vor den Augen der Besucher ununterbrochen Karten des Mittelschulatlasses gedruckt. Bei Kriegsausbruch im Herbst 1939 stellten wir den Weiterdruck vorläufig ein. Die Ereignisse und politischen Gebietsveränderungen waren nicht vorauszusehen, und überdies fehlte es uns infolge der Mobilmachung an Arbeitskräften. Im Jahre 1941 aber war die letzte Auflage erschöpft, und so waren wir zur Fertigstellung genötigt. $\mathrm{Da}$ wir in einem offiziellen schweizerischen Schulatlas den rasch wechselnden Machtverschiebungen weder folgen konnten noch wollten, stellten wir das politische. Weltbild so dar, wie es unmittelbar vor.Kriegsbeginn gewesen war. Mobilmachung, Arbeitsunterbrechungen und Materialschwierigkeiten konnten auf die Qualität dieser 1942 erschienenen "Kriegsaus gabe » nicht ohne Einfluß sein. Einige Karten litten unter etwas zu kräftigen Tonwerten einzelner Farben. Im ganzen aber blieb, trotz der Tücken der Zeit, die graphische Qualität der beiden früheren Ausgaben gewahrt. 
Nach Kriegsende im Jahre 1945 mußte erneut an eine Revision des Atlasses herangetreten werden. Die politischen Gebietsveränderungen, die stark erhöhte Bedeutung von Rußland und Amerika und auch ein unerwartet rasches Veralten mancher Spezialkarte drängten dazu.

Es war vorauszusehen, daß bis 1948 die bisherigen Bestände der deutschen, französischen und italienischen Ausgaben erschöpft sein würden. 1948 aber war das Jahr des fünfzigjährigen Bestehens des Atlasunternehmens. So sollte der Atlas zu einer Jubiläumsausgabe gestaltet werden. Regierungsrat Dr. A. Rudolf in Bern kommt das Verdienst zu, diesen Plan mit allen Kräften gefördert zu haben. Er war von 1929 bis 1946 Präsident der Atlasdelegation der Erziehungsdirektorenkonferenz. Stets hatte er geographischen Fragen und im besonderen dem Mittelschulatlas außerordentliches Interesse und Wohlwollen entgegengebracht. Seinen Bemühungen war es zu verdanken, $\mathrm{da} B$ der Bund und die Kantone beträchtliche Geldmittel für die erneute Umarbeitung zur Verfügung stellten.

Die Atlasumformung 1928-1932 war eine erste große Etappe gewesen auf dem Wege nach einer systematischeren, ausgeglicheneren, vollständigeren Kartenauswahl und nach verbesserter graphischer Form. Manches aber blieb damals noch recht unvollkommen. Die Umformung 1945-1948 bot nun die erwünschte Gelegenheit, eine $z$ weite Etappe auf diesem Wege zurückzulegen. Eine Vermehrung von 136 auf 144 Kartenseiten sollte endlich die notwendige Entlastung im Dilemma zwischen Inhaltswünschen und Raum bringen.

\section{ARBEITSORGANISATION UND MITARBEITER}

Im Herbst 1944 bestellte die Atlasdelegation eine neue Redaktionskommission, bestehend aus dem Verfasser dieser Zeilen als Präsidenten, Prof. G. FreI (Prorektor der kantonalen Handelsschule Zürich) als Sekretär und aus folgenden weiteren Mitgliedern: Privatdozent Dr. H. Annaherm (Basel), Prof. Dr. H. Boesch (Zürich), Prof. Dr. Ch. Burky (Genf), Prof. Dr. E. Letsch (Zollikon-Zürich), Prof. Dr. F. Nussbaum (Zollikofen-Bern) und Prof. Dr. W. Wirth (Winterthur).

Die Bearbeitung des Werkes wurde wiederum mir, die Reproduktion der Art. Institut Orell Füßli AG. in Zürich übertragen.

Auch diesmal ergab eine Umfrage bei den Mittelschulen aller Landesteile einige gute und nützliche Anregungen.

Mein Entwurf eines neuen Inhaltsplanes wurde 1945 in zwei Sitzungen der Redaktionskommission durchberaten, näher festgelegt und in manchen Teilen verbessert.

Die Art der meisten neuen Karten (Spezialkarten) und der Mangel an Berufskartographen führten dazu, viele Entwürfe durch einige meiner Topographenschüler, Studierende und Absolventen der Eidgenössischen Technischen Hochschule zeichnen zu lassen. Es waren dies F. Lutz (Genf), R. Scholl (Zürich), E. Roos (Zürich), H. REIMANN (Winterthur) und andere. Für längere Zeit angestellt wurden als Geograph J. HösLr (Glarus) und als Zeichner K. FrCKer (Bern). HösıI war vor dieser Anstellung Assistent bei Prof. Dr. H. Boesch am Geographischen Institut der Universität Zürich und hatte dort eine große, neuartige wirtschaftsgeographische Weltkarte entworfen, die auch den entsprechenden Karten des Mittelschulatlasses als wertvolle Unterlage diente. Als mein Mitarbeiter widmete er sich während zweier Jahre der Neubearbeitung aller wirtschaftsgeographischen Karten. Es galt dabei nicht nur, die neuesten Quellen zu sammeln und kritisch zu sichten, sondern für einzelne Karten methodisch neue Wege zu finden. Während kürzerer Zeit wirkten an den Arbeiten Höslis auch W. Frer, cand. phil. (Zürich), und G. Srmmen, cand. phil. (Zürich), mit. 
Wie bei der Atlasumarbeitung 1928-1932, stellten sich auch jetzt wieder bewährte Fachspezialisten aus allen Teilen der Schweiz in den Dienst des Unternehmens.

Die neue geologische Alpenländerkarte wurde unter der Leitung von Prof. Dr. J. Cadrsch (Bern) durch Dr. K. Arbenz jun. (Bern) entworfen. Sie ist das Ergebnis intensivster Sammler- und Bewertungsarbeit. Prof. CADISCH revidierte auch das tektonische Kärtchen der Schweiz.

Ebenfalls für die besonderen Zwecke des Mittelschulatlasses bearbeitet wurde die Karte der Gesteine und Bodenschätze der Schwieiz. Dies besorgte in vorzüglicher Weise Privatdozent Dr. F. DE QuervaIN (Geotechnische Kommission der Schweizerischen Naturforschenden Gesellschaft, Zürich).

Dr. M. SchüEpp (Eidgenössische Meteorologische Zentralanstalt, Zürich) entwarf das originelle und lehrreiche Blatt der für den Witterungsablauf in der Schweiz besonders typischen europäischen Wetterlagen.

Prof. Dr. E. Schmid (Botanisches Museum der Universität Zürich) bearbeitete den Inhalt der Vegetationskarten der Erdteile und Erde. Er stellte damit dem Atlas in selbstloser Weise die Früchte seiner langjährigen und pionierhaften Forscherarbeit zur Verfügung. Diese Karten zählen methodisch und stofflich heute zu den neuesten und sinnvollsten Übersichtsdarstellungen der Vegetationsgebiete.

Prof. Dr. Ch. Burky (Genf) und zum Teil auch Prof. P. Dubors (Genf) besorgten die Übersetzungen aller neuen Schriftentwürfe und Texte für die französische Ausgabe. Die entsprechenden Arbeiten für die italienische Ausgabe waren Dr. E. Dal Vesco (Bellinzona) und dipl. Ing. ETH. M. ERmanNI (Sorengo und Zürich) übertragen.

Besondere Anerkennung verdient H. HürTENMOSER in St. Gallen. Er macht es sich seit Jahren zur freiwilligen Pflicht, den Mittelschulatlas auf Fehler zu untersuchen und seine Funde dem Redaktor zu melden.

Neben den Kommissionsmitgliedern und Mitarbeitern waren uns durch Uberlassung von Quellenmaterial oder durch Mitteilungen und Ratschläge behilflich: R. BArThel (Orell Füßli, Zürich), Prof. Dr. H. Bernhard (Zürich), Prof. Dr. P. Brunner (Winterthur), Prof. Dr. A. U. Döniker (Zürich), Prof. Dr. E. Egri (Zürich), Prof. Dr. H. Gutersohn (Zürich), Prof. Dr. F. Jaeger (Basel), Prof. Dr. E. Rebsamen (Zürich), Dr. R. Steiger (Zentralbibliothek Zürich), Prof. Dr. A. Sreinmann (Zürich), Privatdozent Dr. K. Suter (Zürich), Prof. Dr. P. Vosseler (Basel), Dr. E. Wanner (Eidgenössische Meteorologische Zentralanstalt, Zürich), Prof. Dr. E. Werrer (Zürich), Prof. Dr. O. WIdmer (St. Gallen), Privatdozent Dr. E. Winkler (Zürich), Prof. Dr. P. Buchner (Basel), ferner die Redaktion der Neuen Zürcher Zeitung, das Geologische Stichting in Haarlem und nicht zuletzt die Chinesische Gesandtschaft in Bern. Prof. Dr. M. WardmeIer (Eidgenössische Sternwarte, Zürich) half mir auf der Jagd nach dem vor einigen Jahren entdeckten Planeten Pluto.

All den Genannten sei für ihre Mithilfe bestens gedankt. Besonderer Dank gebührt auch diesmal wieder RrCHARD BARTHEL, dem umsichtigen und unermüdlichen Chef der kartographischen Abteilung von Orell Füßli, und ebenso seinen Kartographen und Druckern; denn nur durch die Sorgfalt und Präzision ihrer Arbeit erreichte der Atlas seine heutige Stufe.

Eine Zusammenstellung der benützten Quellen findet sich im Anhang, Seite 371.

\section{DIE WESENTLICHSTEN INHALTSÄNDERUNGEN}

a) Schweiz und Alpenländer: Die Reihe amtlicher Karten erfuhr eine Kürzung von drei auf zwei Seiten. Die Streichung des Grundbuchübersichtsplanes 1:5000 erfolgte, um bei Unkundigen den Eindruck zu vermeiden, dieses eidgenössische Planwerk bestehe sowohl im Maßstab 1:5000 wie auch in 1:10000. Die bisherige Normalform ist diejenige in 1:10000. Das Beispiel der Generalkarte 1:250000 wurde fallengelassen, da diese in Kupfer gestochene Schraffenkarte stark veraltet und in Offsetdruck auf unserem Atlaspapier nicht befriedigend wiederzugeben ist. Dies gilt 
übrigens auch für das Beispiel der Dufourkarte 1:100000 auf Seite 3. Sie bleibt nur noch im Atlas als Platzhalter für die zukünftige amtliche Karte 1:100000.

Die schöne geologische Karte der Schweiz wurde auf vielseitigen Wunsch durch eine solche der Alpenländer ersetzt. Auch Atlasersteller kehren gelegentlich zu ihrer alten Liebe zurück; denn es sei daran erinnert, daß eine solche Karte vor 1932 den Atlas bereichert hatte. Man glaubte sie dann infolge der neu eingefügten geologischen Europakarte entbehren und durch eine kleinere Karte der Schweiz ersetzen zu können. Nun drehte sich das Rad wieder rückwärts. Für Europa erachtete man - wohl mit Recht - die tektonische Karte als ausreichend. Man strich also ihr geologisches Gegenstück, womit die Alpenländerkarte wieder notwendig wurde. $\mathrm{Da}$ aber deren einstige Druckplatten längst abgeschliffen waren, mußte sie neu erstellt werden. Dies erwies. sich inhaltlich als großer Gewinn; denn die Forschung hatte in der Zwischenzeit nicht haltgemacht. Ein Vergleichen der früheren Karte (in den Auflagen 1910-1928) mit der neuen zeigt dies eindrücklich (Trennung von tertiärem und jurassischem Schiefer in Graubünden, neuere Gliederung der kristallinen Gesteine, völlig veränderte Kartierung im Apennin, in Kroatien und in einigen ostalpinen Gebieten). - Die tektonische Karte (S. 5) wurde ebenfalls auf den heutigen Stand der Forschung gebracht. Eine neue Karte der Gesteine und Bodenschätze ergänzt die drei übrigen geologischen Karten und leitet über zu denjenigen der Wirtschaftsgeographie.

Zuvor aber sei ein Blick geworfen auf die Reliefkarten schweizerischer Landschaften. Neu ist die Karte der Zentralschweiz 1:200000 auf Seite 1 des Atlasses. Sie ist gleichsam dessen Titelbild. Mit dieser Darstellung der eidgenössischen Keimzellen soll die geographisch-kartographische Bilderreihe der Schweiz eröffnet werden. Diese Karte fügt sich auch in die nachfolgende Maßstabsreihe der Vierwaldstätterseekarten. Sie ersetzt darin die ausgeschaltete Generalkarte 1:250000. An Stelle der Karte von Vevey-Montreux trat eine solche des Waadtländer Faltenjura mit den eigenartigen Verschiebungen zwischen Lac de Joux und Vallorbe. Die Karte der Säntisgruppe und des Appenz:llerlandes entstammt dem von mir bearbeiteten Schweizerischen Sekundarschulatlas. Sie stellt eine Erweiterung der bisherigen Karte des Appenzeller Molassegebietes dar. Leider mußte ihr die Reliefkarte des Oberengadins geopfert werden. Letztere enthielt inneralpine, vorwiegend kristalline Hochgebirgslandschaften. Solche aber sind auf Seite 4 (Fletschhorn) und Seite 9 (Jungfraugruppe und Aletschgletscher) vertreten. Die Säntiskarte jedoch zeigt einen neuen, sehr charakteristischen Landschaftstypus, den nördlichen Alpenrand mit dem Südwest-Nordost-Streichen eng zusammengeschobener Kalksteinfalten und den schräggestellten Nagelfluhtafeln der Molasse.

Ein Vergleichen entsprechender Städtekarten der Ausgaben 1932 und 1948 läßt das beängstigende Anwachsen der Randzonen und Vororte von Bern, Genf, Basel und besonders Zürich erkennen.

In der Reihe schweizerischer Spezialkarten wurden, außer den schon genannten, neu bearbeitet die folgenden: Zu- und Abnahme der Bevölkerung im Zeitraum von 1860-1941, Landwirtschafts- und Industriegebiete, Industrie und Gewerbe. Die erste dieser drei Karten ergänzt diejenige der Volksdichte in nützlichster Weise; sie fordert Überlegungen über die Ursachen von Veränderungen (Saugwirkung großer Industrie- und Kurorte und anderes) geradezu heraus. Die neuen wirtschaftsgeographischen Karten lassen, trotz einfacher Darstellung, die lokalen Erscheinungen oder Vorkommnisse viel präziser erfassen als die früheren Karten. Im Gegensatz zu den letzteren geben sie auch quantitative Hinweise. Dies aber ist zur Charakterisierung und Differenzierung der Gebiete und Erscheinungen von großer Bedeutung. In der Sprachenkarte wurden die größten fremdsprachigen Kolonien nachgetragen und Ungenauigkeiten der deutsch-rätoromanischen Sprachgrenze behoben. Die beiden meteorologischen Karten (Luftdruckverteilung bei Föhn und nach dessen Abzug) finden sich in neuer Form im Blatt der typischen europäischen Wetterlagen (S. 77). 
b) Europäische Länder. Die allgemeinen Übersichtskarten wurden um diejenige des europäischen und innern Rußland (S. 70-71) vermehrt. In Anbetracht der Bedeutung der Sowjetunion konnte der Hinweis auf die physischen und politischen Europakarten das Fehlen einer solchen Karte nicht mehr länger rechtfertigen. Gestrichen wurden die politischen Kärtchen der Donauländer und von Deutschland. Erstere gab neben der politischen Europakarte nichts Neues. Eine Karte der innern Ländergliederung Deutschlands aber konnte zur Zeit der Atlaserstellung nicht gezeichnet werden. Sie wird erst für spätere Auflagen wieder zur Diskussion stehen.

Folgende, wenig benötigte Neben- oder Detailkärtchen (einstige Füllkarten) wurden weggelassen: Marseille, Straßburg, Prag, Budapest, Ungarische Puszta, Belgrad, Spitzbergen. Die Karten der Fehnkolonien (Deutschland) und der finnischen Seenplatte konnten auf die Hälfte ihrer Gebiete verkleinert werden, ohne der Charakterisierung dieser eigenartigen Landschaften Abbruch zu tun.

Am wenigsten befriedigt hatte im bisherigen Atlas die Gruppe von Spezialkarten europäischer Länder. Ihre Auswahl war zu lückenhaft, ihre Maßstäbe teilweise zu klein. Selbst wenn im Unterricht nicht alle Gebiete betrachtet werden können, so ist nicht einzusehen, wieso im Atlas z. B. dem Balkan geringere Rechte eingeräumt werden als der Pyrenäenhalbinsel. Ein Schulatlas soll den Lehrer in der Stoffauswahl nicht allzusehr einengen, sondern ihm möglichste Freiheit lassen. Dies aber kann nur erreicht werden, wenn Gleichwertiges in gleicher oder ähnlicher Weise mit Karten ausgestattet wird. Eine solche Auffassung steht dem Prinzip zentrifugaler Stoff kürzung keineswegs entgegen. Es wurden daher mehrere neue Karten eingefügt und die meisten bisherigen neu bearbeitet und vergrößert. Maßstabsänderungen von 1:15000000 auf 1:12000000 oder sogar 1:8000000 führten zu 1,6- bis 3,5fachen Flächenvergrößerungen. Am günstigsten wirkten sich diese Äriderungen in. den beiden neuen Doppelblättern von Frankreich und Deutschland aus. Der Ausbau von Spezialkarten europäischer Länder war wohl der wichtigste Schritt in dex Atlaserneuerung. Was 1928-1932 begonnen, ist nun hier zu Ende geführt worden. Damit hat auch diese Kartengruppe die Stabilität erreicht, wie sie für die Erd- und Erdteilübersichten im großen ganzen schon seit 1924 bzw. 1932 bestanden hatte.

c) Europa, Übersichtskarten. Wie schon erwähnt, wurde die geologische Karte gestrichen, ebenso diejenige der Zugstraßen barometrischer Minima. Die letztere war 1924 von einzelnen Geographielehrern gewünscht, von den Fachmeteorologen jedoch als reichlich problematisch stets abgelehnt worden. Viel realer und methodisch brauchbarer ist das neu aufgenommene Blatt typischer Wetterlagen. Die Umformung der Kartengruppe Klima-Vegetation-Wirtschaft soll zusammen mit den übrigen Erdteilen besprochen werden. Ein Vergleichen der revidierten Sprachenkarte mit ihrer früheren Form läßt die umwälzende Verdrängung des Deutschtums aus den Ostgebieten erkennen. Eine endgültige Bereinigung dieser Karte wird erst vorgenommen werden können, wenn dereinst wieder stabile Zustände bestehen und zuverlässige Quellen vorliegen werden.

d) Fremde Erdteile, Gesamtkarten. Die physischen Übersichten zeigen keine, die politischen aber um so zahlreichere Änderungen (mittleres, östliches und südöstliches Europa, Sowjetunion, Syrien, Libanon, Palästina, Transjordanien, Hindustan, Pakistan, Burma, Siam, China, Tibet, Mongolei, Mandschurei, Korea, Japan; Lybien, Erythräa, Abessinien, Somaliland; Ecuador, Peru). - Die Karte von A ustralien erfuhr eine Erweiterung, so daß dér umliegende Inselkranz und Neuseeland miteinbezogen werden konnten.

Alle Vegetationskarten der Erdteile wurden neu erstellt, die Klimakarten jedoch weggelassen. Klima und Vegetation sind zwar keineswegs identische Begriffe. Dies geht u. a. aus den Ausführungen von E. Schmrd im vorliegenden Hefte deutlich 
hervor. $\mathrm{Da}$ aber die Vegetation der weitaus umfassendste, engmaschigste, langperiodigste und empfindlichste Klimaanzeiger ist, so muß in den sehr kleinen Maßstäben unseres Atlasses (1:60000000 und 1:90000000) und bei den hier notwendigen starken begrifflichen Zusammenfassungen die graphische Darstellung beider Erscheinungen zu nahezu identischen Bildern führen. Teilweise verschieden zu formulieren wären nur die Legendentexte. Wenn im bisherigen Atlas diese figürliche Übereinstimmung nicht ganz erreicht war, so lag dies an den Unvollkommenheiten der Forschung und Kartengeneralisierung. Das räumlich und zeitlich weitmaschige, höchst lückenhafte Netz von klimatischen Messungen (Wärme, Feuchtigkeit, Niederschläge, Winde und deren jahreszeitliche Verschiedenheiten usw.) kann nur mangelhaft belegen, was die Vegetationsdecke mit unendlich viel größerer Sicherheit verrät. Je vollkommener Klima- und Vegetationskarten entwickelt würden, um so mehr müßten sie sich, mindestens in unsern kleinen Maßstäben, einander angleichen. Es ist somit sinnlos, im Atlas beide Karten zu geben. Unsere Vegetationskarten lassen sich ohne weiteres auch als Klimakarten lesen. Einer begrifflichen Ergänzung bedürfen nur die Legendentexte; hiezu dient die Erdübersichtskarte der Klimatypen, wie sie auf Seite 136 der Jubiläumsausgabe vorliegt. Gerade diese Karte zeigt - abgesehen von ihrer weitergehenden Zusammenfassung - die zonale Übereinstimmung mit der danebenstehenden Karte der Vegetationsgebiete (S. 137). Es dürfte sich vielleicht empfehlen, die Legendentexte der Erdteil-Vegetationskarten in Zukunft in diesem Sinne zu ergänzen.

Für Erdteile und Erde war es gegeben, die bewährte Trennung in Karten der Wirtschaftsgebiete und solche wichtigster Produkte beizubehalten. Beide Kartengruppen wurden jedoch neu und zum Teil nach neuen Gesichtspunkten bearbeitet. Besondere Schwierigkeiten verursachte die erste dieser beiden Gruppen. Bloßes Aufzählen einiger Haupterzeugnisse und Wiederholen von Vegetationsbezeichnungen reichen zur Charakterisierung der vom Menschen gestalteten Wirtschaftslandschaften nicht aus. Die Begriffe waren umfassender zu formulieren, deutlicher auf die Tätigkeit des Menschen zu beziehen und die Gebiete neu abzugrenzen. Wirtschaftsformen oder Wirtschaftsstufen (wie z. B. Sammelwirtschaft, nomadische Wirtschaft, Hackbau, Pflugbau), die Markt- und.Versorgungsverhältnisse (Selbstversorgung oder Marktbelieferung) usw. waren mit zu berücksichtigen. Hier wie auch in den Produktekarten suchten wir nicht nur Art und Vorkommen von Erzeugnissen zum Ausdruck zu bringen, sondern, soweit dies ihre Maßstäbe zuließen, auch Unterschiede der wirtschaftlichen Intensität. Die Sowjetunion besaß in den bisherigen Atlasausgaben keine wirtschaftsgeographischen Karten; die entsprechenden Darstellungen beschränkten sich auf das südliche und südöstliche Asien. Dieser Mangel wurde nun behoben durch eine große, doppelseitige Wirtschaftskarte von Asien und durch eine kleinere, aber ebenfalls den ganzen Kontinent umfassende Produktekarte. - Die Anzahl der Produktekarten von Südamerika wurde von zwei auf sechs erhöht. Beide amerikanischen Kontinente erhielten neu eine gemeinsame Sprachenkarte. Die Völkerdarstellung wurde verbessert und einheitlich gestaltet, diejenige der Volksdichte in größerem Maßstab nach neueren Quellen gezeichnet. Als großen geographisch-methodischen Gewinn betrachten wird den Zusammenschluß von Nord- und Südamerika in den Karten für Tektonik, Niederschläge, Völker, Kolonistensprachen und Volksdichte. Die von Alaska bis Feuerland ziehende tertiäre Faltenzone ließ sich auf solche Art eindrücklicher darstellen als in den früheren, getrennten Karten. Diese neue Gruppierung ermöglichte in der Sprachenkarte ein deutliches Herausstellen der Begriffe Angloamerika und Lateinamerika. Aber auch in ästhetischer Hinsicht war der Zusammenschluß ein Gewinn. Die Räume sind freier gestaltet, die Gesamtbilder bewegter und weniger eingeengt.

e) Teilgebiets- und Nebenkarten fremder Erdteile. Neu aufgenommen wurde eine Karte der wichtigsten Teile der Sowjetunion (die schon erwähnte Karte 
des europäischen und innern Rußland). Die in der Ausgabe 1932 ausgeschaltete Karte von Palästina erfuhr in neuer Form ihre Auferstehung. Das Heilige Land beansprucht nicht nur besonderes kulturelles und aktuelles Interesse, seine Karte bereichert den Atlas um das klassische Beispiel eines Grabenbruches (Jordansenke). Eine neue, doppelseitige Orientkarte ersetzt die kleinere Karte von Westasien, gibt ein eindrückliches Bild der geopolitisch hochbedeutenden Räume zwischen Mittelmeer und Indischem Ozean, führt hinüber von Südwestasien nach Nordostafrika und ersetzt dort die bisherige Karte der Nilländer. Etwas voreilig war seinerzeit die zu exklusive Bevorzugung von Britisch-Indien. Der neue Atlas zeigt nun Vorder- und Hinterindien in gleicher Weise und in maßstäblicher Ubereinstimmung mit vielen andern Teilgebietskarten. - Die Gruppe amerikanischer Karten wurde durch eine längst gewünschte Karte von Mittelamerika und Westindien bereichert. Die Gebietserweiterung der australischen Hauptkarte führte zu einem belanglosen Zurückstutzen dortiger Nebenkärtchen.

f) Erdübersichtskarten. Obgleich diese Kartengruppe in ihren Hauptzügen am stabilsten blieb, zeigt sie im einzelnen doch einige bemerkenswerte Veränderungen. Es sei aufmerksam gemacht auf die Eintragung der Kälte- und Wärmepole in die Isothermenkarten, der Regenmaxima in die Niederschlagskarte, der Zugstraßen tropischer Wirbelstürme in die Karte der Regenzeiten. Die beiden Karten für Luftdruck und Winde wurden auf Grund neuer Quellen umgezeichnet und dabei die Luftdruckangaben nicht mehr in Millimeter, sondern in den heute üblichen Millibar gegeben $(1 \mathrm{mb}=3 / 4 \mathrm{~mm})$. Die Karten der Isoamplituden und Klimatypen konnten durch Wegschneiden unnötiger Teile und durch freiere Legendendisposition wesentlich vergrößert werden. In der letzteren wurden auch Inhalt und Legendentexte verbessert. Die sprachlich unschönen Bezeichnungen der Fachwissenschaft («warmes, sommertrockenes Klima»; "feuchttemperiertes Klima» usw.) wurden in ein besseres Deutsch übertragen («warmes Klima mit trockenem Sommer, Mittelmeerklima»; «mildes, feuchtes Klima» usw.). Die Spezialkarte der Wirtschaftsformen fiel weg, weil ihr Inhalt in den bisherigen kleinen Maßstäben nicht annähernd richtig darstellbar und übrigens in den neuen und größeren Wirtschaftskarten der Erdteile und Erde mitenthalten ist. Den freigewordenen Raum hält nun eine neue Karte der Mala riagebiete besetzt,jalso die Darstellung einer klimatisch bedingten anthropogenen Erscheinung. Die Karte der Vegetations gebiete wurde völlig umgestaltet und auf Grund neuester Forschungen bearbeitet. - Die große Übersichtskarte des heute etwas anrüchigen und schwankenden Kolonialbesitzes und des Weltverkehrs wich einer neuen Übersichtskarte der Weltwirtschaft und des Welthandels. Diese sowie die vier neuen Produktekarten auf Seite 140-141 zeigen besonders deutlich unser Bestreben, auch Intensitätsunterschiede, ferner Export- oder Importlinien und deren mengenmäßige Bedeutung zum Ausdruck zu bringen. Quantitative und dynamische Betrachtung hat die statische, diejenige bloßen lokalen Vorkommens, zu ergänzen. Nur so können die Karten gewisse Vorstellungen weltwirtschaftlicher Schwergewichte und $\mathrm{Zu}$ sammenhänge vermitteln. - Die Darstellung des Weltverkehrs in der bisherigen Form (Atlas 1932, S. 130-131) ist durch die moderne Technik überholt. Festliegend sind nur die Bahnlinien; diese aber ergeben sich besser aus den politischen Erdteilkarten. - Die Volksdichtekarte wurde revidiert und vergrößert, diejenige der Verkehrssprachen jedoch durch eine zusammengefaßte, flächentreue Darstellung der größten Weltreiche ersetzt. Von der bisherigen Weltübersichtskarte der Verkehrssprachen gilt dasselbe wie für diejenige der Wirtschaftsformen. Eine den tatsächlichen Verhältnissen auch nur annähernd entsprechende Darstellung ist in so kleinem Maßstab nicht möglich. Der Begriff «Verkehrssprache» ist an und für sich unklar. Die Karte ist um so eher zu entbehren, als nun der Atlas neben der Sprachenkarte von Europa 
auch eine solche beider Amerika enthält. Für die übrigen Gebiete geben die Völkerkarten und die politischen Karten der Erdteile Auskunft. In allen selbständigen Staaten (Türkei, China, Ägypten usw.) herrscht die Sprache der betreffenden Völker. In den Kolonien, Dominien usw. bestehen nebeneinander die Eingeborenensprachen (nach den Völkerkarten) und diejenigen der sogenannten Schutzmächte usw. (nach den politischen Karten).

h) Himmelsgewölbe, Mond und Gestirne. In die Familie der Planeten (Sonnensystem) wurde der vor einigen Jahren entdeckte Pluto aufgenommen, was eine graphisch recht heikle Verschiebung der Mondkarte zur Folge hatte. Bedeutender waren die Änderungen auf dem letzten Atlasblatt. Die Vorsteherschaft eines Mädchengymnasiums drohte dem Redaktor mit einem Marsch nach Bern, falls er sich weigere, die vier inkonsequent gezeichneten Figuren des Himmelsgewölbes nach den Regeln der Darstellenden Geometrie richtigzustellen. Dieser Wunsch ist nun erfüllt. Doch fürchte ich, daß nächstens ein Knabengymnasium anrückt, mit dem Begehren, die neuen Figuren wieder in die alte, anfechtbare, aber vielleicht verständlichere Form zurückzutransformieren!

i) Bemerkungen zu den Projektionen. Die neuen Gesamtkarten von Nordund Südamerika (Tektonik, Niederschläge, Völker, Sprachen, Volksdichte) besitzen eine schiefachsige, flächentreue Zylinderprojektion. Berührungskreis von Kugel und Zylinder (Zylinderquerschnittskreis) ist ein Kugelgroßkreis, der von Alaska über Savannah (Florida), Santiago (Kuba) in Richtung Porto Alegre (Südbrasilien) führt. Die Entfernungen der äußersten Kartenteile von diesem Krẹis sind relativ gering, so $\mathrm{da} ß$ die Winkelverzerrungen nicht störend in Erscheinung treten. Die mittleren Meridiane bilden Wendekurven, was diesem Netz seine elegante Eigenart verleiht.

Die neue Erdkarte der Weltwirtschaft und des Welthandels (S. 138-139) wurde in der Merkatorprojektion (einer normalen, winkeltreuen Zylinderprojektion) entworfen. Mitbestimmend für diese Wahl war eine analog konstruierte Karte, die kurz zuvor im Geographischen Institut der Zürcher Universität entstanden war und die unserer Karte als Grundlage diente. Die inhaltlich reichsten Gebiete, Europa, Japan, die Vereinigten Staaten von Amerika usw., gelangen darin zu relativ großer Abbildung, und die ozeanischen Handelslinien erscheinen sehr übersichtlich. Auch die Beziehungen $z$ wischen Wirtschaftsformen und Breitenzonen sind leichter zu überblicken als in Karten mit gekrümmten Parallelkreisen. Solchen Vorzügen steht jedoch der Nachteil starker Flächenverzerrungen gegenüber, was für eine Wirtschaftskarte keineswegs belanglos ist. Die beiden Nebenkärtchen dieses Blattes iṇ normaler, flächentreuer, modifizierter Zylinderprojektion (von Hammer) ermöglichen jedoch eine gewisse Korrektur allzu irriger Vorstellungen der Flächengrößen.

Wir behalten die allgemein übliche Bezeichnung «Projektionen» bei, auch da, wo es sich nicht um Projektionen im Sinne der Darstellenden Geometrie handelt. Die letztere besitzt kein Recht, diesen Ausdruck für sich allein zu beanspruchen. Der Ausdruck "Kartennetz» eignet sich nicht als Ersatz, $\mathrm{da}$ er vieldeutig ist.

\section{GESAMTAUSMASS DER ATLASUMFORMUNG}

Völlig neu erstellt wurden 91 von total 266 Karten. Die Flächen dieser neuen Karten zusammengerechnet, ergeben 44 von insgesamt 144 Seiten. Durch solche Zahlen ist jedoch das Ausmaß der Atlasumformung nicht erfaßt. Politische und andere Nachführungen, graphische Verbesserungen, im ganzen Tausende von Nachträgen und Korrekturen, ferner Umstellungen der Kartenreihenfolge und damit verbundene Umdruckarbeiten usw. traten hinzu. Für die französische und italienische Ausgabe waren überdies Übersetzungen und Gravuren der Beschriftungen aller neuen Karten zu besorgen. 
Der Inhalt von 52 der neu erstellten Spezialkarten konnte nicht irgendwelchen bereits vorliegenden Karten entnommen, sondern mußte auf Grund wissenschaftlicher und statistischer Literatur neu und erstmalig bearbeitet und kartographisch geformt werden. Dies führte zu einer weiteren außerordentlichen Arbeitsvermehrung, aber auch zu einer entsprechenden Wertsteigerung des Atlasses. Nicht zuletzt durch die große Anzahl solch originaler, erstmals publizierter Spezialkarten unterscheiden sich seine jüngern Ausgaben von den ältesten und auch von vielen andern Schulatlanten. Ihre Vermehrung im Laufe der Atlasentwicklung ergibt sich aus folgender Zusammenstellung:
Ausgabe $1910=5$ original bearbeitete Spezialkarten.
Ausgabe $1924=32$ original bearbeitete Spezialkarten.
Ausgabe $1932=54$ original bearbeitete Spezialkarten.
Ausgabe $1948=60$ original bearbeitete Spezialkarten.

Diese Zahlen beruhen zum Teil auf Schätzungen, da der Anteil originaler Bearbeitung bei den ältesten Ausgaben nicht mehr überall mit Sicherheit festgestellt werden kann und sich in mancher Karte übernommene und original entworfene Elemente mischen. Der Vergleich hinkt überdies zuungunsten der jüngsten Ausgabe, da hier oft in eine Karte zusammengefaßt ist, was in der Ausgabe 1932 auf mehrere Karten aufgeteilt war.

Den Ausgaben vor 1932 entstammen nur die Gebirgsschraffen von 281/2 Kartenseiten und ein Teil des Situationsinhaltes einiger weniger Blätter.

Die Verteilung der Karten auf die einzelnen Inhaltsgruppen und die entsprechenden Änderungen gegenüber der Ausgabe 1932 sind aus folgender Tabelle ersichtlich:

\begin{tabular}{|c|c|c|c|c|c|c|}
\hline gruppen & \multicolumn{2}{|c|}{ Ausgabe 1932} & \multicolumn{2}{|c|}{ Ausgabe 1948} & \multicolumn{2}{|c|}{ Änderungen der Anzahl } \\
\hline Schweiz und Alpe & 48 Karten & $=27$ Seiten & 48 Karten $=$ & $=29$ Seiten & & +2 Seiten \\
\hline briges Europa & 126 Karten & $=53 \mathrm{~s}$ & 110 Karten $=$ & $=53$ & -16 Karten & - \\
\hline Erdteile & 85 & $=$ & en $=$ & $=49$ & - 1 Karte & $+6 \mathrm{Se}$ \\
\hline en & 24 & $=10$ & 24 Karten $=$ & $=10$ & - & - \\
\hline limmelskunde & 18 Figuren & 3 Seiten & 18 Figuren $=$ & 3 Seiten & - & - \\
\hline tal & $283 \mathrm{~K}$ & & $\begin{array}{r}266 \mathrm{~F} \\
18 \mathrm{~F}\end{array}$ & $=$ & -17 & \\
\hline
\end{tabular}

Die Ausgabe 1948 wurde somit um 8 Seiten vermehrt, die Anzahl der Karten aber um 17 verkleinert. Dieser scheinbare Widerspruch erklärt sich aus den Vergrößerungen mancher Karten und Maßstäbe. Bei der früheren Umarbeitung (1928-1932) war bei gleichbleibender Seitenzahl diejenige der Karten um 69 vermehrt worden, was da und dort zu allzu kleinen Kärtchen geführt hatte. In der Jubiläumsausgabe 1948 wurde endlich Luft geschaffen. Die Seitenvermehrung und vielenorts bessere Raumdispositionen erlaubten die Erstellung größerer, weniger eng eingeschachtelter Karten, was nicht nur inhaltlich, sondern auch in ästhetischer Hinsicht zu begrüßen war.

\section{ZEITBEDINGTE SCHWIERIGKEITEN}

Die zeichnerische und technische Erstellung der Jubiläumsausgabe 1948 hatte mit ungewöhnlichen Schwierigkeiten zu kämpfen.

Bei Beginn der Arbeiten im Jahre 1945 bestand wohl Waffenstillstand, aber es herrschte noch kein Friede, und niemand wußte, wann die verschiedenen Friedensverträge abgeschlossen und wie sie einst aussehen würden. Anderseits sollte der Atlas im Augenblick seines Erscheinens möglichst die neuesten geopolitischen Zustände wiedergeben. Dies zu erreichen, war nicht leicht, da der Druck des Werkes etwa zweieinhalb Jahre beanspruchte und bereits im Frühjahr 1946 einsetzte. Unsere Zeit- 
tabelle für Bearbeitung, Plattenerstellung und Druck der einzelnen Bogen war diesen Umständen anzupassen. Alle Karten schweizerischen Gebietes, amerikanische Karten und solche der Polargebiete, unpolitische Erdübersichtskarten und die Darstellungen des Himmels wurden vorangestellt, die in politischer Gärung begriffenen Räume von Europa, Asien und Afrika jedoch möglichst zurückgeschoben. So gelang es durch wiederholtes Umdisponieren, die neuen Friedens- oder Staatsverträge für Finnland, die Donaustaaten, Italien und Triest, ebenso die Neuordnung der Dinge in Korea, China, Siam und Abessinien abzuwarten. Selbst die Neugestaltungen in Vorderindien und Burma konnten in letzter Stunde wenigstens teilweise Berücksichtigung finden.

Weitere Schwierigkeiten waren personeller Art. Infolge des kriegsbedingten eidgenössischen Kartenverbotes hatte das privatwirtschaftliche Kartengewerbe von 1939 bis 1945 an Arbeitsmangel gelitten und damit auch qualitative Schwächungen erfahren. Der beste Wille bringt keinen guten Atlas zustande, wenn es an genügend eingeübten Hilfskräften fehlt. Die Lage wurde weiter erschwert durch die nach Kriegsende unvermittelt einsetzende Hochkonjunktur. Diese führte zu Überbeanspruchungen, zu Verspätungen, zu einem Rennen um die Zeit. Solches aber ist nicht von Gutem für ein Werk, dessen Erstellungsdauer von nur drei Jahren in Anbetracht der umfangreichen Teilerneuerungen ohnehin äußerst kurz bemessen war.

Zu den Personalschwierigkeiten gesellten sich die Tücken des Materials. Umdruckpapiere, Fette, Öle, Farben, alle die Spezialitäten, die die Qualität lithographischer Erzeugnisse mitbedingen, waren nicht mehr in gewohnter Qualität erhältlich. Defekte Druckerpressen konnten nicht leicht und nicht rasch repariert oder ersetzt werden, da sie ausländischer Herkunft sind.

Ein kritischer Beurteiler wird Spuren solcher Schwierigkeiten in einzelnen Karten erkennen können. $\mathrm{Da}$ die Jubiläumsausgabe, im ganzen gesehen, aber trotzdem keinen Vergleich zu scheuen braucht, stellt den aufopfernden Bemühungen all meiner Mitarbeiter und vor allem dem graphisch-technischen Personal des Hauses Orell Füßli das schönste Zeugnis aus.

\section{G. BEZIEHUNGEN ZU DEN NEUEREN VOLKS- UND SEKUNDARSCHULATLANTEN}

Im Schoße der Erziehungsdirektorenkonferenz hatte man schon 1898, anläßlich der Gründung des Mittelschulatlasses, auch die Erstellung und Herausgabe von Unterstufenatlanten auf interkantonaler Basis erwogen. Die Ansichten waren indessen geteilt. Die Vertreter der welschen Kantone konnten sich für solche Projekte nicht erwärmen, diejenigen der deutschen Schweiz aber befürworteten einen Sekundarschulatlas, der als Auszug aus dem Mittelschulatlas erstellt werden sollte. Überdies wurde vom Kanton Zürich eine zweite, noch engere Kartenauswahl als Atlas für die 7. und 8. Klasse der Primars chule gewünscht. Die gemeinsame Verwirklichung dieses letzteren Projektes wurde jedoch abgelehnt.

"Um eine Wegleitung zu erhalten, wie aus dem Atlas für Mittelschulen durch richtige Auswahl der Darstellungen ein solcher für die Sekundarschulen zu erstellen sei, der den Bedürfnissen dieser Schulstufe entspricht, wurden die Ansichten einer Konferenz von Schulmännern eingeholt, die am 15. Mai 1909 in Zürich tagte und an der 20 Kantone und Halbkantone vertreten waren. Aus den Beratungen dieser Konferenz mit der Redaktionskommission des Mittelschulatlasses ging das Programm hervor, das im Sekundarschulatlas mit 88 Seiten ausgeführt ist. »

Also steht es geschrieben im Vorwort zur 1910 erschienenen ersten Auflage des Schweizerischen Sekundarschulatlasses. Herausgeber und Ersteller waren dieselben wie für den Mittelschulatlas. 
1914 und 1925 erschienen unveränderte zweite und dritte Auflagen. Dann übernahm die Erziehungsdirektion des Kantons Zürich, ihrer alten Tradition folgend, die weitere Herausgabe. Eine Kommission zürcherischer Sekundarlehrer legte gemeinsam mit Prof. Dr. A. AEppli einen neuen Inhaltsplan fest. In der abgeänderten, auf 80 Kartenseiten gekürzten Form erschienen 1926 eine vierte und 1930 eine fünfte und letzte Ausgabe.

Schon lange vorher hatte der Kanton Zürich sein von mehreren Kantonen abgelehntes Projekt eines Primarschulatlasses zähe weiter verfolgt. Im Jahre 1913 kam ein Vertrag zwischen der Erziehungsdirektorenkonferenz und der Erziehungsdirektion des Kantons Zürich zustande, wonach der letzteren gegen eine Entschädigung das Recht eingeräumt wurde, Druckplatten des Mittelschulatlasses zur Erstellung und Herausgabe des gewünschten Lehrmittels zu benützen. Dieser, 44 Kartenseiten umfassende "Atlas für die Oberstufe der Primarschule des Kantons Zürich» erschien erstmals im Jahre 1920. Eine weitere Auflage folgte 1922.

Alle diese Sekundar- und Primarschulatlanten waren Notbehelfe. Dank dem Mittelschulatlas hatten die deutschschweizerischen Schulen innert nützlicher Frist und zu niedrigem Preise kartographische Lehrmittel erhalten und somit ein Ziel erreicht, das auf gesamtschweizerischem Wege unerreichbar schien. In methodischer Hinsicht waren jedoch solche Kartenzusammenstellungen höchst unzweckmäßig. Aus einem Mathematikbuch der Mittelschule kann man durch Herausschneiden jeder zweiten oder dritten Seite keine Rechenbücher für Primar- und Sekundarschulen machen. Nicht ganz, aber fast so ungeschickt war die Erstellungsart der genannten Unterstufenatlanten. Ihre Mängel ermutigten das Art. Institut Orell Füßli in Zürich und die Geographische Anstalt Kümmerly \& Frey in Bern zur Erstellung und Herausgabe eigener Volksschulatlanten.

Geistiger Urheber des Orell-Füßli-Atlasses war Fridolin BeCKer, Professor für Topographie und Kartographie an der Eidgenössischen Technischen Hochschule in Zürich. Krankheit und Tod rissen ihn jedoch mitten aus der Arbeit. Ich führte dann sein Werk zu Ende. Dieser "Neue schweizerische Volksschulatlas» erschien im Jahre 1924. Er wies 2 Signaturentafeln und 41 Kartenseiten auf. Seine äußere, buchtechnisch-typographische Gestaltung und die Einführungsblätter in die Kartenlehre fanden allgemeine Anerkennung. In Auswahl, Inhalt und Form der Karten ausländischer Gebiete aber war er zu dürftig und selbst für die Oberstufe der Primarschule zu elementar. Obschon er in den Schulen einzelner Kantone Aufnahme fand, unterblieb seither die Herausgabe weiterer Auflagen.

Unter der Bezeichnung "Schweizerischer Schulatlas» erschien kurz vorher ein zunächst 37, später 41 und dann 50 Seiten umfassender Unterstufenatlas des Geographischen Kartenverlages Kümmerly \& Frey. Buchtechnische Ausstattung und Karten-Einführungsblätter konnten sich mit dem Orell-Füßli-Atlas nicht messen; doch überbot er diesen in der Anzahl und Qualität allgemeiner und spezieller Karten ausländischer Gebiete. Er erfuhr mehrere erweiterte (leider nicht datierte) Auflagen.

Kehren wir zurück zum Sekundarschulatlas, der als Kürzung des Mittelschulatlasses durch die Erziehungsdirektion des Kantons Zürich herausgegeben worden war.

Das Verlangen nach einem methodisch besser aufgebauten, der Sekundarschule angepaßten und von Nebenrücksichten befreiten Atlas wurde immer stärker. Ende 1929 bestellte die Sekundarlehrerkonferenz des Kantons Zürich eine Kommission zur Aufstellung eines Inhaltsplanes für ein neues, vom Mittelschulatlas unabhängiges Lehrmittel. Der Entwurf dieser Kommission wurde in Beratungen mit den Vertretern von zwölf andern deutschsprachigen Kantonen bereinigt. Im Mai 1931 richtete die Zürcher Kommission ein Gesuch an den Erziehungsrat, der Kanton Zürich möchte das gewünschte Werk an die Hand nehmen und herausgeben. Dieses Gesuch wurde 
günstig aufgenommen. Kostenberechnungen ergaben jedoch die Unmöglichkeit, einen Atlas von 80-90 vollständig neuen Kartenseiten zu einem erträglichen Preise herstellen und an die Schulen abgeben zu können. Darauf, im Sommer 1931, beauftragte mich die Erziehungsdirektion des Kantons Zürich, die Angelegenheit ebenfalls zu prüfen und einen gangbaren Weg zu suchen. Um jene Zeit lagen bereits die meisten der für den Mittelschulatlas des Jahres 1932 neu erstellten Karten vor. Nach dem Urteil sachkundiger Schulmänner waren manche derselben, z. B. die schweizerischen Reliefund Städtekarten, ohne weiteres, andere, wie z. B. die Länder- und Erdteilübersichten, mit gewissen Vereinfachungen auch für einen Sekundarschulatlas geeignet. Ich stellte ein neues Programm auf, das zunächst nur auf die Bedürfnisse der Sekundarschule, nicht aber auf eventuelle Karten des Mittelschulatlasses Rücksicht nahm. Im Gegensatz zum früheren Projekt hielt ich mich jedoch im Kartenformat und in den Maßstäben einiger Hauptkarten an den letzteren. Darauf wurde untersucht, welche Karten oder welche einzelnen Druckplatten ohne Zwang der neuen Aufgabe dienstbar gemacht werden könnten. Das neue Programm umfaßte, gleich wie dasjenige der Kommission, 80 Seiten. Hievon sollten 31 Seiten völlig neu erstellt und 49 Seiten dem Mittelschulatlas entnommen werden, jedoch auch diese nicht ohne die erforderlichen Anpassungen. Für viele Karten war eine Neuerstellung der Schriftplatten vorgesehen. Kostenberechnungen erwiesen die Durchführbarkeit des Projektes. Eine von der Zürcher Erziehungsdirektion bestellte Kommission, bestehend aus Vertretern von fünf Kantonen, empfahl die neuen Vorschläge einstimmig und ohne Abänderungen zur Ausführung. Die Kartenbearbeitung wurde mir, deren Reproduktion dem Art. Institut Orell Füßli übertragen. Das neue Werk erschien unter der Bezeichnung «Ed. Imhof, Schweizerischer Sekundarschulatlas " im Jahre 1934 in einer ersten Auflage. Seither sind 1937, 1940 und 1946 neue, nachgeführte, aber im übrigen unveränderte Auflagen herausgegeben worden.

Dieser Atlas war nicht nur Nutznießer des Mittelschulatlasses, sondern in bescheidenem Ausmaß auch dessen Förderer. Das Relief der doppelseitigen physischen Karte der Schweiz, die neue Säntiskarte, die Volksdichtekarte von Skandinavien, die neue, erweiterte Australienkarte sind vom Sekundarschulatlas demjenigen der Mittelschule zur Verfügung gestellt worden. Überdies kamen gelegentlich auch Nachführungen von Druckplatten des kleinern Atlasses dem größeren zugute. - Die wechselseitigen Beziehungen rechtlicher, finanzieller und technischer Art wurden durch einen Vertrag zwischen der Konferenz der kantonalen Erziehungsdirektoren und der Erziehungsdirektion des Kantons Zürich geregelt.

Ausführlicheres vgl. Lit. Nr. 17 und 19. Siehe auch die Buchbesprechung von K. Suter in der Geographica Helvetica 1948, Heft III. 


\section{TEIL: FORM UND ERSTELLUNG DES MITTELSCHULATLASSES UND SEINER KARTEN}

\section{Vorbemerkungen}

Moderne Oberstufenatlanten weisen in ihren Karten die verschiedenartigsten Inhalte und Maßstäbe auf. Sie übertreffen hierin alle andern Kartensammelwerke. Sie enthalten allgemeine topographische und geographische Karten in allen Abstufungen vom Detailortsplan bis zur Erdübersichtskarte. In der Vielfältigkeit der Spezialdarstellungen reichen sie an die heutigen großen geographischen Landesatlanten heran. Solche Mannigfaltigkeit ist auch dem Schweizerischen Mittelschulatlas eigen. Seine Bearbeitung stellt daher so viele Aufgaben oder Probleme, daß deren lückenlose Darlegung nahezu den.Inhalt eines Lehrbuches der Kartographie ergäbe. Es kann sich nicht darum handeln, hier ein solches vorzulegen. Wir beschränken uns auf einige wenige Hinweise, vor allem auf diejenigen Dinge, die unserm Mittelschulatlas eigen sind. Überdies soll die Aufmerksamkeit auf folgeńde Umstände gelenkt werden:

Die Form einer Atlaskarte ist durch Rücksichten auf die übrigen Blätter und aufs Ganze weitgehend gebunden und eingeengt. Diese Erschwerung läßt sich durch gewisse Maßnahmen vermindern.

Während die Herstellung der Karten stets Sache des Fachtechnikers bleibt, werden vielenorts die Dispositionen über deren Auswahl, Inhalt, formale Gestaltung, Maßstäbe, ferner über Anordnung und Reihenfolge von Geographen und Pädagogen mitbestimmt. So notwendig dies im Interesse des geographischen Gehaltes und des didaktischen Zweckes ist, so verhängnisvoll können die Folgen sein, wenn dabei buchund kartentechnische Spezialerfahrungen fehlen. Es bestehen wesentliche Unterschiede $z$ wischen der Bearbeitung eines Textbuches und derjenigen eines Kartenbandes. Der Autor des ersteren braucht in der Formulierung und Anordnung des Stoffes auf die nachfolgende technische Erstellung keine besondere Rücksicht zu nehmen. Bei Atlanten hingegen sind inhaltliche, didaktische, kartographische, reproduktionstechnische und buchtechnische Dinge unlösbar miteinander verknüpft. Der Inhalt wird in vollem Maße nur durch gute kartographische und buchtechnische Lösung greifbar. Ebenso falsch aber wäre es, Schulatlanten und Schulkarten ohne Mitwirkung des Pädagogen und Geographen erstellen zu wollen. Ein solches Vorgehen hat schon oft $z u$ Mißerfolg oder bloßem, unkritischem Kopieren geführt.

Die Arbeit am Mittelschulatlas gab mir Gelegenheit, über Aufbau und Gestaltung solcher Werke und über viele kartographische Fragen Erfahrungen zu sammeln. Sie sollen hier im Interesse der Weiterentwicklung dargelegt werden. Zudem hoffe ich, damit auf manche Frage, die sich der Atlasbenützer stellen mag, Auskunft geben zu können.

\section{A. DISPOSITIONSFRAGEN}

\section{BUCH- UND KARTENFORMATE}

Im Durchschnitt einer Vielheit von Karten verschiedenster Länder und Gebiete ist die quadratische Blattform am rationellsten; denn für die Erstreckung geographischer Areale ist keine Himmelsrichtung besonders bevorzugt. Wohl aus diesem Grunde besitzen sehr viele, besonders ältere Schulatlanten dem Quadrat angenäherte Quer- oder Hochformate. Querformate sind in neuerer Zeit wenig beliebt, weil die breiten Karten- 
blätter zu schwer in den Buchrücken hängen und die aufgeschlagenen Bücher auf den Schulbänken seitwärts zuviel Raum beanspruchen.

Das Format von 23 auf $35 \mathrm{~cm}$ des Schweizerischen Mittelschulatlasses entspricht angenähert demjenigen des "Diercke». Der "Satzspiegel», d. h. das für die Karten zur Verfügung stehende Rechteck, mißt für die einfache Buchseite 17 auf $29 \mathrm{~cm}$. Dieses Verhältnis von zirka 1:1,7 weicht auffallend stark vom Quadrat ab, erscheint somit auf den ersten Blick recht ungünstig. Tatsächlich aber hat es sich sehr bewährt. In der neuesten Altasausgabe finden sich nämlich nur 21 einseitige Karten, also solche, für die sich die schmale Rechteckform nachteilig auswirken könnte. In der ersten Ausgabe (1910) waren es sogar nur 18. Für einige dieser Karten ist überdies das Verhältnis von Breite zu Höhe durch Abtrennen einer Legendenfläche verbessert. Für alle die zahlreichen halb- oder doppelseitigen Karten aber führt das schmale Buchformat zu recht günstigen, dem Quadrat angenäherten Rechtecken. Dies trifft auch für Seitenaufteilungen in 6 oder 8 kleine Kärtchen zu. Besonders geeignet ist das Buchformat für die $2 / 3$ seitigen und die 1932 eingeführten, nahezu quadratischen $11 / 2$ seitigen Karten. In Abweichung vom Durchschnitt aller Fälle erfordern die relativ zahlreichen Übersichtskarten der Schweiz und der Erde rechteckige Querformate. Solche aber stehen in den Drittel-, Halb- und Doppelseiten zur Verfügung.

Je größer das Atlasformat und insbesondere die Buchhöhe, um so günstiger für die Karten. Der Schweizerische Mittelschulatlas geht hierin bis nahe an die praktisch zulässige obere Grenze heran. Diese ist gegeben durch die Dimensionen der Schülermappen und der Tischplatten in den Schulzimmern. Die Höhe des Atlasses $(35 \mathrm{~cm})$ übersteigt diejenige der meisten ausländischen Schulatlanten um etwa $4-6 \mathrm{~cm}$, ermöglicht aber dafür größere Maßstäbe für die Hauptkarten. Dies ergibt sich aus folgender Zusammenstellung:

Schweizerischer Mittelschulatlas

$\begin{array}{lll}\text { Europäische Länder } & 1: 4000000 & 1: 5000000-6000000 \\ \text { Europa } & 1: 15000000 & 1: 20000000-25000000 \\ \text { Fremde Erdteile } & 1: 30000000 & 1: 40000000-50000000\end{array}$

Nur sehr wenige Schulatlanten, so z. B. der im übrigen ausgezeichnete österreichische Slanar-Atlas, besitzen wesentlich größere, jedoch für die Hand des Schülers zu große Formate.

All diese Bztrachtungen zeigen, daß die einstige Redaktionskommission bei der Gründung des Schweizerischen Mittelschulatlasses in der Wahl des Buchformates eine glückliche Hand hatte.

\section{WAHL DER KARTEN UND IHRER MASSSTÄBE}

Menge und Auswahl der Karten, ihre Abhängigkeit von den Lehrzielen des Geographieunterrichtes und die Entwicklungen im Laufe der Zeit sind im ersten Teil dieser Abhandlung dargelegt worden. Hier sind nur noch einige allgemeine und praktische Hinweise nachzutragen.

Die Karten eines Schulatlasses bilden einen aufs äußerste konzentrierten, durchgesiebten Extrakt aus einer zunächst fast unübersehbaren Menge von Möglichkeiten. Um in diese Flut möglicher Karten und Maßstäbe eine gewisse Ordnung zu bringen, ist ein stufenweises Vorgehen erforderlich:

Zunächst werden alle Hauptkarten, d. h. die unentbehrlichen großen Übersichtskarten der Schweiz, der übrigen europäischen Länder, der Erdteile und Erde in zentrifugal abnehmenden Maßstäben zusammengestellt. Sie bilden das feste Gerüst des Ganzen. Ihre Maßstäbe ergeben sich Hand in Hand mit der Wahl des Buchformates. 
Dann folgen für all diese Gebiete in analoger Abstufung die Spezialkarten. Obschon hier, wie überall, Unwichtiges hinter Wichtigerem zurückstehen soll, ist auf eine gewisse Systematik und Konsequenz in der Auswahl zu achten. Diese Auswahl soll eine vergleichende und erklärende Art der Stoffbetrachtung erleichtern und Kulturgeographisches auf die Naturgegebenheiten aufbauen lassen. Solche systematische Auswahl war für die Erdübersichten und im wesentlichen auch für das eigene Land, die Schweiz, schon in der ersten Ausgabe des Mittelschulatlasses erreicht. Die verschiedenen Umarbeitungen führten dann schrittweise zu einem besseren Ausbau auch für die Erdteile und europäischen Teilgebiete.

Erst an dritter Stelle der Inhaltsplanung stehen die sogenannten Nebenkarten, d. h. die allgemeinen Teilgebiets- und Regionalkarten. Sie sind nicht etwa von geringerer Bedeutung, ganz im Gegenteil. Erst diese detailreicheren Karten besonders wichtiger, stark gegliederter oder charakteristischer Gebiete führen zu einigermaßen realen Vorstellungen. Doch empfiehlt es sich, sie zuletzt in das Programm einzufügen, weil sie im Gegensatz zu den Haupt- und Spezialkarten - in Gebietsauswahl und Maßstäben unbegrenzte Variationen zulassen. Sie bilden zwischen den beiden andern, starreren Kartengattungen die Füll- und Ausweichmasse, so wie der Flysch zwischen harten Kalk- und Kreidegesteinen. Ihre geschickte Wahl verlangt umfassende allgemeinund regionalgeographische Kenntnisse und ein sehr umfangreiches kartographisches Vergleichsmaterial. Die Überfülle an Geeignetem bringt es mit sich, daß keine Auswahl alle Wünsche befriedigen kann. Viele dieser Nebenkarten, selbst solche ganz verschiedener Erdstriche, stehen miteinander in enger Wechselbeziehung, etwa in der Art des Inhaltes kommunizierender Röhren. Es sollen z. B. verschiedenartige Vulkanlandschaften, Küstenformen, Oasentypen, Städte- und Hafentypen usw. irgendwo im Atlas zu finden sein. Fehlt in der einen Ländergruppe der Raum, um ein vorhandenes Beispiel unterzubringen, so ist ein entsprechender Typ anderswo zu suchen und einzuschalten.

Ist einmal ein Atlas geschaffen, so können bei einer späteren Umarbeitung Karten nicht überall nach Belieben ein- und ausgeschaltet werden. In solchen Dispositionsfragen ist ein Atlas mit einem vielstöckigen Gebäude vergleichbar, wobei jede Karte einem Zimmer, jede Länder- oder Gebietsgruppe einem Stockwerk entspräche. Es ist nicht möglich, das erste Stockwerk eines Gebäudes um ein Zimmer zu vergrößern und den hiefür nötıgen Raum drei Treppen höher oben einzusparen. Ebensowenig kann man im Atlas, ohne durchgreifende Neudispositionen großer Buchteile, irgendwo eine halbseitige Karte einfügen, um ihre Fläche z. B. 30 Seiten weiter hinten durch Streichung einer halben Seite wieder einzusparen. Selbst für ganzseitige Karten geht dies in der Regel nicht. Die Mannigfaltigkeit der Kartengrößen und die unabänderliche Aufeinanderfolge von einfachen und Doppelseiten verhindern ein beliebiges Vor- oder Zurückschieben der Inhaltsteile. Hierin unterscheiden sich Atlanten von Textbänden. Dies sei betont, um eine gewisse Zurückhaltung des Redaktors gegenüber gelegentlichen - scheinbar geringfügigen - Änderungswünschen zu rechtfertigen. Ein Abtauschen ist nur für sehr nahe benachbarte Karten möglich.

In der methodischen Literatur über Schulatlanten wird mit Eifer die leichte Vergleichbarkeit der Kartenmaßstäbe betont. Dieser Gesichtspunkt wird indessen überschätzt. Wichtig ist maßstäbliche Übereinstimmung nur für Karten analoger Art, also z. B. für möglichst viele Karten ausländischer Städte, für die Übersichtskarten europäischer Länder, für diejenigen fremder Erdteile usw. Ob aber die Maßstäbe der Alpenländerkarte 1:2500000, der Balkankarte 1:4000000 und der Asienkarte 1:30000000 leicht miteinander meßbar sind, ist nebensächlich. Niemand wird sie unmittelbar miteinander vergleichen. Im Atlas bietet sich reichliche Gelegenheit, Gebietsdimensionen in gleichmaßstabigen Karten unmittelbar miteinander in Beziehung zu setzen. Wo dies nicht möglich ist, sind entsprechende kleine Vergleichskärtchen in leere Ecken der wichtigsten Karten gestellt. Wesentlich hingegen ist, daß 
die Maßstäbe der allgemeinen Karten einfach sind: Für gewisse spezielle Darstellungen erscheint mir jedoch auch dies ziemlich belanglos.

Von großer Bedeutung, jedoch in Schulatlanten oft vernachlässigt und in der methodischen Literatur übersehen, ist folgende Anforderung:

Die Maßstäbe sollen dem gewünschten Inhalt und dem didaktischen $\mathrm{Zweck}$ der Karte an gepaßt sein. Hierin wird oft gesündigt. Unnötig große Maßstäbe bedeuten Platzverschwendung. Bei der Altasumformung 1928-1932 gelang es mir, beträchtlichen Raum zu gewinnen durch Verkleinerung unnötig groß gezeichneter Karten.

Beispiele: Frankreich: Departemente. Europäische Länder: Volksdichte. Einzelne Erdteile: Niederschläge, Volksdichte, Völker, Religionen. Erde: Vegetationsgebiete und Meeresströmungen.

Viel häufiger finden wir zu kleine Maßstäbe, besonders in Städte-, Landschaftsund allgemeinen Gebietskarten. Eine Karte der Niagarafälle soll, wenn sie wirklich eine solche sein will, nicht nur deren geographische Lage und den Niveauunterschied zwischen Eriesee und Ontariosee angeben; denn solches zeigen auch die großen Gebietsübersichten. Sie soll vielmehr die Form der Fälle, ihre Fallhöhe und die wechselnden Taltypen des Niagara River erkennen lassen. Bei der soeben genannten Umformung wurden daher viele Karten maßstäblich vergrößert.

Beispiele: Schweizerische Landschaftstypen, |Albaner (Gebirge, [Genua," ¡Kairo, [Niagarafälle, New York, östlicher Teil der USA., Panamakanal usw.

Weitere Vergrößerungen folgten anläßlich der Erstellung der gegenwärtigen Jubiläumsausgabe. Die Fähigkeit, für vorgesehene Inhalte die genügenden, aber anderseits nicht übersetzten Maßstäbe richtig vorausschätzen zu können, ist zur Disposition eines Atlasses unentbehrliches Erfordernis.

Ebenso wichtig wie die Maßstabswahl ist eine zweckmäßige Begrenzung der Karten. Der ursprüngliche, älteste «Diercke» war querformatig und besaß einseitige Erdteilübersichtskarten. Durch den späteren Wechsel zum Hochformat wurden diese zu zweiseitigen Doppelblättern, wobei zur Raumfüllung Kartenverbreiterungen erforderlich waren. So setzte man bei Afrika und Nordamerika links und rechts Streifen leerer Ozeanflächen an. Maßstäbe und Begrenzungen dieser beiden Karten wurden dann auch vom Schweizerischen Mittelschulatlas übernommen. Sie zeigten daher eine zwecklose Raumverschwendung, bis ich 1928-1932 ihre Doppelblätter auf $1 \frac{1}{2}$ seitige Karten zurückschnitt. Ähnlich verhielt es sich mit den Übersichtskarten einiger europäischer Länder.

Wie bei den Maßstäben, so finden wir auch in den Kartenbegrenzungen viel häufiger das gegenteilige Übel: zu enge Einschachtelung eines Gebietes infolge Raumnot. Städtekarten helfen in der Schulgeographie wenig, wenn nicht auch eine gewisse Umgebung mitabgebildet wird, so daß die Stadtlage betrachtet werden kann. Die neueren Umformungen des Mittelschulatlasses schufen hierin Luft. Es ist freilich zu sagen, $\mathrm{da} ß$ auch in seinen ursprünglichen Ausgaben der Landkartengeiz nirgends derart groteske Formen angenommen hatte wie in gewissen, sehr bekannten ausländischen Oberstufenatlanten. In solchen finden sich nicht selten Kärtchen von den Dimensionen größerer Briefmarken. Umfangreiche Inhaltsverzeichnisse schienen ihren Erstellern wichtiger als die Brauchbarkeit der Karten.

\section{KARTENREIHENFOLGE}

Wegleitend für die Reihenfolge der Karten sind in erster Linie didaktische Gesichtspunkte und das Streben nach möglichster Übersichtlichkeit. In diesem Sinne ist die beste und daher im Schweizerischen Mittelschulatlas eingehaltene Reihen- 
folge: Einführung in die Kartenlehre, Schweiz, übrige europäische Gebiete, Gesamtkarten von Europa, fremde Erdteile und Ozeane, Erdübersichten, Himmelskunde. Dies entspricht dem Aufbau geographischer Vorstellungen durch sukzessives Fortschreiten vom Detail zum Ganzen, vom Nahen und Bekannten zum Fernen, Unbekannten, vom leicht zu Überblickenden zum Unerreichbaren. Innerhalb der einzelnen Erdräume wäre am übersichtlichsten und methodisch zweckmäßigsten etwa folgende Anordnung: Allgemeine physische oder physisch-politische Übersichtskarten, Teilgebietsoder Nebenkarten mit Landschaftstypen, Siedelungen usw., Spezialkarten, und bei den letzteren Struktur der Erdrinde (Tektonik, Geologie usw.), Klima, Vegetation, Wirtschaft und Verkehr, Volksdichte, Völker oder Sprachen, Religionen und eventuell innere politische Gliederung. Karten, deren Inhalte in enger Beziehung miteinander stehen, sollten - soweit dies möglich ist - auf derselben Seite oder Doppelseite angeordnet werden, so daß sie leicht miteinander verglichen werden können. Beispiele: Schweiz, Niederschläge und Landwirtschaftsgebiete; Erde, Klimatypen und Vegetationsgebiete oder auch Klimatypen und Verbreitung der Malaria.

Obschon solche Gesichtspunkte bei der Erstellung und allen Umarbeitungen des Mittelschulatlasses Beachtung fanden, entsprechen seine Kartenfolgen innerhalb der Gebietsgruppen keineswegs dem obigen Normalschema. Überdies wurden die Karten immer wieder stark umgestellt, was für den Unterricht lästig ist. Es sind Hindernisse buch- und drucktechnischer Art, die einer didaktisch wünschbaren Reihenfolge im Wege stehen. So können z. B. nie zwei doppelseitige Karten aufeinander folgen, und die verschiedenen, oft ungleich großen Karten haben in ihrer Kombination stets ganze Seiten oder Doppelseiten zu ergeben. Nicht alle Kartentypen erheischen im Druck dieselben Farben oder völlig übereinstimmende Farbabstimmung. Ohne Vermehrung der Farb- bzw. Druckplattenzahl und entsprechend auch der Druckgänge wäre es z. B. nicht möglich, auf ein und denselben Bogen eine farbig scharf akzentuierte geologische Karte und eine tonig abgestufte, schattenplastische Reliefkarte zu drucken. Solche Nebenumstände zwingen im einzelnen wie im ganzen zu Abweichungen von der didaktisch wünschbaren Kartenfolge. Dies zeigt sich z. B. in den Atlasausgaben 1932-1942: Die Anordnung europäischer Gebiete ist wenig übersichtlich. Der Atlantische Ozean mußte zwischen Europa und Asien eingeschaltet werden. Entgegen allgemeinem Brauch steht Südamerika vor Nordamerika.

In der Jubiläumsausgabe 1948 gelang es, die Kartenreihenfolge in vielen Einzelheiten wie auch im gesamten wesentlich zu verbessern. Sie ist übersichtlich und den didaktischen Erfordernissen so gut wie möglich angepaßt. Der Rundgang durch Europa beginnt mit Frankreich, wie dies auch im Unterricht meist der Fall ist. Er führt dann in einfach geschlossenem Zuge durch die übrigen Länder. Die Gebietsfolge DonauländerBalkan-Italien ermöglichte ein Zusammenlegen der Spezialkarten und damit beträchtlichen Raumgewinn. Rußland stellt die Verbindung mit Asien her. Der Atlantische Ozean ist auf den ihm zukommenden Platz zwischen alter und neuer Welt gewiesen. Nach dessen Überquerung stoßen wir, wie weiland Christoph Columbus, zuerst auf die Antillen. Nord- und Südamerika folgen in üblicher Reihenfolge, wobei die neuen, kombinierten Spezialkarten an letzteres anschließen. Ebenfalls allgemeinem Brauche entsprechend bilden Australien und der Große Ozean den Abschluß der kartographischen Weltreise.

\section{ALLGEMEINE GRAPHISCHE DISPOSITIONEN}

Jede Karte, jeder Atlas ist nicht nur ein geographisches, sondern auch ein graphisches Erzeugnis. Gute Graphik erfreut das Auge, schlechte aber ist Barbarei.

Kennzeichen guter Graphik sind unter anderem Ordnung und Einfachheit in den räumlichen Dispositionen und gutes Zusammenspiel der verschiedenen Elemente. 
Diese sollen sich nicht gegenseitig in ihrer Wirkung beeinträchtigen. Gute Graphik ist stets sauber und exakt, jedoch nie kleinlich oder geizig. Dies letztere zu betonen, ist besonders für die Kartengraphik wichtig; denn der ihr innewohnende Konflikt zwischen der Vielheit des Darzustellenden und der Kleinheit der Abbildung drängt nirgends mehr als hier zu Überlastungen und verworrenen Verfilzungen.

Gute Graphik ist überall, aber ganz besonders in Lehrmitteln, nicht nur ein ästhetisches und erzieherisches, sondern auch ein praktisches Postulat; denn einfache, klare Raumgliederung und sinnvolles Abstufen erleichtern die Übersicht und das rasche Auffinden und Erfassen der Dinge.

Das Zusammenstellen verschiedener, oft ungleich dimensionierter Karten auf Einzel- oder Doppelseiten der Atlanten, ferner die den Karten eigenen Verbindungen der Bilder mit Beschriftungen, Legenden usw. bieten eine Fülle von graphischen Aufgaben.

In früheren Jahrhunderten wurde auf dekorative Rahmen, Titel usw. und auf wohlabgewogene Raumdispositionen größtes Gewicht gelegt. Wie wir eingangs feststellten, zeichneten sich vor hundert Jahren die ältesten Schulatlanten durch sorgfältigste graphische Pflege aus. Später aber, gegen das Ende des letzten und während der ersten Jahrzehnte unseres Jahrhunderts, wurde die Buch- und Atlasgraphik in den allgemeinen geschmacklichen Zerfall hineingerissen. Der materialistische Zeitgeist zersetzte den Sinn für die Bedeutung solcher Dinge. Professoren, Pädagogen und Verleger — bar jeder graphischen Kultur, aber im übrigen ehrenwerte Männer - schneiderten kleine und große Kärtchen zu Atlasblättern zusammen. In einzelnen der bekannten ausländischen Oberstufenatlanten der letzten Jahrzehnte finden wir jeden freien Winkel mancher Hauptkarte mit Nebenkärtchen vollgestopft. Selbst vor mehrfach geknickten, vor schrägen und bogenförmigen Trennungslinien schreckte man nicht zurück. Man schob Karten eng zusammen und trennte ihre Farbflächen oft nur durch eine schwarze Linie. Man «zierte» die Blätter mit groben Blocktiteln, die den kartographischen Bildern ins Gesicht schlugen, und man übersättigte die Karten mit Einzelheiten - all dies im Namen des geographischen und didaktischen Fortschrittes. Solche Kritik mag hart klingen, doch muß sie geübt werden, da die graphischen Zerfallserscheinungen selbst in heutigen - Atlanten noch nicht überwunden sind. Es ist höchste Zeit, die Karten- und Atlasgraphik an der Gesundung der allgemeinen Graphik teilnehmen zu lassen.

Auch die vor 1932 erschienenen Ausgaben des Schweizerischen Mittelschulatlasses zeigten in den allgemeinen graphischen Dispositionen bedauerliche Mißgriffe, obschon sie sich von den schlimmsten Entgleisungen freizuhalten vermochten. Die Zusammenstellungen mehrerer Karten auf den einzelnen Seiten war stets einfach und klar. Man vermied allzu geizige Raumfüllungen. Durchgehende horizontale oder vertikale Abgrenzungsstreifen trennten die Karten. Schlecht war jedoch die Art, wie Größenvergleichskärtchen oder Legendenrechtecke aus den Hauptkarten herausgeschnitten wurden. Unbefriedigend war z. B. die Raumdisposition der politischen Frankreichkarte (S. 38-39) der Ausgaben 1924 und 1928, unschön da und dort die Zusammenstellung von Karten völlig verschiedenartigen graphischen Charakters auf ein und derselben Seite (Beispiele: Ausgabe 1924-1928, S. 60 und 116) und die allzu häufigen, leider kaum ganz zu vermeidenden Randdurchbrechungen durch Kartenkröpfe. Schweres graphisches Versagen zeigte die wirre Anhäufung von Sternnebeln im "himmlischen Teil» der ältesten Ausgaben. Alle frühere Kritik an den Atlanten sah jedoch seltsamerweise über solche Mängel hinweg.

Bei der Umarbeitung 1928-1932 und wiederum anläßlich der jüngsten Umformung wurden endlich auch solche allgemein-graphische Dinge verbessert. Dies zeigte sich $\mathrm{da}$ und dort in freieren und räumlich besser abgewogenen Legendenanordnungen, im organischeren Eingliedern der Größenvergleichskärtchen, in der Verminderung der Kartenkröpfe und in einheitlicheren Kartenzusammenstellungen. 


\title{
B. KARTOGRAPHISCHE GESTALTUNG
}

\author{
1. ALLGEMEINES ÜBER DIE BEZIEHUNGEN \\ ZWISCHEN ENTWURF UND REPRODUKTION, KOORDINIERUNG \\ DER ELEMENTE UND GENERALISIERUNG
}

Malt ein Künstler ein Bild, so kümmert er sich bei der Wahl seiner Ausdrucksmittel nicht um dessen eventuelle spätere Reproduktion. Nicht so der Kartograph. Aus graphischen, technischen und ökonomischen Gründen besteht bei der Karte in der Regel keine scharfe Trennung von Original- und Druckplattenerstellung. Beides greift in mannigfachem Wechsel ineinander. Der Kartenzeichner ist weitgehend zugleich Druckplattenersteller und umgekehrt. Im Gegensatz zu andern Druckerzeugnissen sind in vielen Karten allerfeinste, schärfste, lineare Elemente mit Farbtönen und Beschriftungen kombiniert. Dies führt dazu, zuerst nur die ersteren zu zeichnen und auf Druckplatten zu übertragen. Erst nachher werden dann in Probeabzüge dieser linearen Elemente die Schatten, Schraffen, Flächenfarben, Schriften usw. entworfen und sukzessive auf Platten gebracht. Selten entsteht ein mehrfarbiger Kartenentwurf als Ganzes. Sowohl in den Originalzeichnungen wie auf den Druckplatten ist somit der Karteninhalt in verschiedene Elemente aufgeteilt. Diese können sich durch schlechtes Zusammenspiel gegenseitig stören oder geradezu vernichten, bei geschickter Kombination aber in ihrer Wirkung steigern. In früherer Zeit, als Karten durch Holzschnitt oder Kupferstich einfarbig reproduziert wurden, ergab sich ein gewisses graphisches Koordinieren relativ leicht. Seit sie aber mehrfarbig erstellt werden, was an und für sich ihre Ausdruckskraft außerordentlich erhöhen kann, ist das Zusammenspiel verschiedenfarbiger Elemente leider sehr oft ungenügend.

Man kann in dieser Beziehung geradezu von einer Krise der neueren Kartographie sprechen. Einer geschickten Elementenkombination kommt für jede Karte entscheidende Bedeutung $z u$. Es ist eine Unterlassungssünde der bisherigen theoretischen und praktischen Kartographie, dies zu wenig erkannt und betont zu haben.

Das Koordinieren der Elemente hat sowohl inhaltlich-geographisch wie auch zeichnerisch-ästhetisch und reproduktionstechnisch zu erfolgen.

Wenn viele Karten des Schweizerischen Mittelschulatlasses seit der Ausgabe 1932 ihre Vorgänger an Klarheit und Schönheit übertreffen, so liegt dies nicht zuletzt an einer bewußten Pflege solcher Dinge. Wachsende Erfahrungen werden in dieser Richtung zu weiteren Fortschritten führen.

Es gibt viele Möglichkeiten stufenweisen Aufbauens von Karten. In jedem Falle aber sind die zeichnerischen Ausdrucksmittel weitgehend von der Reproduktion abhängig, und stets erscheint das kombinierte Bild erst in den fertigen Druckproben. Die graphische Beurteilung der Teilentwürfe erheischt daher beträchtliche Erfahrung.

Zahllose Karten - nicht nur solche eines Schulatlasses - sind Ergebnisse von Umformungen aus andern, meist detailreicheren Karten. In der Regel handelt es sich nicht um ein Umzeichnen nach einer einzigen Vorlage, sondern um ein Bearbeiten nach verschiedenen kartographischen, statistischen und weiteren Quellen. Verkleinerung und didaktischer Zweck bedingen ein Ausscheiden von Unwesentlichem, ein figürliches Vereinfachen, ein Überdimensionieren und Hervorheben gewisser Dinge. Solches Generalisieren führt schließlich zu Schablonisierungen, zur Unterdrückung oder aber zur Überbetonung individueller Formunterschiede.

Das kartographische Generalisieren ist nicht allein eine graphisch-formale Angelegenheit, sondern auch eine begriffliche. Am deutlichsten zeigt sich dies in sehr klein gezeichneten Spezialkarten großer Gebiete. Reich differenzierte Dinge müssen darin 
zusammengefaßt und in den Legenden mit kurzen, allgemeinverständlichen und trotzdem treffenden Sammelbezeichnungen versehen werden, eine Aufgabe, die gar nicht immer leicht ist und oft der Mithilfe des Spezialkenners bedarf.

Das Koordinieren von Kàrtenelementen hat sich auch auf deren Generalisierung zu erstrecken. Es darf nicht der eine Inhaltsteil, z. B. das Geländerelief, fein gegliedert, ein anderer, z. B. das Verkehrsnetz, stark vereinfacht werden, vielmehr sind alle Elemente in ihrer Generalisierung aufeinander abzustimmen.

Die bisher erörterten Gesichtspunkte, Beziehungen zwischen Entwurf und Reproduktion, Koordinieren der Elemente und Generalisierungsfragen, gelten nicht nur für jede einzelne Karte, sondern mit gewissen Sinnverschiebungen auch für einen Atlas im gesamten.

Bei Erstellung von Atlaskarten ist man in der Wahl und im Abstimmen der Farben weniger frei als bei Einzelkarten. Die Farben sind hier zum vornherein normalisiert. Überdies müssen oft Karten ganz verschiedener Art auf ein und demselben Druckbogen vereinigt werden. So kommt es, daß z. B. ein Gelb gleichzeitig einer allgemeinen Länderkarte und einer speziellen wirtschaftsgeographischen Karte anzupassen ist, wobei es dann vielleicht für diese zu schwach, für jene zu stark erscheinen mag.

Weitere Einschränkungen bestehen aus folgendem Grunde: Analoge Inhaltsteile verwandter Karten sollen überall im Atlas so gut wie möglich übereinstimmende Farben und Signaturen erhalten. Dieselbe Höhenlage, Temperatur, Volksdichte oder Industrie ist somit möglichst überall in derselben Weise darzustellen. Eine einzelne Karte enthält oft nur ein Stück der Gesamtskala des dargestellten Stoffes, folglich kann darin auch graphisch nur ein Teil der Skala ausgenützt werden. Solche Einschränkungen sind in Kauf zu nehmen, da die didaktischen Vorteile konsequenter Gestaltung weit schwerer wiegen.

Räumliche Verbreitungsgebiete verschiedener Art stehen oft miteinander in engen kausalen Zusammenhängen. Eine vergleichende Stoffbetrachtung im Unterricht wird erleichtert, wenn solche Beziehungen in den Atlanten durch ähnliche graphische Gestaltung hervorgehoben werden. Somit sollen, so gut wie möglich, auch Karten verschiedener Inhalte in Generalisierung und Farbgebung miteinander koordiniert werden. Da sie aber oft zeitlich getrennt, unter verschiedenartigen Umständen oder nach ungleichartigen Quellen entstehen, ist dies gar nicht immer leicht.

Gewisse Zustände oder Vorgänge auf der Erdoberfläche sind noch längst nicht überall so genau erforscht, wie es ihre kartographischen Darstellungen vortäuschen. Neue Forschungsergebnisse vermögen daher oft selbst die kleinen, zusammengefaßten Kärtchen eines Schulatlasses zu verändern.

Ergänzungen und Beispiele zu diesen Hinweisen, ebenso die Darlegung von Mitteln und Wegen zur möglichsten Überwindung der genannten Schwierigkeiten finden sich in den folgenden Abschnitten.

\section{RELIEFKARTEN SCHWEIZERISCHER LANDSCHAFTEN}

Schon die frühesten Ausgaben des Mittelschulatlasses enthielten sechs ganzseitige Reliefkarten in dem etwas ungewohnten Maßstabe 1:125000, und zwar zwei für den Jura, zwei für Mittelland und Voralpen und zwei hochalpine Beispiele. Ihre Entwürfe stammten von Professor FrIDOLIN BECKER (meinem Vorgänger an der Eidgenössischen Technischen Hochschule in Zürich). Sie bildeten damals für Schulatlanten eine viel beachtete Neuheit, und noch heute besitzt kein ausländischer Atlas Karten von ähnlicher Anschaulichkeit. Die beiden Mittellandbeispiele sind dann leider 1925 dem Raummangel zum Opfer gefallen. 
Bei Anlaß der Umarbeitung in den Jahren 1928-1932 baute ich die Reliefkartenreihe neu auf und änderte dabei die Gebiete, die Maßstäbe und vor allem die zeichnerische Form. Mit Einschluß der seither in gleicher Art gezeichneten Städtekarten enthält der Atlas nun zehn Seiten solcher Darstellungen in den Maßstäben 1:50000, 1:100000 und 1:200000. Sie zeigen, wie wir gesehen haben, charakteristische Landschaften aus Jura, Mittelland, Alpen und südschweizerischem Alpenvorland.

Die Höhen wurden überall auf den «alten Horizont» transformiert, da die Ergebnisse der Neuvermessungen zur Zeit der Atlasbearbeitung für die meisten Gebiete noch nicht zur Verfügung standen.

Eine eingehende Besprechung der Form und Erstellung von Reliefkarten soll einer besonderen Veröffentlichung vorbehalten bleiben; doch mögen einige Hinweise auch hier interessieren.

Die 1932 in den Atlas eingefügten Darstellungen weisen gegenüber den früheren folgende Neuerungen auf:

1. Die Schattierung wurde konsequent nach schiefer Beleuchtung, jedoch unter lokalen Anpassungen an die Geländeformen, durchgeführt. Die Lichthänge erscheinen somit überall heller als die in Halbtöne getauchten ebenen Flächen, so wie dies auch bei schräg beleuchteten Landschaftsmodellen der Fall ist (Abb. 1). Damit wich ich ab von der früheren, konventionell umgeformten Schattierung, bei der i- entgegen jeglichem natürlichem Licht- und Schattenspiel - die Ebenen heller getönt wurden als die ihnen entsteigenden Lichthänge.

2. Die früher herrschende Auffassung, die Schattierung sei lediglich ein Mittel zur Veranschaulichung der Großformen, wurde fallen gelassen. Je genauer auch die Einzelheiten durchgearbeitet werden, um so zwingender der plastische Ausdruck und um so besser die morphologische Charakterisierung. Bei guter Eingliederung der Kleinformen ins Ganze besteht keine Gefahr unruhiger Bildwirkung. Das Licht- und Schattenspiel soll alle in den Höhenkurven erkennbaren Formen zum Ausdruck bringen und in gewissen Fällen sogar darüber hinausgehen und Kleinformen, wie z. B. Moränen, herausarbeiten, selbst wenn sie durch die lineare Zeichnung nicht mehr erfaßt werden. Die Form liegt an den Übergängen vom Licht zum Schatten. Den Übergängen wurde daher überall besondere Aufmerksamkeit geschenkt.

3. Die allgemeinen Flächentöne wurden wie bisher hypsometrisch, d. h. nach Höhenlagen, abgestuft. Mehr als bei den meisten früheren Karten erfolgte hiebei eine enge Anlehnung der Farben an landschaftlich-luftperspektivische Natureindrücke.

4. Ein weiterer Unterschied gegenüber den Vorläufern liegt im Hervortreten der Schattenplastik über die hypsometrischen Färbungen. Die letzteren wurden möglichst leicht gehalten. Auf diese Art entsteht eine klarere Gliederung als bei älteren Reliefkarten, in welchen die Schatten sehr oft in den allgemeinen Farbtönen verschwimmen.

5. Großes Gewicht wurde auf gutes Zusammenspiel aller linearen und tonigen Elemente, der Höhenkurven, Schatten und Geländefarben, gelegt. Aber auch Bodenbedeckung, Beschriftung usw. haben sich dem Gesamtbild unauffällig und doch lesbar einzufügen. Das Koordinieren ist besonders für die Felszeichnung von Bedeutung. Diese soll mit den Licht- und Schattentönen ein Ganzes bilden und gleichsam deren letzte, feinste Gliederung und Akzentuierung geben. Bei ihrer Ausführung ist äußerste Zurückhaltung geboten. "Zeichnen heißt weglassen» gilt vor allem auch hier.

Ein Beispiel ist in Abb: 2 und 3 dargestellt. Abb. 2 zeigt eine als Grundlage dienende Felszeichnung der Siegfriedkarte 1:50000, Abb. 3 dasselbe Gebiet in generalisierter Form für die Reliefkarte Oberengadin und Berninagruppe 1:1.00000 der Atlasausgabe 
1932. Weitere Beispiele siehe Atlasausgabe 1948 auf Seiten 1, 10 und 11. In vielen früheren Karten wurde die plastische Wirkung durch unnötig dichte und unlesbare Felsschraffen zerstört.

Die Vorzüge der neuen Reliefkartenreihe liegen nicht allein im Zeichnerischen und Reproduktionstechnischen, sondern auch in der Gebietswahl. Soll ein bestimmter Landschaftstypus prägnant und leicht erkennbar hervortreten, so darf sein Bild nicht zu sehr durch Nebenerscheinungen gestört werden. Solche Geschlossenheit und Einheitlichkeit zeigen sich besonders in den Karten der Freiburger Gegend, der Stammheimer Glaziallandschaft, der Drumlins im Glattal, der gefiederten, jung durchtalten Napfgruppe und in den Beispielen des Waadtländer und Berner Faltenjura. In der Karte des Basler und Aargauer Jura aber beruht die Wirkung auf dem Gegensatz zwischen tafel- und faltenförmigem Bau. (Der Formengegensatz war auch wegleitend bei der Wahl der beiden Beispiele felsiger Bergformen auf Seite 4 der Ausgabe 1948.)

Einige Reliefkarten des Mittelschulatlasses besitzen eine bisher wenig gebräuchliche Südwest- oder Südostbeleuchtung. Solcher Lichteinfall entspricht natürlichen Besonnungszuständen und Landschaftsaspekten. Er wird daher von vielen Geographen der üblichen Nordwestbeleuchtung vorgezogen, kann aber beim Ungeübten leicht zu argen Formtäuschungen, zur "Reliefumkehr», führen. Sollte dies für einzelne Atlasbenützer der Fall sein, so empfiehlt es sich, die Karten zunächst bei vertauschter Orientierung zu betrachten. Die ungewohnte Beleuchtungsrichtung fand im Atlas da Anwendung, wo es die Reliefgliederung besonders wünschenswert erscheinen ließ. Sie bringt den enormen, schroffen Nordabfall der Jungfraukette und ihre sanftere Südabdachung prägnanter zum Ausdruck, als dies bei Nordwestbeleuchtung der Fall wäre. Ähnlich sind die Verhältnisse im Säntisgebiet. Das nördliche Überliegen der Gesteinsfalten führt hier fast überall zu steileren Nordflanken und flacheren Südhängen. Jungfrau- und Säntiskarte (Atlas 1948, S. 10 und 11) stehen nun seit 16 bzw. 14 Jahren im Schulgebrauch. Bisher sind dem Verfasser keine Klagen gegen ihre ungewohnten Beleuchtungsrichtungen bekannt geworden.

Die Vorzüge der Reliefkarten, ihre Naturähnlichkeit und Anschaulichkeit, werden erkauft durch gewisse Schwierigkeiten der Erstellung.

Mehr als für konventioneller gestaltete Karten verlangt ihr Entwurf starke zeichnerische Begabung, ihre Reproduktion aber besondere Erfahrung. Die Druckplatten$z a h l$ ist größer als bei den meisten andern Karten, so daß ihre Herstellungskosten relativ hohe sind.

Je vollkommener eine Karte, um so empfindlicher ist sie. Je klarer ihr Antlitz, um so leichter sind darin Unstimmigkeiten zu erkennen. Modellierungsfehler treten deutlicher hervor als in verschwommenen Karten. Wird beim Druck ein einziger der verschiedenen Farb- und Schattentöne nicht ganz gut gewählt, so ist das Schlußergebnis um seine volle Wirkung gebracht. Entscheidend für den plastischen Eindruck sind die leichten Halbschatten, die Übergangstöne. Oft erscheinen sie im Druck entweder zu kräftig oder aber zu schwach. In beiden Fällen drohen die Formen zu zerfallen.

Folgen solcher Empfindlichkeiten sind in den verschiedenen Ausgaben des Mittelschulatlasses an gewissen Nüancen einzelner Karten zu erkennen. So ist beispielsweise die neue Karte der Säntisgruppe und des Appenzellerlandes auf Seite 11 der Jubiläumsausgabe im Druck durch zu schweres Blau um ihre letzte, feinste Formen- und Höhengliederung gebracht worden.

Schwierigkeiten sind dazu da, überwunden $z u$ werden. Sie fallen gegenüber den großen Vorzügen der Reliefkarten nicht schwer ins Gewicht.

Im weiteren werden wir auf die technische Erstellung im Abschnitt über die Reproduktion zurückkommen. 


\section{GELÄNDEDARSTELLUNG ALLGEMEINER KARTEN AUSLÄNDISCHER GEBIETE}

a) Gebirgsschraffen. Die Darstellung des Reliefs erfolgte in der traditionellen Form durch sogenannte allgemeine Gelände- oder Gebirgsschraffen. Die natürliche Gliederung ist jedoch überall viel reicher und komplizierter, als durch die kartographischen Miniaturbilder zum Ausdruck gebracht werden kann.

In Karten kleiner Maßstäbe läßt sich flachansteigendes Gelände durch Schraffen nicht befriedigend ausdrücken. Selbst die zartesten Strichlagen täuschen, wenn sie in kontinuierlicher Scharung auftreten, zu starkes Gefälle vor. Werden sie aber ganz unterdrückt, so ergibt sich das Bild ebenen Geländes. Die Flucht aus diesem Dilemma drängt den Zeichner zur Auflösung geschlossener Schraffenflächen in isolierte Schraffenreihen, wodurch jedoch der Eindruck terrassenförmigen Ansteigens erweckt wird. Solche Täuschungen lassen sich nicht ganz vermeiden. Zeichnungsart und Reproduktionstechnik sind, trotz größtmöglicher Verfeinerung und Präzision, zu grob, um all den flachen Wellen und Schwellen und den Knitterungen der Erdoberfläche Ausdruck geben zu können. Mancher Kartograph glaubt aus der Not eine Tugend machen und die Pseudo-Terrassierung betonen zu müssen. Gewiß sind Geländeterrassen Charaktermerkmale unzähliger Landschaften. Nach den Schraffenbildern der bekannten Hand- und Schulatlanten zu schließen, würden sich jedoch all die flachwelligen oder flachansteigenden. Gebiete der Erdoberfläche aus Terrassen aufbauen. Diese Feststellung soll weniger eine Kritik der Karten als ein Fingerzeig für den Kartenbenützer sein. Karten kleiner Maßstäbe tragen die Tendenz zur Scheidung des topographischen Formenschatzes in seine Extreme - Ebenen und Hochgebirge - in sich. Wir stehen mit der üblichen Schraffenmethode an gewissen Grenzen des Darstellbaren.

Úbertriebene Terrassierungen zeigt $u$. a. die Karte der Oberrheinischen Tiefebene des Mittelschulatlasses, so vor allem im Sundgau und am Südostabfall des Schwarzwaldes.

Die Geländeschraffen dieser und einer Reihe früher genannter Karten (Alpenländer, Atlasländer, Vereinigte Staaten von Amerika, Erdteile usw.) entstammen den Ausgaben vor 1932. Einige dieser alten "Terrains» kranken übetdies an zu weitgehender Auflösung der Formen.

In den neuerstellten Karten suchten wir die Gebirgszüge geschlossener aufzubauen, ihre Bilder massiger und ruhiger zu gestalten und übertriebene Terrassierungen nach Möglichkeit zurückzudrängen. Der Wechsel von Hell und Dunkel an den Gebirgskämmen wurde stärker betont; denn je konsequenter die schräge Beleuchtung zur Anwendung gelangt, um so plastischer und anschaulicher die Karten.

b) Farbige Höhenschichten. Diese bilden eine notwendige Ergänzung der Gebirgsschraffen. Sie gliedern die Räume in Hoch und Tief. Die Zahl geeigneter und leicht unterscheidbarer Druckfarben und damit auch diejenige der Höhenschichten ist jedoch gering. Äquidistante Stufen eignen sich nicht, da sie zu groß angenommen werden müßten. Tiefgelegene flache Gebiete würden keine genügende Gliederung erfahren, während sich im Hochgebirge die Ausdrucksmittel in verwirrender Weise verdichten würden. Man wählt daher von unten nach oben wachsende Stufen. Dabei sind ungewohnte, schwer einprägsame Stufengrenzen zu vermeiden. Eine unglückliche Lösung zeigte W. SchüLEs hypsometrische Karte der Schweiz, erschienen in Lit. Nr. 34 . Sie wies u. a. folgende Stufengrenzen auf: 800, 1200, 1700, $2300 \mathrm{~m}$.

Auch im Mittelschulatlas war die Wahl der Stufengrenzen ursprünglich wenig geschickt. Seit 1932 ist sie umgestellt auf eine einfachere und gesetzmäßiger wachsende Zahlenreihe. Die beiden Systeme sind in folgender Tabelle zusammengestellt: 
Atlasausgaben 1910-1928

$0 \mathrm{~m}$

$(100 \mathrm{~m})$

$200 \mathrm{~m}$

$600 \mathrm{~m}$

$1500 \mathrm{~m}$

$2500 \mathrm{~m}$

$4000 \mathrm{~m}$
Atlasausgaben seit 1932

$$
\begin{gathered}
0 \mathrm{~m} \\
(100 \mathrm{~m}) \\
200 \mathrm{~m} \\
500 \mathrm{~m} \\
1000 \mathrm{~m} \\
2000 \mathrm{~m} \\
4000 \mathrm{~m}
\end{gathered}
$$

Die Aufteilung des Tieflandes in zwei Stufen $0-100 \mathrm{~m}$ und $100-200 \mathrm{~m}$ gelangte in den alten und neuen Ausgaben nur für größere Maßstäbe zur Anwendung. 1932 wurde sie auch in der physischen Europakarte eingeführt.

Die neuere der beiden Reihen weist im Bereiche 200-1000 m kleinere Stufen auf als die frühere. Dies ist ihr weiterer Vorzug, da auf solche Art ausgedehnte Hauptwohnräume des Menschen besser gegliedert werden.

In einigen Karten kleiner, flacher und tiefgelegener Gebiete wurde zur Erhöhung der Ausdruckskraft von der normalen Skala abgewichen.

1932 änderten wir auch die Einordnung der Farben in die Stufenleiter. Die frühere Farbschichtung aller Übersichtskarten war derjenigen der Schweiz angepaßt. Diesem, freilich nicht unbedeutenden Sonderfall zuliebe hatte man alle übrigen Gebiete benachteiligt. Nun wurden die Farben nach abwärts verschoben. Gelb beginnt seither bei $200 \mathrm{~m}$ (früher bei $600 \mathrm{~m}$ ), Braun bei $500 \mathrm{~m}$ (früher bei $1500 \mathrm{~m}$ ). Diese Farbverlagerung änderte das Bild der Karten vollständig. Alle tiefliegenden Gebiete - es sind dies naturgemäß die überwiegenden - wurden hiedurch reicher und prägnanter gegliedert, die Gebirge aber massiger zusammengefaßt.

c) Zusammenspiel von Geländeschraffen und Höhenfarben. Ausdruckskraft und Klarheit der Karten sind wesentlich bedingt durch gutes $\mathrm{Zus}$ ammenspiel von Geländeschraffen und Höhenfarben. Dies gilt in doppelter Hinsicht: in der Formengeneralisierung und in der Schraffen- und Rasterüberlagerung.

Weder die Geländeschraffen noch die Schichtgrenzen der Höhenfarben entsprechen den richtigen Formen; beide sind stark vereinfacht. Oft werden beide von verschiedenen Zeichnern und nach verschiedenen Grundlagen entworfen. Weiß aber die linke Hand nicht, was die rechte tut, so ist eine Übereinstimmung der formalen Gliederung nicht zu erwarten. In der fertigen Karte fahren dann nur allzuoft Höhenstufengrenzen bergauf und bergab über das Schraffenrelief hinweg. Solches Unheil ist nur zu vermeiden, wenn die Höhenschichten erst nach Fertigstellung der Schraffen gezeichnet und in der Generalisierung streng an diese angepaßt werden.

Viel schwieriger zu erreichen ist ein gutes Zusammenspiel von Schraffen und Höhenfarbenrastern. Farbige Volltöne, selbst wenn sie ziemlich stark sind, stören das Schraffenbild wenig. Aus ökonomischen Gründen differenziert man jedoch die verschiedenen Höhenfarben nicht nur durch Volltöne, sondern zum Teil auch durch Raster. Dies sind feine, regelmäßige Schraffuren. Ihre Strichabstände und Tonstärken können leicht mit denjenigen der Geländeschraffen in Konflikt geraten, so daß der plastische Eindruck der Gebirge beeinträchtigt oder vernichtet wird. Viele Schulatlanten leiden an solchem Versagen der Koordinierung. Die älteren Ausgaben des Mittelschulatlasses zeigen krasse Beispiele; aber auch dessen heutige Form befriedigt hierin nicht überall.

Das Übel wird gemildert durch möglichst feinen Raster und helle Farben der Höhenschichten und anderseits durch kräftige Töne der Gebirgsschraffen. Damit aber schwächt man die Höhengliederung wie auch die Lesbarkeit vieler Namen. 
So sucht der Kartenersteller sein Schiffchen behutsam zwischen Skylla und Charybdis hindurchzusteuern. Radikale Verbesserungen wären nur erreichbar durch Volltöne an Stelle der Raster oder vielleicht durch Umstellen auf schattenplastische Reliefkarten. Beides aber erforderte viel Geld. Die Reliefkartendarstellung in kleinen Maßstäben verspricht für die Zukunft wesentlichen Gewinn an Klarheit, Anschaulichkeit und Schönheit der Übersichtskarten; sie bedarf aber vorerst weiterer Abklärung, bevor sie im Mittelschulatlas eingeführt werden kann. Versuche sind im Ausland wie bei uns im Gange; doch wäre es verfrüht, hier darauf einzutreten.

d) Ozeanische Tiefenstufen. Die Reliefgliederung am Meeresgrunde unterliegt anderen Formungskräften als diejenige des Festlandes. Die Landoberflächen dehnen sich im allgemeinen mit abnehmender Meereshöhe immer weiter aus. Dies ist eine natürliche Folge von Abtragung, Vetfrachtung und Aufschüttung durch das fließende Wasser. Im Gegensatz hiezu finden sich ausgedehnte submarine Flächen in allen beliebigen Tiefenlagen. Landhöhen über $4000 \mathrm{~m}$ beschränken sich auf kleine Gebiete, während anderseits mehr als Zweidrittel des Ozeanbodens tiefer als $4000 \mathrm{~m}$ gelegen sind. Das submarine Relief ist viel einfacher gegliedert, aber auch weniger genau erforscht. Es läßt sich durch großabständige äquidistante Tiefenkurven (Isobathen) und entsprechend abgestufte Blautöne genügend zum Ausdruck bringen. Dies gilt auch für die ozeanischen Gräben; denn sie befinden sich ebenfalls in sehr ungleichen Tiefen.

Von $100 \mathrm{~m}$ an abwärts betragen die Stufenhöhen im Atlas je $1000 \mathrm{~m}$. Nur in der physischen Erdübersichtskarte wurden sie infolge des kleinen Maßstabes auf $2000 \mathrm{~m}$ vergrößert. Kleinere, nicht äquidistante Stufen gelangten für Tiefen von 0 bis $1000 \mathrm{~m}$ zur Anwendung. Sie verengern sich um so mehr, je näher sie an den Meereshorizont heranrücken. Gewisse Variationen ergaben sich durch Verschiedenheiten der Gebiete, Maßstäbe und Bearbeitungsgrundlagen.

Nicht nur Kontinentalsäume sollen deutlich zum Ausdruck gebracht werden, sondern auch submarine Gebirgszüge, Erosionsrinnen einmündender Ströme, seichte Fischerbänke und Schiffahrtsrinnen. In diesen letzteren wie in den Häfen wurden Isobathen und Farbtöne durch zahlreiche Tiefenkoten ergänzt.

Anläßlich der Umarbeitung 1928-1932 und seither in vermehrtem Maße wurden die Blauabstufungen reicher und intensiver gestaltet, als sie es früher waren. Instruktiv ist eine Zusammenstellung der Karten des Malaiischen Archipels der Ausgaben 1928 (oder älter), 1932 und 1936 (oder jünger). In Zukunft werden weitere Karten, so z. B. diejenige von Westindien, in ähnlicher Weise verbessert werden können; doch ruft dies einer zweiten, bisher nicht für alle Druckbogen vorgesehenen Blauplatte und damit vermahrten Druckkosten.

e) Trennung von Land und Wasser. Bei Anlaß der Umarbeitung 1928-1932 wurden Wasser und Land viel deutlicher voneinander geschieden, als dies früher der Fall war. An das satte Blaugrün der Tiefländer grenzt nun ein weißliches Blau der ersten Ozeanstufe. Durch diesen hellen Saum werden alle Landmaßen deutlich umrissen, während in den alten Ausgaben Tiefländer und Meere visuell ineinander verschwammen.

\section{SITUATIONSZEICHNUNG DER ALLGEMEINEN KARTEN}

Wir verstehen darunter die Darstellung des Gewässer- und Verkehrsnetzes, der Siedelungen, der übrigen Bodenbedeckung, der politischen Grenzen usw.

Menschliche Bauwerke, Pflanzen, alle Dinge auf der Erdoberfläche sind als EinzeIerscheinungen so klein, so vielgestaltig, so außerordentlich zahlreich, daß sie selbst in Karten großer Maßstäbe nur in enger Auswahl und in stark zusammengefaßter und 
vereinfachter Form darstellbar sind. Die Generalisierung macht sich hier rascher und stärker bemerkbar als beim Geländerelief.

Mit abnehmendem Maßstab gleichen sich Unterschiede in der Art der Bodenbedeckung, der Dichte von Fluß- und Verkehrsnetzen, von Siedelungen usw. mehr und mehr aus. Linien, besonders Flußlinien, werden durch Streckung kleinerer Krümmungen verkürzt. Die Länge des Rheins vom Ursprung am $\mathrm{Piz}$ Badus bis zur Einmündung ins Meer beträgt zirka $1320 \mathrm{~km}$. Eine Messung in einer Karte 1:4000000 ergibt nur etwa $1000 \mathrm{~km}$. Maßstabsverkleinerungen verändern auch die Art von Signaturabstufungen. Dies zeigen die Bahnlinien. Karten großer Maßstäbe, wie z. B. die Siegfried- und Dufourkarte, unterscheiden durch verschiedene Liniensignaturen Normalund Schmalspurbahnen, ferner eingeleisige und doppelgeleisige Anlagen. In unseren Atlaskarten kleiner Maßstäbe, wie z. B. in 1:4000000, wäre dies sinnlos, da selbst normalspurige und doppelgeleisige Anlagen nur in Auswahl eingetragen werden können. Die verstärkten Linien bedeuten hier durchgehende, stark frequentierte Hauptverbindungen, die dünnen Linien baulich gleiche, jedoch weniger wichtige Anlagen.

Je kleiner der Maßstab, um so dichter und feinmaschiger wird das Kartenbild und um so mehr stören sich Relief und Bodenbedeckung. Da aber ersterem in der Regel größere Bedeutung zukommt, so läßt man letztere mit abnehmendem Maßstab zurücktreten. Karten kleiner als 1: 200000 verzichten — von Ausnahmen abgesehen - auf die Wiedergabe der Wälder, Rebberge, des Gerölles usw. Neben den wichtigsten Gewässern, Ortssignaturen, Verkehrslinien und politischen Grenzen geben sie nur noch die nackte, sterile Oberfläche. Nur Erscheinungen in flachem Gelände und von großer Ausdehnung, wie Wüsten, Tundren, große Sumpfgebiete, werden eingetragen.

Die Signaturen im Mittelschulatlas sind nach einheitlichem, maßstäblich abgestuftem Gesamtplan gewählt, und zwar so, daß sie sich in der Regel selber erklären. Nur für spezielle, nicht ohne weiteres verständliche Zeichen sind die erforderlichen Erläuterungen beigefügt.

Schon wiederholt wurde die Frage aufgeworfen, ob in den allgemeinen Karten das Dunkelbraun (Situationsbraun) der Fluß- und Küstenlinien durch Dunkelblau zu ersetzen sei, so wie dies in den Karten schweizerischer Gebiete des Mittelschulatlasses oder auch in den sehr schönen Übersichtskarten des österreichischen Sla narAtlasses der Fall ist. Durch eine solche Änderung erschiene das Liniennetz differenzierter, die Höhen- und Tiefentöne reiner und schöner als bei schwarzbraunen Gewässerlinien. Auch die Lesbarkeit vieler Namen dürfte gewinnen. Trotzdem scheuten wir bisher von dieser Verbesserung zurück, und zwar aus ökonomischen und technischen Gründen. (Größere Anzahl von Druckfarben und vermehrte Passerschwierigkeiten.)

Besondere Sorgfalt wurde der Auswahl und Darstellungsform von Siedelungen geschenkt. Seit 1932 ist der Mittelschulatlas mehr als früher mit Städtekarten ausgestattet. Siedelungen und im besonderen Städte sind für geographische Betrachtungen sehr anregend. Jede Stadt verrät durch Lage, Gliederung und Bauformen ihre Geschichte. Selbst das bloße, stark vereinfachte Grundrißbild, die Stadtkarte, ermöglicht weitgehende kausale, historische und funktionelle Deutungen. Die Auswahl erstreckte sich daher nicht nur auf allgemein wichtige, sondern auch auf besonders charakteristische Städte, auf Alt- und Jungformen, Binnen- und Küstenorte, Brückenköpfe, Festungsstädte, Residenzen, Industrieorte, Verkehrsknoten, Hafentypen usw. Überall wurde genügend Umgelände mit einbezogen, da dies für Betrachtungen der Städtelagen unumgänglich ist. Art der Generalisierung oder Tonabstufungen lassen vielenorts die wichtigsten Wachstumsphasen erkennen.

Weiter soll hier auf Klassifizierung und Generalisierung von Siedelungsformen nicht eingetreten werden, da dies vor einigen Jahren in meinem Aufsatz über "Das Siedelungsbild in der Karte» (Lit. Nr. 20) geschehen ist. 
'Seit 1932 werden im Mittelschulatlas die politischen Grenzbänder nicht mehr orangefarbig, sondərn grün gedruckt. Entscheidend für diese Farbwahl sind die komplizierten Kartenteile, d. h. die Hügel- und Bergländer. Infolge des Gegensatzes zu den braunen und rotbraunen Höhenfarben wirken grüne Bänder klarer, schöner und weniger verschwommen.

Sie lassen sich schmäler ziehen, ohne deshalb an Sichtbarkeit einzubüßen. Damit aber wird das Relief weniger gestört. Außerdem ist Grün als zusätzliche Farbe im graphischen Gesamtplan des Atlasses viel nützlicher als der frühere Orangeton.

\section{SPEZIALKARTEN}

Wie in jeder Karte, ist auch in der Spezialkarte nur darstellbar, was in Beziehung steht zum topographischen oder geographischen Raum. Der Begriff Karte schließt diese Voraussetzung in sich. Die Kartierungsmöglichkeiten sind sehr vielseitig und verschiedenartig. Nicht nur unmittelbar und visuell erfaßbare Dinge lassen sich abbilden, sondern auch solche, die indirekt, z. B. auf statistischem Wege, erhoben werden. Der Kartierungsbereich umfaßt stabile und variable Zustände, Häufigkeiten, Schwankungen, zeitliche Entwicklungen usw. Mittelbildung und Fiktion treten in den Dienst der Karte. Beispiele hiefür sind die auf den Meeresspiegel reduzierten Isothermen; denn sie entsprechen keinen wirklichen Wärmezuständen.

Die Spezialkarten stehen im allgemeinen in ihrer Entwicklung und Genauigkeit hinter den gewöhnlichen topographischen und geographischen Karten zurück. Ihre Erstellung ist erst auf Grund der letzteren möglich. Von Ausnahmen abgesehen, fehlen Aufnahmeorganisationen und Mittel, die mit denjenigen der Landesvermessungen vergleichbar wären. Für manche variable Erscheinung sind die bisherigen Beobachtungsreihen noch nicht genügend lang. Selbst die eine oder andere Karte kleinsten Maßstabes weist inhaltliche Schwächen auf, da sie sich manchenorts auf sehr weitmaschige Beobachtungsnetze oder auf bloße Hypothesen stützt. Dies zu betonen ist wichtig, weil solche Unvollkommenheiten aus der Karte nicht ohne weiteres ersichtlich sind.

Hiezu drei Beispiele aus dem Mittelschulatlas:

\section{Diluviale Vergletscherung der Schweiz 1:2000000}

Zwischen stets eisfreien Gebieten und Gletscherfächen der letzten Eiszeit fehlt in den Vogesen, im Schwarzwald, in einzelnen Gegenden des südlichen Alpenrandes und, soweit darstellbar, auch im Innern der Alpen die Zone der größten Vergletscherung. Sie fehlt, weil sie ungenügend bekannt ist, nicht aber weil sie in Wirklichkeit nicht vorhanden war.

\section{Volksdichte der Schweiz 1:2000000}

Innerhalb des feinmaschig erfaßten schweizerischen Territoriums lagern sich Gebiete verschiedener Dichte vielenorts sprunghaft aneinander. Im Schwarzwald aber tun sie dies in kontinuierlicher Folge, was lediglich auf Interpolation zurückzuführen ist.

\section{Niederschläge in Asien 1:80000000}

Die allzu einfache Gliederung in Zentral- und Südostasien entspricht nicht den tatsächlichen Verhältnissen; sie ist im bewegten Relief jener Gebiete ebenso differenziert wie in Europa; doch fehlen zu ihrer Erfassung genügende Messungen.

Die Inhaltsbearbeitung von Spezialkarten, 'seien es Originalaufnahmekarten oder aus solchen umgearbeitete Blätter, stellt eine Reihe begrifflicher Generalisierungsfragen. Die natürliche Vielgestaltigkeit kann in keiner Karte wiedergegeben 
werden. Es müssen Sammelbegriffe gebildet und bei allmählichen Übergängen bestimmte Grenzlinien gezogen werden. Gute Wahl der Begriffe, Gruppen, Stufen und Grenzen ist für den Wert und Ausdruck der Karten von größter Bedeutung.

Ebenso wichtig aber ist die graphische Form. Zwar war die Produktion an Spezialkarten während der letzten Jahrzehnte außerordentlich reich. In den großen geographischen Landesatlanten verschiedener Staaten, in neueren Schulatlanten usw. finden sich viele gute Lösungen. Ebensooft aber stößt man auf graphisch Schlechtes, auf Verschleierung und Verwirrung wertvollen Inhaltes durch unzweckmäßige Darstellung.

Die Ausdrucksformen von Spezialkarten werden in der Regel durch Spezialwissenschafter festgelegt. Diese schenken solchen Fragen nicht immer die notwendige Beachtung. Manchmal trampelt der gescheiteste Mann in graphischen Dingen herum wie ein Elefant in einem Porzellanladen.

Nicht besser aber wird die Sache, wenn sich ein Nur-Graphiker in die kartographischen Gefilde verirrt. Erzeugnisse solcher Künstler waren an der Schweizerischen Landesausstellung 1939 in Zürich zu sehen. Einige derselben gelangten im großen Ausstellungsbuch (Lit. Nr. 7, I. Band, S. 464-465) zur Abbildung. Sie stellen Bevölkerung und Kulturland der Schweiz in mengenmäßigen Abstufungen dar, entbehren aber jeglicher Anschaulichkeit, weil ihre allzu bunten, sprunghaften und beziehungslosen Tonskalen babylonische Verwirrung anrichten.

Trotz reicher Produktion fehlt für die graphische Gestaltung der Spezialkarte eine methodische Lehre. Die Umformungen der schweizerischen Atlanten für die Sekundar- und Mittelschulen boten mir die erwünschte Gelegenheit, solchen Fragen näherzutreten. Ich folgte bei der Kartengestaltung bestimmten graphisch-stilistischen Richtlinien. Damit soll nicht gesagt sein, daß nun alle Karten geglückt oder neuartig seien. Die Einsicht kommt auch beim Kartographen oft erst nach der Tat. Ich glaube aber, daß im ganzen wesentliche Fortschritte erzielt worden sind.

An einigen Kartengruppen möge gezeigt werden, worauf es in solchen Dingen ankommt. Die inhaltliche Bearbeitung der Karten soll nur nebenbei und ausnahmsweise berührt werden; denn die Aufsätze von J. Höslr, E. Schmid und M. SchüEpp vermitteln hierüber genügenden Einblick. Um so nachdrücklicher möchte ich auf einige Fragen des graphischen Ausdruckes hinweisen. Die Reihenfolge der folgenden Kartenbesprechungen richtet sich daher nicht nach inhaltichen, sondern nach graphischen Gesichtspunkten. Dabei bedeuten:

Mittelschulatlas alt: Ausgaben vor 1932.

Mittelschulatlas neu: Ausgaben seit 1932.

Sekundarschulatlas: Imhof, Schweizerischer Sekundarschulatlas, 1.-4. Auflage. Zürich 1934-1946.

Diercke : Diercke, Schulatlas für höhere Lehranstalten, große Ausgabe. 64. Auflage. Braunschweig 1926.

Haack : Oberstufenatlas für höhere Lehranstalten, bearbeitet von H. Haack. Gotha 1914. Sydow-Wagner: Sydow-Wagners Methodischer Schulatlas. 19. Auflage. Gotha 1931. Slanar: Atlas für Hauptschulen, Mittelschulen und verwandte Lehranstalten. Von H. Slanar. Wien 1927 und 1933.

Geographisches Lexikon: Geographisches Lexikon der Schweiz, geographischer, volkswirtschaftlicher, geschichtlicher Atlas der Schweiz. Neuchâtel 1910.

Diese Kartenwerke seien für Vergleichszwecke beigezogen. Unsere Auswahl ausländischer Atlanten beschränkt sich auf solche, die in der Schweiz stark verbreitet sind, so daß sie manchem Leser zur Verfügung stehen dürften. Es handelt sich dabei um führende Atlanten von hohem Ruf; denn schlechte Werke wären ungeeignete Zeugen. 
Wenn im folgenden einiges in diesen Atlanten beanstandet wird, so geschieht dies ausschließlich im Interesse des graphisch-stilistischen Fortschrittes. Ihre hohen inhaltlichen und kartographischen Qualitäten sollen damit in keiner Weise herabgesetzt werden.

a) Niederschlagskarten. Zwischen Niederschlagsmenge und Farbton soll stets die Beziehung je - desto bestehen. Je mehr Niederschläge, desto dunkler der Ton. Sprunghafte oder zu bunte Skalen chaotisieren das Bild.

Für große Maßstäbe wählt man in der Regel äquidistante Stufen, für kleine hingegen progressiv wachsende.

Die Farben sollen möglichst an den dargestellten Stoff erinnern. Blau oder Blaugiün sind daher hier am zweckmäßigsten. Blau eignet sich auch deshalb, weil für den Druck der meisten Atlanten zwei Blauplatten zur Verfügung stehen, so daß durch deren Kombination und unter Ausnützung von Voll- und Rastertönen eine genügende HellDunkel-Staffelung erzielt werden kann. Zur Skalenverlängerung nach unten eignet sich ein leichtes Gelb, da dieser Ton die Hell-Dunke]-Skala nicht stört und zugleich Trockenheit symbolisiert. Um optische Sprünge oder Lücken zu vermeiden, soll der Gelbton auch unter den Blaustufen mitgeführt werden.

In Karten großer Maßstäbe ist in der Regel die Stufenzahl so groß, daß die GelbBlau-Skala nicht ausreicht. Man baut dann vom Gelb aus Intensitätstreppen sowohl nach oben wie auch nach unten, und zwar die erste, längere in grünblauen, die zweite, kürzere in gegensätzlichen orangefarbenen, rötlichen oder rotbraunen Tönen. Ähnliche zweiseitige Farbskalen besitzen auch die gewöhnlichen Höhenschichtenkarten. Sie entbehren zwat einer gewissen Logik, doch haben sie sich infolge ihrer guten Gliederung und Ausdruckskraft bewänrt. Sie lassen sich auch in Niederschlagskarten rechtfertigen, da die Rot- oder Braunsteigerung recht gut die mit abnehmender Regenmenge zunehmende Dürre kennzeichnet.

Beispiele:

Mittelschulatlas neu : alle Karten, ebenso Haack. Ein schönes Beispiel größeren Maßstabes mit blaugrüner Farbtreppe nach oben und rötlicher nach unten wird nächstens erscheinen: die von H. UTTINGER entworfene Niederschlagskarte der Schweiz 1: 500000, herausgegeben von der Schweiz. Meteorologischen Zentralanstalt in Zürich.

Gegenbeispiele:

Sydow-Wagner (nicht falsch, jedoch unausgeglichen in den Tonstärken); Geographisches Lexikon (unstetige und zum Teil rückwärtsfallende Farbtreppe).

Vergleichen wir älteste und jüngste Niederschlagskarten der Schweiz (Geographisches Lexikon - Mittelschulatlas alt - Mittelschulatlas neu), so zeigt sich mit wachsender Genauigkeit eine auffallende Annäherung des Regenmengenreliefs an das topographische Relief. Diese Feststellung sei für die Interpretation weniger genauer Regenkarten fremder Gebiete ein Fingerzeig; sie ist jedoch mit einer gewissen Vorsicht aufzunehmen; denn die zeichnerische Detailgliederung von Niederschlagskarten erfolgt vielenorts unter Anlehnung an das topographische Relief, so daß die genannte Ähnlichkeit da und dort künstlich erzeugt sein mag.

b) Karten der Temperaturen. Auch die Isothermenkarten geben quantitative und stetig verlaufende Abstufungen einer einzigen Erscheinung. Was in bezug auf Farbgliederung für die Niederschlagskarten gesagt wurde, gilt auch hier. Die Scheidung in zwei auseinanderstrebende, verschiedenfarbige Intensitätsskalen ergibt sich zwanglos aus den Begriffen Kalt und Warm. Je kälter, desto blauer; je wärmer, desto röter. Während die Niederschlagsmengen nur ein Vorzeichen, das positive, besitzen, haben wir es hier mit Plus- und Minuswerten zu tun. Beide erreichen an- 
nähernd gleich hohe Beträge, so daß auch die beiden Farbtreppen zu ähnlichen Intensitätsgraden auf- bzw. absteigen. Wie für Blau, bietet sich auch für Rot die Möglichkeit genügender Abstufungen, da für die meisten Atlanten ebenfalls zwei Druckplatten dieser Farbe zur Verfügung stehen.

Im natürlichen Farbkreis gibt es zwei Wege von Rot zu Blau, entweder den direkten über Violett oder den indirekten über Orange-Gelb-Grün. Im Mittelschulatlas (neu) wurden beide beschritten. In kleinsten Maßstäben mit großen, aber wenigen Wärmestufen (Erdkarten) reichte die kürzere Skala über Violett aus. Für die enger gestuften Treppen größerer Maßstäbe aber empfahl sich die längere Farbfolge über Gelb.

Die allgemein übliche Zusammenstellung je einer Karte für Januar- und für JuliIsothermen vermittelt eine anschauliche Vorstellung der jährlichen Temperatur-Pendelbewegung, dies jedoch nur, wenn - wie im Mittelschulatlas - dieselbe Wärmestufe in beiden Karten gleiche Farbe besitzt.

Beispiele :

Mittelschulatlas neu : alle Karten, vor allem diejenigen von Frankreich, Deutschland und Europa; Sekundarschulatlas; Haack: Erdübersichtskarten.

Gegenbeispiele mit unstetigen, unausgeglichenen Farbreihen:

Mittelschulatlas alt: Europa und Erde (die Erdkarte der Januar-Isothermen besitzt für tropische und polare Zonen nahezu dieselbe Farbe!);

Diercke: Erd- und Erdteilkarten (soweit sie Farben enthalten);

Sydow-Wagner: Erde, Erdteile, Mitteleuropa;

Haack: Mitteleuropa (verkehrte Farbskala: warme Töne für kalte, kalte Töne für warme Gebiete).

Der Mittelschulatlas gibt für die Schweiz wirkliche, nicht auf den Meeresspiegel reduzierte Werte. Das nicht reduzierte Wärmerelief ist in alpinen Gebieten so reich gegliedert, das Temperaturgefälle so stark, daß äquidistante Stufen ebenso unzweckmäßig wären wie für Höhenschichtenkarten. Man begnügte sich im Mittelschulatlas bisher mit einigen wenigen, progressiv wachsenden Stufen, für welche die Rot-ViolettBlau-Skala als ausreichend erachtet wurde. Das Bild mittlerer Wärmestufen gleicht im Gebirge demjenigen der Höhenschichten. Die Generalisierung in den beiden Isothermenkarten der Schweiz ist nicht überall gut; im allgemeinen geht sie unnötig weit. Die Darstellungen werden erneuert, reicher differenziert und in den Farben plastischer gestaltet, sobald die klimatologische Forschung bessere Grundlagen zur Verfügung stellen kann.

Die übrigen Wärmekarten des Atlasses geben reduzierte Isothermen, da zu ihrer Bearbeitung für viele Gebiete bisher nur solche zur Verfügung standen. Sie lassen die Abhängigkeit der Wärme von der Breitenlage, von der Land- und Wassergliederung der Erde, von Meeresströmungen und solchen der Lufthülle leichter erkennen als die komplizierteren realen Isothermen. Sie werden daher auch für den Unterricht oft vorgezogen. Nach meiner Ansicht aber eignen sich Karten mit reduzierten Isothermen höchstens für Denksportaufgaben. Sie geben grobe Zerrbilder der tatsächlichen Verhältnisse und lassen sich länderkundlich nicht auswerten. Es ist ein Unding, den Einfluß der Höhe, also der Gebirge, auszuschalten, da ja anderseits dieselben Gebirge Luftströmungen, Bewölkung, Niederschläge usw. und damit auch die reduzierten Isothermen dann doch wieder entscheidend beeinflussen.

Zwei interessante Beispiele nicht reduzierter Isothermen enthält Sydow-Wagner (für Mitteleuropa). Leider sind ihre Farbskalen unstetig und ihre Stufen durchwegs äquidistant. Dieser letztere Umstand zwang im alpinen Gebiet zu starken Formverfälschungen. 
c) Erdkarte der Wärmeschwankung. Die Isoamplituden-Erdkarten in den älteren und jüngeren Ausgaben des Mittelschulatlasses bieten Schulbeispiele schlechter und guter kartographischer Stilistik. Das Mehr oder Weniger der Schwankung kommt in der Karte seit 1932 durch ein Mehr oder Weniger an Farbintensität sehr klar zum Ausdruck. Die frühere Karte aber war seltsam sprunghaft und inkonsequent. Es genügt nicht, in einer Legende lesen zu können, was ein Farbton bedeutet. Wichtiger ist, daß die Karte selbst verständlich ist. Klar ist auch die Lösung bei Haack, nicht gut jedoch in den Atlanten von Diercke und Sydow-Wagner.

In ähnlicher Weise ließen sich die Karten der Is obar en betrachten, ferner gewisse, im Mittelschulatlas nicht vorhandene geophysikalische, ozeanographische und klimatologische Karten, wie z. B. solche des Erdmagnetismus, des Salzgehaltes im Meere, des Frühlingseinzuges. Diese letzteren, die sogenannten phänologischen Karten, sind bei Diercke und bei Haack Muster verwirrender Farbgebung.

d) Volksdichtekarten. Volksdichte und auch andere Mengen-oder Streuungsverhältnisse können auf verschiedene Arten kartiert werden. Man unterscheidet die absolute und die relative Darstellung und bei der letzteren die statistische und die geographische Art der Bearbeitung. Eine Wiedergabe tatsächlicher Zustände und Gliederungen ist ebensowenig möglich wie für irgendwelche andere Karteninhalte. Die genannten Kartierungsarten unterscheiden sich durch ihre begriffliche und graphische Generalisierung.

In der absoluten Darstellung ist je eine bestimmte Anzahl benachbarter Objekte zu einem Punkt zusammengefaßt. Es entstehen Streubilder, sogenannte Punktkarten. Oft werden die Punkte bzw. Miniaturscheibchen in ihrer Größe gestaffelt und neuerdings sogar als Kugelbilder aufgefaßt. Der Rauminhalt jeder einzelnen Kugel soll der Anzahl zusammengefaßter Objekte proportional sein. Solche allzu ausgeklügelte Darstellungen übersteigen jedoch die Differenzierfähigkeit des Kartenlesers und für kleine Maßstäbe auch die Möglichkeiten klarer Reproduktion. Was man in die Karten hineinzulegen wähnt, kann ihnen nicht genügend entnommen werden. Ein Beispiel hiefür bietet Sydow-Wagner: die Europakarte 1:15000000 der Verteilung der Bevölkerung im Jahre 1928. Niemand ist hier in der Lage, in den dichten Gebieten die Punkte zu zählen oder gar die Rauminhalte der Miniaturkugelbilder zu schätzen. Durch unvermeidliche Unschärfen des Druckes wird auch das Bild wechselnder Punktdichten verfälscht. Die Karte vermittelt zwar einen gewissen Eindruck der Streuung, doch sind die Dichteabstufungen weniger genau erfaßbar als aus relativen Darstellungen. Punktkarten können vereinfacht werden durch Vergrößerung der Punkteinheiten. Solche Objektkonzentrationen verschlechtern jedoch den Streucharakter, und sie vermindern die Anpassungsfähigkeit an schwach besetzte Gebiete.

Punktdarstellungen sind heute sehr beliebt; doch sollten sie im allgemeinen auf größere Maßstäbe oder aber auf gewisse Karten kombinierter Inhalte beschränkt bleiben. Blaue, braune und rote Punkte in ein und derselben Karte können nicht nur Hindus, Mohammedaner und Christen auseinanderhalten, sondern gleichzeitig ihre ungefähren Mengen und Streuungen angeben. Oder Punkte können wertvolle Zusatzelemente zu flächenhaften Kartenfüllungen sein usw.

Die relative Darstellung gibt die Anzahl von Objekten pro $\mathrm{km}^{2}$, wobei auch hier das Dichterelief nur in stark zusammenfassenden Stufen zum Ausdruck gebracht werden kann. Man läßt diese Stufen progressiv wachsen, da auf solche Art beste Annäherung des Stufenreliefs an das tatsächliche Dichterelief erreicht wird. Die statistische und die geographische Art der Bearbeitung solcher Dichtekarten unterscheiden sich durch die Flächenabgrenzungen. Im ersten Falle bezieht man die Anzahl der Objekte auf administrative oder politische Areale, also auf Gemeinden, Bezirke usw. Dies ist bequem, da solche Einheiten durch die statistischen Zählungen erfaßt werden. 
Die geographische Bearbeitung führt über die statistische hinaus. Die Flächenabgrenzungen erfolgen unter Betrachtung der tatsächlichen Streuung und der gesamten Landschaft. Das entstehende Bild ist zwar oft subjektiver, meist aber auch wirklichkeitsnäher, charakteristischer, organischer und verständlicher.

Im Gegensatz zu den absoluten eignen sich für relative Dichtekarten im allgemeinen nur kleine Maßstäbe. Je mehr die Karten und damit auch die statistischen Flächenoder Aufnahmeeinheiten zusammenschrumpfen, desto mehr verschwinden die Unterschiede zwischen statistischer und geographischer Bearbeitung. Schließlich werden sie durch Generalisierungseinflüsse völlig überlagert.

Beispiele statistischer Darstellungsart sind u. a. die oben erwähnten Schweizerkarten im großen Landesausstellungsbuch (Lit. Nr. 7), solche geographischer Bearbeitung die Volksdichtekarten im Mittelschulatlas.

Das Intensitäts- oder Quantitätsrelief relativer Volksdichtekarten weist, im Gegensatz zu den Niederschlags- und Wärmekarten, vielenorts Unstetigkeiten auf. Sehr dichte und sehr schwach besetzte Gebiete können sich unmittelbar berühren. Linien, die den Isothermen, Isobaren, Isohypsen usw. entsprächen, sind hier undenkbar. Es fehlt somit im Innern der Karte eine kontinuierliche und ordnende Stufenleiter, an der man die Dichtegrade messen könnte. Allzu bunte, sprunghafte Flächentonskalen wirken sich daher verheerend aus. Klarheit verschafft nur das stilistische Prinzip «je dichter, desto satter».

Die Volksdichtekarten des Mittelschulatlasses entsprechen diesem Prinzip. Die Wahl roter Töne erfolgte aus folgenden Gründen: Wie oben erwähnt, stehen für den Druck zwei Rotplatten zur Verfügung, so daß in roter Farbe deutliche Abstufungen erreicht werden können. Die beiden überall wiederkehrenden und oft auf derselben Atlasseite stehenden Quantitätskarten, diejenige der Niederschläge und diejenige der Volksdichte, harmonieren gut zusammen, da sie Komplementärfarben aufweisen. Ihr Farbengegensatz läßt jede der beiden Kartengattungen sofort erkennen.

Ausgesprochene Zweifarbigkeit innerhalb einer Quantitätskarte ist angezeigt, wenn es sich nicht um Mengen an sich handelt, sondern um deren Wachsen und Schwinden. Ein Beispiel hiefür bietet die neue Karte der Zu- und Abnahme der Bevölkerung in der Schweiz im Mittelschulatlas 1948. Gegensätzliche Farben symbolisieren somit auch hier, ähnlich wie in Wärmekarten, das verschiedene Vorzeichen. Die geringsten positiven und negativen Mengenänderungen besitzen hellste Farben, so daß sich Ähnliches in der Tönung nahekommt. -

Beispiele :

Mittelschulatlas alt und neu; Sekundarschulatlas; Haack.

Gegenbeispiele : zum Teil mit unausgeglichenen, zum Teil mit zu bunten Skalen; Sydow-Wagner: Bevölkerungskarte von Südostasien (die übrigen Volksdichtekarten sind Punktdarstellungen); Diercke; Slanar; Geographisches Lexikon; Landesausstellungswerk (Lit. Nr. 7); Krebs: Die österreichischen Alpen, Volksdichtekarte S. 224.

e) Sprachen-, Völker- und Religionskarten. Kaum eine Kartengattung wird so oft zur Dirne imperialistisch-politischer Ziele herabgewürdigt wie die Sprachenund Völkerkarte. Selbst ein so bedeutendes Kartenwerk wie Sydow-Wagners methodischer Schulatlas (Ausgabe 1931) ist nicht frei von solcher Geisteshaltung. Es zeigt in einer Karte des deutschen Sprach- und Kulturbodens u. a. die rätoromanischen Gebiete Graubündens als "deutschen Kulturboden», eine Entgleisung, über die jeder Kenner der Schweiz im besten Falle lachen wird. - Es ist anzunehmen, daß schweizerische Autoren gegen solche und ähnliche Tendenzkrankheiten immun sind; doch sind sie für fremde Gebiete weitgehend auf ausländische Quellen angewiesen. Und selbst 
bei objektivster Bearbeitung setzen sie sich der Kritik durch die Behexten aus, so wie dies Charles BuRKy mit seiner vorzüglichen Sprachenkarte von Europa erlebt hat.

Der Mensch kann seine Schädelform nicht ändern, und auch die Hautfarbe wechselt höchstens saisonmäßig. Die Religionen weisen im allgemeinen große Beharrlichkeit auf. Verschiedene Lehren und Auffassungen können am selben Orte während Jahrhunderten nebeneinander bestehen, selbst wenn sie sich gegenseitig nicht lieben. Sprachmischungen hingegen scheiden sich im Laufe weniger Generationen aus. Einsprenglinge werden durch die Mehrheit assimiliert. Praktische Notwendigkeiten des täglichen Lebens führen dazu. So verschwinden Minderheiten oder sie bilden räumliche Exklaven, die in sich sprachlich einheitlich sind. In der Regel lassen sich daher ihre Abgrenzungen scharf erfassen, während völkische und religiöse Überlagerungen und Mischungen länger bestehen bleiben und oft große Räume einnehmen.

Solche Unterschiede der räumlichen Lagerung kommen in den Spezialkarten zum Ausdruck. Sprachenkarten zeigen vorwiegend ein klares Nebeneinander verschiedener Farbzonen. In Völkerkarten aber und mehr noch in denjenigen der Religionen finden sich selbst in großen Gebieten Mischungen oder Durchdringungen. Wir betrachten zuerst den einen, dann den andern Fall.

1. Das Nebeneinander. Das Artmosaik steht in einem gewissen Gegensatz zum Dichterelief. Im letzteren bedeutet der Hell-Dunkel-Unterschied ein und derselben Farbe einen Mengenunterschied ein und desselben inhaltlichen Stoffes. In den Sprachen-, Völker- und Religionskarten aber handelt es sich um Artunterschiede, jedoch in der Regel nicht um ein einfaches Mosaik von Teilen gleichen Ranges. So bilden z. B. mehrere Sprachen zusammen größere Sprachgruppen. Dies wird zum Ausdruck gebracht, indem Gruppen durch verschiedene Farben, Gruppenglieder aber durch Nüancen oder Helligkeitsunterschiede ein und derselben Farbe bezeichnet werden.

Soweit wie möglich sollen große Flächen leichte, die kleinsten Gebiete aber kräftigste Töne erhalten; denn sonst verlöre sich manch Kleines, Bedeutungsvolles in den weiten Räumen.

Beispiele: Sprachenkarten von Südosteuropa und von Nord- und Südamerika im Mittelschulatlas 1948. Die verschiedenen romanischen Sprachen besitzen darin verschiedenes Blau, die germanischen verschiedenes Rot, die slawischen verschiedenes Grün. Auch die auf ältere Atlasausgaben zurückgehende Sprachenkarte von Europa zeigt eine ähnliche, jedoch nicht überall konsequent eingehaltene Regelung.

2. Mischungen und Durchdringungen. Hier bestehen vier verschiedene Lösungen.

Mischtöne. Ein Beispiel zeigt die Konfessionskarte der Schweiz im Mittelschulatlas. Abgesehen von einzelnen wenigen Punktsignaturen für Israeliten, geht es hier nur um $z$ wei Gattungen, um Protestanten und Katholiken, um rote und blaue Flächen. Mischgebiete erscheinen automatisch als solche, wenn diese beiden Farben gemischt werden. Hiebei sollen die Mischungen den prozentualen Verhältnissen entsprechend abgestuft werden. Diese naheliegende Lösung wurde für die Konfessionskarte erst 1932 getroffen. Die älteren Ausgaben zeigten eine dem Geographischen Lexikon entnommene unlogische und daher verwirrende Skala.

Streifenartige Durchdringung. Bei mehr als zwei Inhalts- bzw. Farbkomponenten kommen Mischtöne nicht in Frage, da durch eine Vielheit von solchen Unklarheit entstünde. Allgemein üblich ist in solchen Fällen die streifenartige Durchdringung, wie sie z. B. die Völker- und Religionskarten von Asien, Afrika und der Erde des Mittelschulatlasses zeigen. Solche farbige Streifungen verzerren den Inhalt oft allzusehr. Auch sind sie graphisch-technisch reichlich kompliziert. Madagaskar, Australien usw. 
erwecken in den genannten Karten den Eindruck seltsam steif gemusterter Teppiche. In Zukunft werden zweifellos bessere Darstellungen streuartiger Durchdringungen gefunden werden.

Zusätzliche Schraffuren oder Punkte. Solche kommen in Frage bei quantitativ sehr ungleichen Mischungen oder auch bei Kombinationen völlig verschiedenartiger Inhalte. Die Grundelemente erhalten farbige Flächentöne, die sekundären Elemente jedoch lockere Strichreihen oder Punkte, wobei sich diese zusätzlichen Elemente durch kräftigere Farben von den Grundtönen abheben sollen, ohne deren Farbeindruck $z u$ verschleiern.

Beispiele: Mittelschulatlas neu: Europa, Religionen; Nord- und Südamerika, Völker und Sprachen (Neger, Chinesen und Japaner) ${ }^{2}$. Sekundarschulatlas : Nordamerika, Völker (und Sprachen).

Verschiedenfarbige Punkte. Alle Elemente werden durch eingestreute Punkte verschiedener Farben dargestellt. Die Farben der Punkte bezeichnen die Arten, ihre Dichte die Mengen. Es handelt sich somit hier um eine instruktive Verbindung qualitativer und quantitativer Darstellung. Ein gutes Beispiel findet sich in Sydow-Wagner : Erdkarte der Bevölkerungs- und Rassenverteilung 1928.

Diese Karte zeigt aber auch die Mängel des Verfahrens:

Verschiedene Farben besitzen verschiedene optische Gewichte, so daß der Mengeneindruck verfälscht wird. Die schwarz punktierten Dravidas in Vorderasien erscheinen gegenüber den hellgelb punktierten Indoiraniern stark überbetont.

Die Abgrenzungen der einzelnen Rassengebiete (in andern Karten eventuell Sprachgebiete) sind bei schwacher Volksdichte bzw. lockerer Punktstreuung nicht zu erkennen. Beispiele in der oben genannten Karte: Durchdringung von Europäern und Mongolen in Rußland. Solche Mängel ließen sich durch dichtere, gleichmäßigere Punktstreuung verringern, wodurch aber anderseits das Quantitätsrelief stark eingeebnet erschiene.

Die Punktdarstellung läßt nicht so viele Artdifferenzierungen zu wie das Flächentonverfahren, da nur kräftige Druckfarben in Frage kommen und überdies für den einzelnen Punkt Farbmischungen drucktechnisch nicht durchführbar sind.

Zwischen Völkern und Religionen bestehen vielenorts kausale Zusammenhänge, was sich in Ähnlichkeiten von Verbreitungsgebieten zeigt. Im Mittelschulatlas (neu) wurde dies durch korrespondierende Farben hervorgehoben. Beispiele: Völker- und Religionskarten von Afrika: Indo-Europäer bzw. Christen rot, Semiten-Hamiten bzw. Mohammedaner braun, Neger bzw. Heiden blau.

f) Politische Karten. Auch hier gelten dieselben graphischen Gesichtspunkte. Man trennt Staaten durch verschiedene Farben, Staatsteile aber durch Helligkeitsabstufungen der betreffenden Staatsfarbe. In größeren Maßstäben differenziert man in analoger Weise, z. B. Bezirke und Gemeinden.

Im Mittelschulatlas erhielt ein und derselbe Staat in allen politisch kolorierten Karten stets dieselbe Farbe. Britisches Gebiet ist überall rot, niederländisches Gebiet überall gelb usw. Die große Zahl von Staaten erlaubte es nicht, jedem derselben eine eigene Farbe zuzusprechen; doch mußte das Aneinanderstoßen gleicher oder ähnlicher Farben vermieden werden. Dies führte zu recht komplizierten Kombinationsaufgaben. Es war kein Zufall, daß für Frankreich und die Sowjetunion grüne, für das Britische Reich rote Farbe gewählt wurde. Diese drei Gebiete bedurften infolge ihrer Größe und Struktur einer inneren Gliederung durch farbige Gtenzbänder. Hiezu waren Grün und Rot besonders geeignet.

${ }^{2}$ Siehe die diesem Hefte beigegebene Kartentafel. 
Auch für das politische Kolorit besteht das Bestreben, große Flächen leicht, kleine Areale stark zu tönen. Überdies sollten Eck- und Randgebiete eines Mosaikblockes nicht zu blaß sein; denn sonst würde das Gesamtgebilde optisch zerfallen. Solche Wünsche müssen leider oft hinter den oben genannten Hauptpostulaten zurückstehen. Ein Schulbeispiel ihrer weitgehenden Erfüllung bot die wieder verschwundene politische Karte von Deutschland in den Ausgaben 1932 und 1936 des Mittelschulatlasses. Die preußischen Provinzen erschienen darin im ganzen gedämpft, die eingestreuten Hansastädte und andere kleine Länder jedoch in intensiven Tönen. Ferner traten die deutschen Eckgebiete Schleswig-Holstein, Ostpreußen, Oberschlesien und Baden relativ stark hervor.

Es ist eine weitverbreitete Sitte, politische Farbflächen durch verstärkte Grenzbänder derselben Farbe einzufassen. Auch in den frühesten Ausgaben des Schweizerischen Mittelschulatlasses war dies überall der Fall. Solche Farbsäume sind im allgemeinen nicht zu empfehlen. Sie wirken nicht klärend, sondern verwirrend. Sie überlasten und verschmieren das Farbmosaik und eignen sich höchstens da und dort zur Zusammenfassung ganzer Mosaikblöcke.

g) Geologische und tektonische Karten. Aus guten geologischen Karten spricht eine ungeheure Dynamik erdgeschichtlichen Geschehens. Die bunten Farbflecken bilden kein regelloses Mosaik; sie fügen sich in Systeme, und sie stehen in engsten Beziehungen zum Relief. Sie symbolisieren Gesteinsmassen, die sich einst abgelagert, gedrängt, gefaltet, überschoben und durchbrochen haben. In Gebirgen tritt das Innere der Erdrinde bunt und nackt zutage, in flachen Wannen aber ist es verhüllt durch das Leichentuch des Quartärs.

Geologische Karten zählen zu den schönsten Spezialdarstellungen. Schön sind sie jedoch nur, wenn der erstarrte Wellenschlag der Natur zum Ausdruck kommt, wenn die Beziehungen $z$ wischen Material und Lagerung erkennbar werden. Dies aber ist in allzu kleinen Maßstäben nicht genügend der Fall; denn zu weit gehendes Generalisieren verschleiert das Organische und schafft oft Farbmuster ohne erkennbare Zusammenhänge. Die Schönheit geologischer Karten liegt nicht so sehr im Farbigen an sich als vielmehr in dessen natürlichem Fluß. Die geologischen Erdteilkärtchen der frühesten Atlasausgaben sind denn auch später preisgegeben worden, da sie nicht viel zu bieten vermochten. Wie so oft bei Kartenbewertungen, deckte sich das didaktische Urteil mit dem graphisch-stilistischen.

Bei Erstellung geologischer Schulkarten ist der graphisch-stilistische Spielraum nicht sehr groß. Er umfaßt begriffliches Generalisieren, zeichnerisches Generalisieren und Abwägen der Farben. Sinnvolles begriffliches Abstufen und gutes zeichnerisches Generalisieren setzen weitgehende geologische Fachkenntnisse voraus. Unverstandenes Vereinfachen vernichtet das Organische.

Die Farbleiter geologischer Karten steht in großen Zügen längst fest. Es haben sich hierüber Normen und Gebräuche herausgebildet. Damit aber ist eine Karte noch nicht gemacht. Trotz der Normen sind Nüancen in Farben und Tonstärken möglich, und gerade diese Nüancen sind es, die das Bild schön und klar oder aber banal und verwirrend erscheinen lassen. Man vergleiche in diesem Sinne die geologische Karte der Schweiz in den Ausgaben 1932-1942 des Mittelschulatlasses mit den inhaltlich und maßstäblich ähnlichen, farbig aber schlechter abgewogenen Darstellungen im Geographischen Lexikon, in FrüHs Geographie der Schweiz oder im Buche von C. Schmid, Bild und Bau der Schweizer Alpen.

Die tektonische Karte der Schweiz (Atlasausgaben seit 1932) faßt der Erscheinungen Flucht stärker zusammen als bisherige Karten ähnlicher Art. Dies liegt zum Teil am kleineren Maßstab, zum Teil aber auch am konsequenteren Herausheben des Wesentlichen. Autochthone Massive und Überschobenes, also tektonisch artver- 
schiedene Dinge, sind scharf getrennt in Rot und Blau. Die Deckengruppen jedoch erfuhren eine ihrer zeitlichen Staffelung entsprechende Helligkeitsabstufung ein und derselben Farbe. Damit sind Klippen und Fenster ohne weiteres als solche erkennbar. Man sieht, was unten und was oben liegt, was in den Bewegungsvorgängen zusammengehört und was miteinander nichts zu tun hat. Frühere tektonische Übersichtskarten waren seltsam unklare Mischungen von tektonischen und stratigraphischen Elementen und daher für den Laien und Schüler verwirrend. Auch in der Kartographie gibt weniger oft mehr. Die stilistischen Prinzipien, wie sie oben bei den Volksdichte- und Sprachenkarten entwickelt worden sind, führten auch hier aus dem Chaos zur Klarheit.

h) Vegetationskarten ${ }^{3}$. Der Aufsatz von E. Schmid erlaubt mir hier eine Beschränkung auf einige graphisch-stilistische Bemerkungen.

Bei der graphischen Gestaltung der neuen Vegetationskarten des Mittelschulatlasses handelte es sich um das Problem der Übereinanderschichtung von zwei verschiedenen Intensitätsskalen.

Die eine Skala führt vom kalten Blau polarer Gebiete zum warmen Rot der Tropen. Sie ist mit der Temperaturskala vergleichbar und baut sich wie diese aus verschiedenen Farben auf.

Die zweite Stufenleiter führt vom Trockenen zum Feuchten, von der wüstenartigen Leere zum üppigen Wachstum, oder in der Karte von schwachen zu starken Tönen.

Die erste Skala umspannt die Erde, sie ist globular; die zweite schwingt in jeder Klimazone auf und ab. Graphisch waren somit mehrere kurze Intensitätswellen mit einer langen zu koordinieren.

Die globulare Skala gliedert sich in folgende fünf Zonen: arktisch und alpin, subarktisch und subalpin, gemäßigt, subtropisch, tropisch. Der direkte Weg von Blau über Violett zu Rot, wie er für die Isothermen-Erdkarten beschritten werden konnte, reichte hier nicht aus. Der längere Weg von Blau über Grün, Gelb, Orange zu Rot, wie ihn die Isothermenkarten europäischer Gebiete zeigen, war auch nicht gangbar; denn Gelb ist stets ein heller Ton, der nicht genügend vom Schwachen zum Starken abgestuft werden kann. So wurde die globulare Skala von Blau über Grün, Braungrün (Oliv) und Braun zu Rot entwickelt. Auch diese Skala ist stetig und harmonisch; denn auch hier nehmen die kalten blauen Töne von den Polen gegen den Äquator ab, die warmen roten aber zu; doch greifen sie weiter aus als in der Blau-Grün-Gelb-OrangeRot-Skala, so daß durch Überlappung von Blau-Gelb-Rot Braunmischungen entstehen. Jedes ihrer Glieder läßt sich in genügender Weise hell — dutnkel abstufen. Lithographisch und drucktechnisch war die Sache mit den zur Verfügung stehenden Druckfarben gar nicht leicht zu lösen, da sich entsprechende Stufen jeder Globulargruppe in der Tonintensität möglichst entsprechen sollten.

Im ganzen bringt eine solche, auf die Hauptfaktoren der Vegetationsphysiognomie bezogene Farb- und Tonskala für Erdteil- und Erdkarten einen großen Gewinn an Klarheit. Man erkennt Ähnlichkeiten und Verschiedenheiten, Kaltes und Warmes, Mageres und Üppiges auf den ersten Blick und ohne erst die Legende befragen zu müssen. So zeigen z. B. die blassen Töne überall steriles Gebiet, lassen aber zugleich erkennen, daß die Trockenwüsten verschiedener Klimazonen in ihrer Vegetation nicht gleichartig sind.

Bisherige Vegetationserdkarten zeigten verwirrende Farben, so z. B. sinnlose Kontraste blauer arktischer und zinnoberroter hochalpiner Vegetation. Zu summarisch war das einheitliche Gelb für alle Trockenwüsten oder gar für Trocken- und Kältewüsten, sinnstörend blaue und violette Töne für Subtropen und Tropen, rote Farben für Polargebiete, unplastisch die Verwendung grüner Farben sowohl für äquatoriale

${ }^{8}$ Siehe die diesem Hefte beigegebene Kartentafel. 
wie für nordische Wälder. Landschaftsähnliche Farben vermögen Vegetationserdkarten nicht zu gliedern; denn grün ist die Pflanzendecke überall von Alaska bis Feuerland und vom Nordkap bis-nach Südafrika.

Solche unzweckmäßige oder unanschauliche Farben enthielten alle bisherigen Vegetationskarten der Erdteile und Erde, so z. B. diejenigen in den Atlanten von Sydow-Wagner, Diercke, Haack, Slanar, ebenso in Atlanten anderer Staaten und die Wandkarte von $\mathrm{H}$. Brockmann-Jerosch.

Auch die Vegetationserdkarte im Schweizer Lexikon zeigt in kartographischstilistischer Hinsicht eine unbefriedigende Form, obschon sie sich auf dieselbe Entwurfsskizze von E. Schmid stützt, wie die Karte im Mittelschulatlas.

Die kleinen Maßstäbe unserer Erd- und Erdteilvegetationskarten gestatten es nicht, über die großen ökologisch-physiognomischen Hauptgruppen hinaus speziellere floristische Differenzierungen in Erscheinung treten zu lassen. Immerhin wurden auch solche berücksichtigt, und zwar in den Erdteilkarten da und dort durch Variationen der Legendentexte, in der Erdkarte aber durch summarische Trennungslinien indoafrikanischer, madagassischer, indo-malesischer, australisch-melanesischer und amerikanischer Vegetation.

Die engen Beziehungen zwischen Klima und Vegetation legten es nahe, die Erdkarte der Klimatypen in Gliederungen und Farben der Vegetationskarte möglichst anzugleichen, wobei freilich stärkere Zusammenfassungen vorzunehmen waren. Bei Sydow-Wagner und in andern Werken besitzen diese einander entsprechenden Karten in ihrem Farbaufbau nicht die geringsten Ähnlichkeiten.

i) Wirtschaftsgeographische Karten*. Auch hier gehen wir nicht auf die Inhalte ein, da dies durch J. Hösur besorgt wird.

In graphischer Hinsicht zählen die wirtschaftsgeographischen Karten, besonders diejenigen synthetisierender Art, zu den kompliziertesten. In den meisten Atlanten «zeichnen sich solche Karten aus» durch sinnverwirrende Kompliziertheit. - Vielheit, Verschiedenartigkeit und Übereinanderlagerung der Dinge stellen schwerlösbare Aufgaben. Auch unsere neuesten Atlaskarten werden in Zukunft da und dort durch leichte Farbvariationen und zeichnerische Gebietsvereinfachungen noch etwas geklärt werden können.

In den wirtschaftsgeographischen Karten gelangt graphisch-stilistisch alles zur Anwendung, was bisher an andern Kartengruppen erläutert worden ist. Zusammenfassend seien nochmals einige Hauptpunkte genannt:

1. Artunterschiede sollen durch verschiedene Farben, Mengenunterschiede durch verschiedene Tonintensitäten zum Ausdruck kommen.

Der Mengenbegriff hat sich auf das kartierte Thema zu beziehen. So besitzen beispielsweise tropische Regenwälder in den Vegetationskarten intensive Färbung, in den Wirtschaftskarten jedoch, da wo ihre Ausbeute gering ist, leichte Töne (Atlasausgabe 1948).

Solche Grundsätze gelten nicht nur für Flächentöne, sondern analog auch für Signaturen, Linien, Pfeile, Punkte usw.

2. Die Farben sollen sich möglichst an natürliche Vorstellungen anlehnen (Getreidegebiete gelb, Grasland grün, Waldflächen blaugrün oder blau, Wein rot, ferner Kohle schwarz oder dunkelbraun, Eisen blau usw.). Dieses Postulat sei wohl wegleitend, doch kann es infolge der Vielheit von Dingen nicht überall streng befolgt werden. Deutliche Differenzierung geht vor.

3. Ähnliches soll graphisch ähnlich, Gegensätze aber durch graphische Kontraste zum Ausdruck kommen.

${ }^{4}$ Siehe die in diesem Hefte beigegebene Kartentafel. 
4. Bei Übereinanderschichtungen können Basiselemente durch Farbflächen, die Variationen oder zusätzlichen Vorkommnisse durch Linienschraffuren, Punkte und Signaturen dargestellt werden. Eine weitere Möglichkeit besteht im Aufdruck farbiger Umfassungslinien für räumliche Verbreitungsgebiete (nördliche Waldgrenze, Weinstockgrenze, Gebiete mit artesischen Becken usw.). Diese Lösung empfiehlt sich oft auch für charakteristische, jedoch sehr kleinräumige, sporadische Vorkommnisse, deten Einzeleintragungen nicht genügend hervortreten würden (Kopra und Sago in der südostasiatischen Inselwelt).

5. Bei graphischen Überlagerungen sollen sich Grundelemente (Farbflächen) und Zusatzelemente (Signaturen, Punkte, Schraffuren) gegenseitig möglichst wenig stören.

6. Kleinräumige, aber wichtige Dinge (Kohle, Erdöl, Eisen usw.) sollen durch kräftigste Farben und Signaturen hervortreten, großräumige Flächen jedoch eher gedämpft werden.

k) Geschichtliche Karten. Solche sind im Schweizerischen Mittelschulatlas als einem Lehrmittel der Geographie nicht enthalten; doch sei an drei Beispielen des Sekundarschulatlasses gezeigt, daß sich für historische Dinge dieselben graphischstilistischen Regeln empfehlen.

Das erste Kärtchen zeigt durch Übereinanderlagerung flächiger und signaturartiger Elemente die Schichtungen frühester Besiedlung unseres Landes.

Das zweite Beispiel läßt durch Helligkeitsabstufungen ein und derselben Farbe das zeitlich abgestufte Wachstum eidgenössischen Territoriums in plastische Erscheinung treten. Die Beziehung «je - desto» gilt nicht nur für quantitative, sondern ebenso für zeitliche Staffelung: je früher angegliedert, desto dunkler.

Das dritte Kärtchen zeigt ein Artmosaik, gegliedert in die beiden Hauptgruppen: Rot für die dreizehn Orte und Blau für die zugewandten Orte. Innerhalb jeder dieser zwei Hauptgebiete sind durch Helligkeitsunterschiede die Untertanenländer von den regierenden Orten geschieden. Als Sonderfall wurden die Untertanenländer der geistlichen Orte violett getönt.

So konnten auf kleinstem Raume und mit einfachsten Mitteln Besiedelung, Wachstum und strukturelle Gliederung der alten Eidgenossenschaft zum Ausdruck gebracht werden.

\section{DIE KARTENBESCHRIFTUNG}

Die Vielheit von Sprachen führt zu einer außerordentlichen Mannigfaltigkeit geographischer Namen. Schreib- und Lesart eines einzelnen Volkes kann solch globularen Reichtum niemals erfassen. Jede irgendwie normalisierte oder transkribierte Schreibweise ist das Ergebnis weitgehender Generalisierung. Das Namengut verhält sich hierin nicht anders als der übrige Karteninhalt. In bezug auf Art und Grad der Vereinheitlichungen gehen die Ansichten auseinander. Die Schreibformen des Mittelschulatlasses suchen den Bedürfnissen möglichst vieler Benützer zu entsprechen; doch ist es nie möglich, alle Wünsche zu erfüllen.

Der Atlas erscheint in deutscher, französischer und italienischer Sprache. Ihre Beschriftungen folgen analogen Richtlinien. Wir betrachten sie an Hand der deutschen Ausgabe.

Diese geht in der Verdeutschung fremdsprachiger Namen weniger weit als reichsdeutsche Atlanten. Für die letzteren ist möglichste Verdeutschung gegeben. Die Franzosen, Italiener, Engländer, Russen usw. halten es in ihren Lehrmitteln analog. Die Schweiz hingegen ist ein viersprachiges Land. Deutsch, Französisch, Italienisch und Rätoromanisch stehen nebeneinander als anerkannte und gleichberechtigte Landessprachen. Es entspricht der schweizerischen Staatsidee und schweizerischem Empfin- 
den, dieses Nebeneinander auch im Mittelschulatlas als einem nationalen Lehrmittel zum Ausdruck zu bringen. Der deutschschweizerische Mittelschüler soll sowohl die Namen Venedig, Tiber, Langensee, Vogesen, Burgund, Prag usw. wie auch Venezia, Tevere, Lago Maggiore, Vosges, Bourgogne, Praha kennenlernen. Dies ist aus kulturellen und praktischen Gründen unerläßlich.

Solche Toleranz darf aber die Liebe zur eigenen Sprache und das Bestreben, sie reinzuhalten, nicht schwächen. Das deutsche Sprachgut umfaßt nicht nur Namen deutschen Sprachraumes, sondern darüber hinaus ein erdumspannendes Netz weiterer geographischer Bezeichnungen. Dasselbe gilt für jede Kultursprache. Ein Vergessen solchen Gutes wäre kulturelle Verarmung. Es besteht kein vernünftiger Grund, im Deutschen die Bezeichnung «Stiller Ozean» durch «Pazific» zu ersetzen.

Länderkundliche Detailbetrachtung hat stets auch einen Blick auf die Sprache zu werfen. Diese soll so gut wie möglich aus dem Schriftbild regionaler Karten hervorgehen.

Solche sich teilweise entgegenstehende Gesichtspunkte lassen sich nicht auf einen Nenner bringen. Für unseren Atlas ergibt sich daraus die Notwendigkeit, gewisse fremde Namen in der einen Karte fremdsprachig, in einer andern verdeutscht zu geben; denn allzu viele Doppelbenennungen innerhalb ein und derselben Karte würden zu unerwünschten Bildüberlastungen führen. Der Atlas enthält daher in sprachlicher Hinsicht drei verschiedene Kartentypen:

1. Einige Übersichtskarten (Alpenländer, Europa physisch und politisch) entsprechen sprachlich in großen Zügen den reichsdeutschen Schulatlanten. Allgemein übliche deutsche Formen fremder Namen wurden deutsch geschrieben (Tiber, Burgund).

2. Detailkarten kleiner Gebiete halten sich an die amtlichen Schreibweisen der betreffenden Staaten. Dies gilt für alle Gebiete mit lateinischem Alphabet. Wo dieses fehlt, wurde deutsch transkribiert.

3. Ubrige allgemeine Karten (europäische Länder oder größere Teilgebiete von Ländern und Erdteilen), ebenso die Spezialkarten. Diese Gruppe steht zwischen den beiden erstgenannten. In ihrer Beschriftung sind drei Zonen auseinanderzuhalten:

Eine erste Zone umfaßt die Gesamtheit des deutsch-französisch-italienischen Sprachraumes, also die Gebiete unserer Hauptlandessprachen. Hier wurde so wenig wie möglich übersetzt. Italienische Namen von Flüssen, Seen, Bergen, Landschaften usw. erscheinen auch in der deutschen Atlasausgabe italienisch (Tevere), entsprechend französische Namen französisch (Bourgogne).

Eine zweite Zone schließt die Gebiete ein, in denen keine unserer Landessprachen gesprochen wird, jedoch das lateinische Alphabet im Gebrauche steht. Für Ortschaftsnamen gelten hier, wie oben, die amtlichen Formen der betreffenden Länder. In wichtigsten Fällen wurde die deutsche Form beigefügt (Bucuresti, Bukarest). Im übrigen aber wurden allgemein übliche deutsche Namen und Bezeichnungen deutsch gegeben (Themse, Andalusien).

Die dritte Zone endlich umfaßt Gebiete ohne lateinisches Alphabet (Rußland, Bulgarien, Griechenland, Ägypten, China, Japan). Allgemein übliche deutsche Namen und Bezeichnungen wurden deutsch gegeben (Olymp, Totes Meer), alle übrigen deutsch transkribiert, $d$. $h$. so geschrieben, da $B$ ihre Aussprache in deutscher Lesart der fremden Sprechform möglichst nahekommt (in China z. B. Tschifu, und nicht die englische Form Cheefu). Einige Städte erscheinen sowohl in deutscher Form (Athen) wie auch in deutscher Transkription (Athinaï).

Weitere Erläuterungen über die Schreibweise der Namen finden sich im Einleitungstext des Atlasses. Der dortige Schlußabschnitt sei hier wiederholt:

«Die Beschriftungsgrundsätze ließen sich nicht immer starr und einheitlich durchführen. Es gibt Grenzfälle zwischen eigentlichen Namen und den (stets deutsch ge- 
schriebenen) Bezeichnungen der geographisch-wissenschaftlichen Terminologie, Grenzfälle zwischen Namen und (deutsch geschriebenen) erläuternden Sachbezeichnungen. Es gibt Zweifelsfälle, ob z. B. der Name für ein Meer, einen Meeresteil in ein einzelnes Sprachgebiet zu weisen sei oder nicht. Solche Dinge hängen nicht zuletzt auch von den Abgrenzungen der Kartenfläche ab, vom Zusammenhang, in welchem ein Name auftritt. Es ist ferner oft eine offene Frage, wie weit man bei einer deutschen Fassung eines fremden Flußnamens noch von einer allgemein gebräuchlichen deutschen Form sprechen kann. Abgesehen von solchen Grenzfällen, schien es manchmal im Interesse der Einheitlichkeit oder der allgemeineren Brauchbarkeit einer Karte geboten, von den Regeln abzuweichen, oder z. B. Namen, die in zwei Formen vorkommen und wichtig sind, hier so, dort in jener Form zu geben. Es wurden z. B. die indischen Provinzen und Fürstentümer einheitlich englisch beschriftet, da nur für den kleinsten Teil derselben deutsche Namenformen existieren, oder es wurden einige Ortsnamen im Orient, die längst allgemeines deutsches Kulturgut sind, in einzelnen Karten deutsch gegeben, statt in der (ehemals) offiziellen französischen und englischen Form usw. Die mitgeteilten Prinzipien der Beschriftung sind somit als allgemeine Richtlinien, nicht aber als starre Gesetze aufzufassen.»

Lateinisches Alphabet und deutsche Transkription können fremde Sprechformen oft nur mangelhaft wiedergeben. Aus Kreisen der Atlasbenützer wurde daher der Wunsch geäußert, besondere Laut-, Betonungs- und Dehnungszeichen einzuführen. Solchen Wünschen kann in einem Mittelschulatlas nur beschränkt entsprochen werden. Die skandinavischen Länder, ferner Spanien, Portugal, Rumänien, Polen, Tschechoslowakei und Ungarn verwenden in ihren amtlichen Schreibweisen besondere zusätzliche Zeichen. Sie gelangten auch im Mittelschulatlas zur Anwendung. In dessen Einleitungstext finden sich die wichtigsten Ausspracheregeln für Namen fremder Sprachgebiete mit lateinischem Alphabet. Daraus ergibt sich auch die Aussprache der mit solchen zusätzlichen Zeichen versehenen Buchstaben.

Wo die Betonung eines Namens von der gewohnheitsmäßigen abweicht, falsche Betonung also leicht möglich wäre, wurden in der deutschen Ausgabe Akzente gesetzt, so z. B. in den Namen Málaga, Granáda, Almería, Panamá, Celébes. Dies ist eine zweischneidige Maßnahme. Sie könnte leicht zu irrigen Auffassungen über die offiziellen Schreibformen führen; doch scheint sie sich bisher im Unterricht bewährt zu haben.

Die Beschriftung der Palästinakarte 1:1000000 enthält versuchsweise einige besondere Aussprachezeichen.

Weitere phonetische Zeichen gehören nicht in den Mittelschulatlas. Wir würden uns damit in die Sphäre sprachlicher Spezialatlanten begeben und Atlas und Schule mit unzulässigen Komplikationen belasten.

Die hier dargelegten Beschriftungsgrundsätze gelten analog auch für die italienische und französische Ausgabe. Letztere macht etwas weniger Konzessionen an fremde Sprachen. Betonungsakzente fallen weg, da sie zu Verwechslungen mit den normalen Schriftakzenten führen würden.

\section{7. ÜBER KÜNSTLERISCHES GESTALTEN}

Karten sollen nicht nur zuverlässig, sondern auch schön sein.

Leute ohne graphisches Empfinden mögen sich gegen diese Auffassung sperren. Sie glauben, daß beim Kartenzeichnen jegliche Voraussetzung für subjektives künstlerisches Gestalten fehle, da alles durch äußere Tatsachen, durch Messung und Statistik festgelegt sei. Sie. übersehen dabei zwei Dinge:

- Jede Karte ist das Ergebnis einer weitgehenden Vereinfachung des unendlich reich gegliederten Weltbildes. Zeichnerisches Vereinfachen aber ist stets subjektiv. Apparate, 
Maschinen und Chemikalien sind wohl wertvolle Hilfen, um rascher und billiger zum Ziel zu gelangen; doch gestalten sie die Karte nicht. So ist und bleibt die Karte, trotz aller Fortschritte des geographischen Wissens und der Vermessungs- und Reproduktionstechnik und trotz besterprobter Zeichnungsnormalien, bis zu einem gewissen Grade ein Werk persönlicher Gestaltung. Es gibt keine objektive Karte.

Zweitens: Jede Karte ist ein graphisches Erzeugnis. Selbst wenn sie noch so wissenschaftlich-zweckbedingt ist, so kann sie sich den graphischen Gesetzlichkeiten trotzdem nicht entziehen. In andern Bereichen mögen Kunst und Wissenschaft verschiedene Wege gehen. Im Gebiete der Kartographie aber kommen sie sich sehr nahe. Eine Karte wird auch in wissenschaftlicher und didaktischer Hinsicht nur als gut bewertet, wenn sie klar ist, wenn deutlich aus ihr spricht, was ihr Ersteller ausdrücken wollte. Eine klare Karte ist jedoch in der Regel auch schön, eine unklare aber häßlich. Klarheit und Schönheit sind eng verschwisterte Begriffe.

Die Beziehungen zwischen Klarheit und Schönheit wurden in unseren Bemerkungen über kartographische Stilistik oft gestreift. Einiges sei hier nochmals betont, anderes nachgeholt.

MAX ECKert (Aachen) schrieb in einem seiner dickleibigen Bücher (Lit. Nr. 9), die heutige Bevorzugung des bunten Kartenbildes sei durch die Verfeinerung des ästhetischen Gefühls der heutigen Menschheit zu erklären.

In dieser Behauptung liegt eine Summe unbegreiflicher Fehlurteile. Seit jeher wurden bunte Karten gezeichnet, in die gedruckten Karten aber gelangten die Farben vom Augenblick an, da dies die Reproduktionstechnik erlaubte. Farbbilder kommen den natürlichen Eindrücken näher als Schwarzweißbilder. Farbige Karten ermöglichen weitergehende inhaltliche Gliederungen als einfarbige Karten. Farben erfreuen das Auge. Doch besteht kein Grund, der heutigen Menschheit verfeinertes ästhetisches Empfinden zuzuschreiben. Viel leichter ließe sich das Gegenteil beweisen. Vor allem. aber ist es falsch, das bunte Bild und im besonderen die bunte Karte in ästhetischer Hinsicht dem Schwarzweißbild allgemein vorzuziehen. Die schweizerische Dufourkarte in ihrer originalen Form bezeugt gegenüber vielen neueren bunten Karten die hohe Ästhetik des Schwarzweißbildes. "Im Schwarzweißbild liegt eine gewisse Abstraktion vom allzu Naturalistisch-Oberflächlichen hinweg zum Wesentlichen, zur Form. Das Schwarzweißbild ist einfacher, strenger und daher in gewissem Sinne ausdrucksstärker» (WindisCH, Lit. Nr. 36). Zur Bestätigung solcher Feststellungen brauchen wir uns nur des Gegensatzes unbemalter und bemalter Statuen zu erinnern.

Die Schönheit der Karte ist nicht an eine einzige Stilart gebunden. Schönheit kann sowohl dem ein- oder mehrfarbigen linearen Bild, dem plastischen Eintonbild, dem flächenhaften Farbmosaik wie auch deren, Verbindungen innewohnen. Charakteristisch für die meisten Karten ist die eigenartige Verschmelzung des Linearen mit dem Tonigen. Wie in der kolorierten Zeichnung bildet das Lineare das feste Gerippe, der Träger des Bildes. Das Lineare soll durch Töne und Farbflächen nicht geschwächt und verwirrt, es soll im Gegenteil gehoben, geklärt und beruhigt werden.

Wie wir mehrfach betonten, liegt ein Hauptproblem jeglicher Kartengraphik im Koordinieren der Elemente. "Die Vielheit, die sich nicht zur Einheit zusammenfügt, ist Verwirrung. Die Einheit, die nicht von der Vielfalt abhängig ist, ist Irrsinn» $\left(\mathrm{Pascal}^{5}\right)$. Warum empfinden wir jede Zeichnung Albrecht Dürers als vollkommen? Nicht zuletzt, weil jeder einzelne Strich seine volle Ausdruckskraft bewahrt, weil keine gegenseitigen Störungen von Strichen und Schraffen, keine unklaren Linienverfilzungen auftreten und weil sich darüber hinaus die graphischen Elemente zu einem Ganzen zusammenfügen. Auch eine Karte ist nur klar und schön, wenn kein Element das andere

${ }^{5}$ Zitiert von Prof. Dr. E. Brennecke (Technische Universität Berlin) in einem Vortrag anläßlich der Gründungsversammlung des Deutschen Vereins für Vermessungswesen in Hannover im April 1948. 
stört oder gar vernichtet und wenn sich trotz der Vielheit von Einzelheiten ein einfaches, geschlossenes Gesamtbild ergibt, wenn Wichtiges hervor- und Unwichtiges zurücktritt, kurz, wenn alle Inhaltsteile sowohl geographisch wie auch graphisch gut koordiniert und gegeneinander abgewogen sind.

Gutes Koordinieren fällt in der einfarbigen Karte leichter als in mehrfarbigen Blättern. Genügendes Differenzieren aber verlangt hier subtilstes Abwägen.

In mehrfarbigen Karten hingegen ist das Differenzieren leichter, das Koordinieren aber schwieriger, da hier die verschiedenen Elemente auf mehrere Druckplatten verteilt sind.

Der Mittelschulatlas zeigt in der Graphik seiner Karten verschiedene Stilarten: das abstrakte, flächenhafte Farbmosaik der Spezialkarte, die naturalistisch-plastische Darstellung der Reliefkarte und, als Kompromisse zwischen diesen beiden, die graphisch gemischten Formen der allgemeinen Länderkarten kleiner Maßstäbe, der Städtekarten usw.

Diese Stilarten seien im folgenden kurz betrachtet.

\section{Das Farbmosaik der Spezialkarte}

Reine, ungemischte Farben, in großen Flächen nebeneinandergestellt, wirken schreiend. Diese Erfahrung führt oft zu einem Vorurteil gegen reine Farben. So wurden in den Ausgaben 1924-1928 des Mittelschulatlasses alle Töne der Wirtschaftskarten in komplizierter Weise gemischt, wodurch Frische, Ausdruckskraft und Schönheit verlorengingen.

Mancher kartographierende Geograph sieht den Ausweg aus solchen Verlegenheiten in der Ostwaldschen Farbenlehre. Diese zeigt farbige Zwei-, Drei- und Vierklänge usw. Sicherlich sind solche Krücken für den Anfänger wertvoll. Die Mosaiks der meisten Karten bestehen jedoch nicht nur aus dem einen oder andern Farbakkord. Ungleiche Flächengrößen, von Ort zu Ort wechselndes Zusammentreffen der Farbflächen, Wiederholungen und viele andere Dinge spielen mit hinein.

Folgende Richtlinien mögen vor allzu krassen Fehllösungen bewahren.

a) Alle Farben und Farbmischungen einer Karte oder eines Atlasses sollen gleichsam einer einzigen, möglichst einfach dosierten Palette entstammen. Mischtöne sind somit stets aus denselben wenigen Grundfarben zu gewinnen. Nur so klingen die verschiedenen Farben zusammen. Die Farben der Landschaft erscheinen uns stets harmonisch, da sie durch das Licht aufeinander abgestimmt werden. In der Abbildung aber hat dieses Abstimmen durch Mischung aus einigen wenigen Grundfarben $\mathrm{zu}$ erfolgen. Rot und Gelb stehen harmonischer nebeneinander, wenn letzteres in schwacher Dosierung auch dem ersteren beigemischt wird. Mehr als in den meisten andern Atlanten wurden im Mittelschulatlas vielenorts Farben nicht nebeneinandergelegt, sondern durch sparsames Übereinanderlagern abgestuft. Dies erklärt großenteils die harmonische Wirkung seiner Farbmosaiks. Beispielsweise verwenden viele bisherige Atlanten für die Tiefländer eine besondere grüne Druckfarbe. Im Mittelschulatlas aber wurde Grün aus einem alle Landflächen deckenden Gelb und aus dem Blau des Meeres gemischt. Das Übereinanderlagern darf jedoch nicht bis zum Schmutzton getrieben werden.

Die Wahl der Druckfarben ist für das Gesicht eines Atlasses von entscheidender Bedeutung. Diese Wahl für den Mittelschulatlas und die Art des Kombinierens werden im folgenden Kapitel zur Sprache kommen.

b) Reine, leụchtende oder sehr kräftige Farbtöne wirken unerträglich, wenn sie große Flächen einnehmen. Doch gelangen sie in sparsamer Dosierung auf oder zwischen gedämpften Grundtönen zu außerordentlicher Wirkung. «Erst auf einem Piano läßt sich ein Crescendo und darauf ein Forte und nur auf ruhigem Untergrund ein farbiges Thema aufbauen.» (WINDISCH, Lit. Nr. 36.) 
Die Gliederung der Erdoberfläche erleichtert graphische Lösungen in diesem Sinne. Extreme jeder Art, größte Landhöhen und Meerestiefen, Wärmemaxima und -minima, höchste Erhebungen des Niederschlags- oder des Volksdichtereliefs, intensivste Bewirtschaftungsgebiete usw. nehmen im allgemeinen kleine Areale ein. Beschränkt man kräftige oder leuchtende Töne auf Extreme, so entstehen kontrastreiche, ausdrucksstarke, klare und schöne Farbmosaiks. Gibt man aber allen Flächen reine, starke Farben, so wirken die Bilder bunt, ungeordnet und verwirrend. Viele Spezialkarten in den Atlanten von Sydow-Wagner und Haack kranken an Farbübersättigung, während im allgemeinen diejenigen unseres Mittelschulatlasses und des Slanar-Atlasses infolge stärkerer Zurückhaltung harmonischer, ruhiger und trotzdem ausdrucksstärker sind.

c) Besteht ein Bild aus zwei großen, geschlossenen, verschiedenfarbigen Flächen, so fällt es auseinander. Es wird jedoch zusammengehalten, wenn sich die Farben der einen Fläche als Einsprenglinge in der andern wiederholen. Die Gliederung der Erdoberfläche führt in den Karten fast überall zu solchen Farbexklaven. Es sind dies die Inseln im Meere, die Seen des Festlandes, es sind Tiefländer, Hochländer usw., die vielenorts auch in den Spezialkarten für genügende Auflösung, Durchdringung und Wiederholung sorgen.

In dieser Hinsicht kommt auch den Kartenzusammenstellungen und Legenden große Bedeutung zu. Man beachte im Mittelschulatlas 1948 auf den Seiten 34 und 35 die vier oberen Kärtchen von Frankreich. Es folgen sich auf verbindender Gelbbasis Blau - Rot - Blau - Rot. Hiedurch erscheint diese Kartenreihe harmonischer, als wenn z. B. links zwei blaue, rechts zwei rote Kärtchen angeordnet wären.

Geschickt angeordnete Farb- und Textlegenden bilden willkommene Gegengewichte zu den übrigen Bildteilen. Sie beleben leere Räume und stellen oft ein gewisses graphisches Gleichgewicht her. Sie vermitteln und sie helfen mit, das Ganze zusammenzuhalten. Dies kommt z. B. in den Amerikakarten, S. 125-127, zum Ausdruck.

In vielen Spezialkarten wurden seit 1932 leere Ozeanflächen leicht blau getönt. Geographisch war dies nicht notwendig; doch ergaben sich damit schönere, geschlossenere, ruhigere Wirkungen. Karten mit viel Gelb, Orange und Braun (Asien-Wirtschaft, S. 88-89) hungern geradezu nach solchem komplementärem Blau. Falsch wäre es jedoch, auf Seite 127 dieses Blau auf das gesamte Kartenrechteck auszudehnen, da hiedurch die Farbtöne des Festlandes erdrückt würden. Die formal und farbig wechselvoll geggliederten Blätter der Seiten 125 und 126 bedürfen des blauen Ozeantones nicht. So variieren die Lösungen von Blatt zu Blatt.

\section{Das plastische Tonbild der Reliefkarte}

Das bisher Gesagte gilt auch hier, obschon der Bildcharakter völlig anders geartet ist. Farben und Töne sind in der Relief karte nicht in selbem Maße abstrakt oder konventionell wie in der Spezialkarte. Zwar wäre es falsch, in den Relief karten unmittelbare Landschaftsabbildungen sehen zu wollen. Es sind gleichsam kartographisch stilisierte Bilder schräg beleuchteter Landschaftsmodelle; doch leiten sich Farb- und Schattentöne und ihr Zusammenspiel aus unmittelbarer Naturbeobachtung ab. So gut wie möglich wird auch der atmosphärische Luftschleier in die Karte gebracht, um damit Naturähnlichkeit und Höhengliederung zu steigern. Die Schattenmodulation, selbst wenn sie auf Grund der Höhenkurven aus der Vorstellung heraus gezeichnet oder gemalt wird, basiert auf direkten Beobachtungserfahrungen. Das Entwerfen der Relieftöne ist plastisches Malen, wobei auch hier der Zusammenfassung der Formen und dem Koordinieren aller linearen und tonigen Elemente besondere Bedeutung zukommt. Die Farb- und Schattentöne und ihr Zusammenspiel sind jedem darzustellenden Gebiet und jedem Maßstab anzupassen. Es gibt hiefür keine allgemein gültige Schablone. 
Der künstlerische Einschlag solcher Kartenentwürfe wird gelegentlich als Nachteil hingestellt. Dies ist ebenso abwegig, wie wenn der mathematische Weg zur Lösung einer mathematischen Aufgabe beanstandet würde. Komplizierte graphische Aufgaben sind nun einmal ohne graphisches Können nicht zu lösen. Geschickt aufgenommene Modellphotographien können wohl den Weg ebnen und abkürzen, sie werden aber ohne die Hand des begabten Zeichners nie zu kartographischen Spitzenleistungen führen.

Die Schönheit guter Reliefkarten beruht nicht allein in einer gewissen Naturähnlichkeit der Bilder, sie liegt auch im Farbigen an sich. Graugrüne oder graublaue Töne überwiegen, da auch Übergangsflächen, wie z. B. Ebenen und Talböden, leicht schattiert sind. Hell und Dunkel und alle bunten Farben erscheinen somit eingebettet in bindende und beruhigende Grautöne. Die hohe ästhetische Wirkung solcher Grundfarben ist in der Malerei längst bekannt. Die Relief karte bedient sich ihrer mehr als irgendeine andere Kartengattung.

\section{Zwischenlösungen}

Die allgemeinen Länderübersichtskarten mit Gebirgsschraffuren, farbigen Höhenschichten usw. stehen in ihrem graphischen Aufbau zwischen den beiden bisher besprochenen Gruppen. Ihr Kompromißcharakter erschwert geschmacklich oder ästhetisch vollbefriedigende Lösungen; doch wird ein weiteres Suchen nach der besten und klarsten Form auch hier zu schöneren Bildern führen.

Ein letzter Hinweis gelte einigen Städtekarten. In denjenigen des Diercke stehen ausgedehnte, leuchtend zinnoberrote Gebäudeareale unvermittelt neben saftigstem Grasgrün ihrer Umgebung. Die Farben erinnern an den Inhalt billiger Baukästen für Kinder. Trotz der Komplementärfarben verletzen solche schreienden Zusammenstellungen. Im Mittelschulatlas dagegen sitzen braunrot gebrochene Gebäudeblöcke auf einem durchgehenden und gedämpften blaugrünen Geländeton. Bei Küstenstädten würde großfächiges reines Rot neben reinem Blau von Seen oder Meeren geradezu banal wirken. Die Karte von New York im Mittelschulatlas (S. 117) zeigt, wie Braun, Gelb, Grün und Blau bei geschickter Abstufung in schönster Weise zusammenspielen.

Linien, Farben und Töne treten in der Karte in so mannigfaltigen Kombinationen auf, daß.die hier gegebenen Hinweise nichts weiter sein können als erste Hilfen. Übung, Erfahrung, Schulung des Auges und vor allem eine gewisse graphische Begabung sind unerläßlich. Ebenso wichtig aber ist hier, wie für jede gute Graphik, das Handwerkliche, die äußerst exakte, sorgfältige Ausführung. Unsaubere Technik verdirbt jegliche Klarheit und damit auch die Schönheit der Karte.

Weder wissenschaftliche, noch künstlerische, noch technische Arbeit allein können zu guten Ergebnissen führen. Nur aus ihrem Zusammenspiel ergibt sich die gute Karte.

\section{DIE REPRODUKTION DER KARTEN}

\section{DRUCKPLATTENERSTELLUNG}

Die Erstellung der Originaldruckplatten des Mittelschulatlasses erfolgte auf lithographischem Wege. Nach photographischer Übertragung der zeichnerischen Entwürfe auf Lithographiesteine gelangten $z u$ deren Bearbeitung folgende Techniken zur Anwendung:

Steingravur für Kartenrahmen, Gradnetze, Situationszeichnungen, Gewässernetze, Höhenkurven und für weitere lineare Elemente und Signaturen, ebenso für die Kartenbeschriftungen und für den größten Teil der Geländeschraffen. 


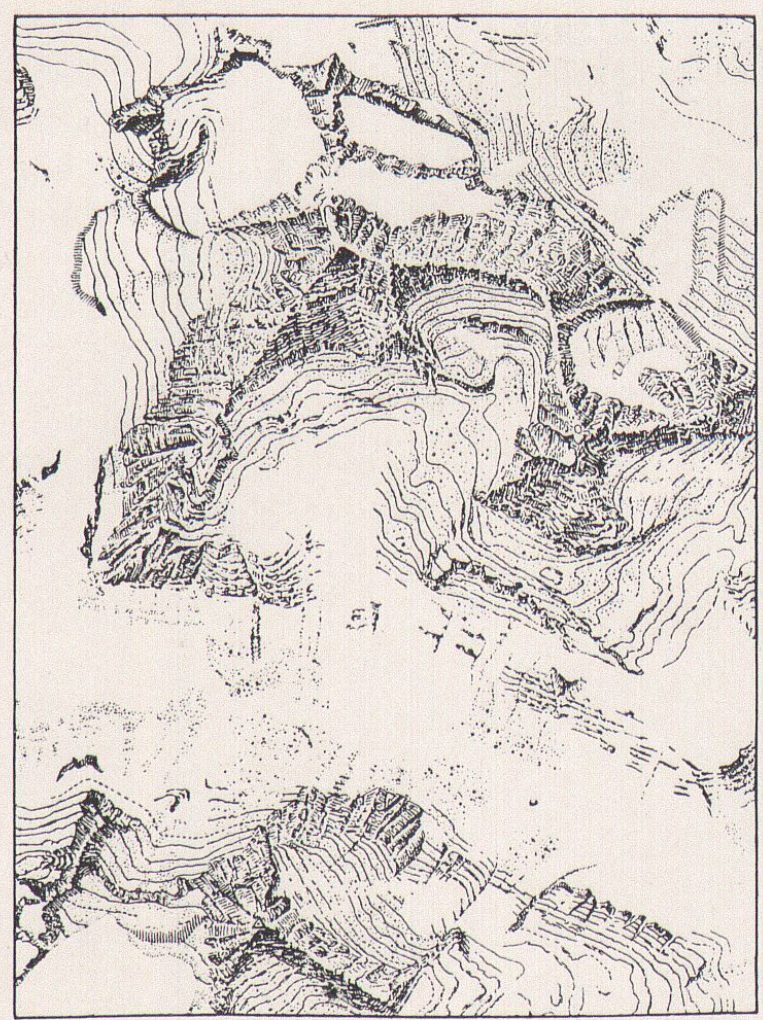

Abb. 1. Felszeichnung des Piz Julier in der Siegfriedkarte 1:50000.

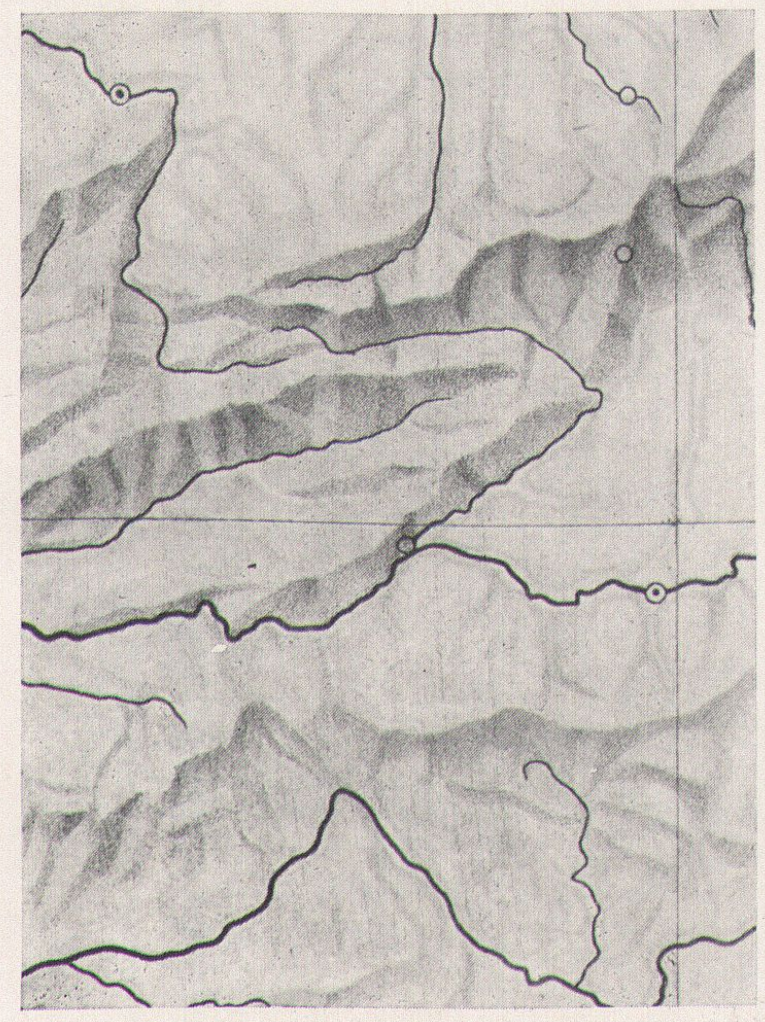

Abb. 3. Bleistiftentwurf für Geländedarstellung 1:4000000. Teilstück der Karte der PyrenäenHalbinsel.

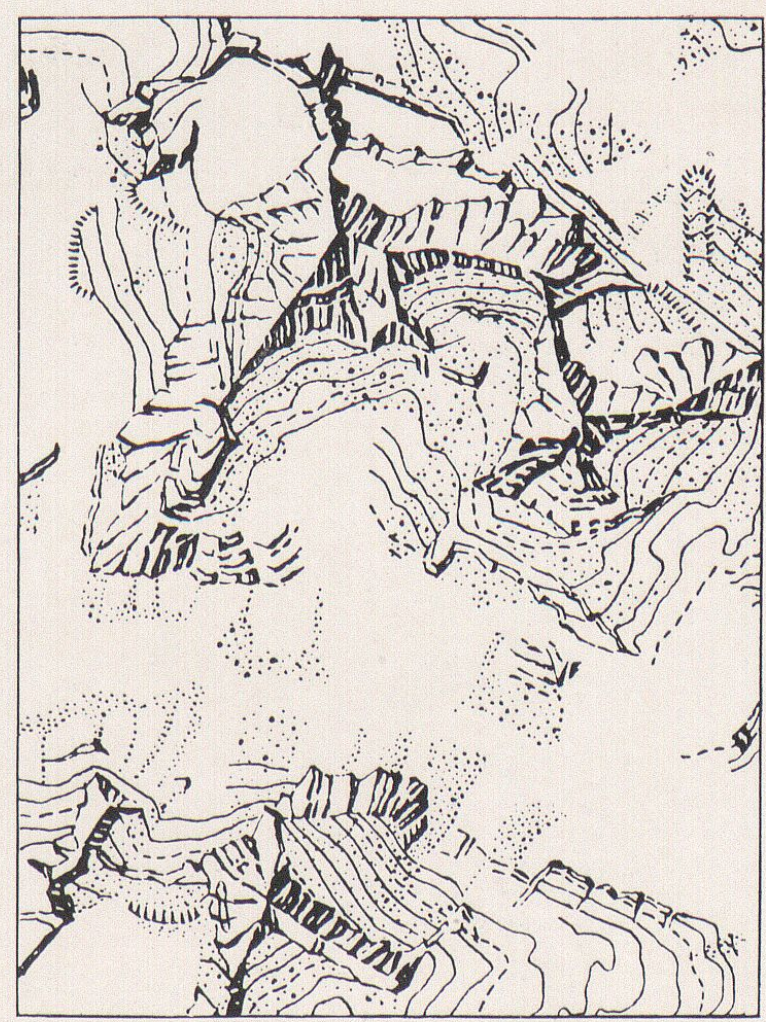

Abb. 2. Dasselbe Gebiet. Generalisierte Felszeichnung für eine Reliefkarte 1:100000.

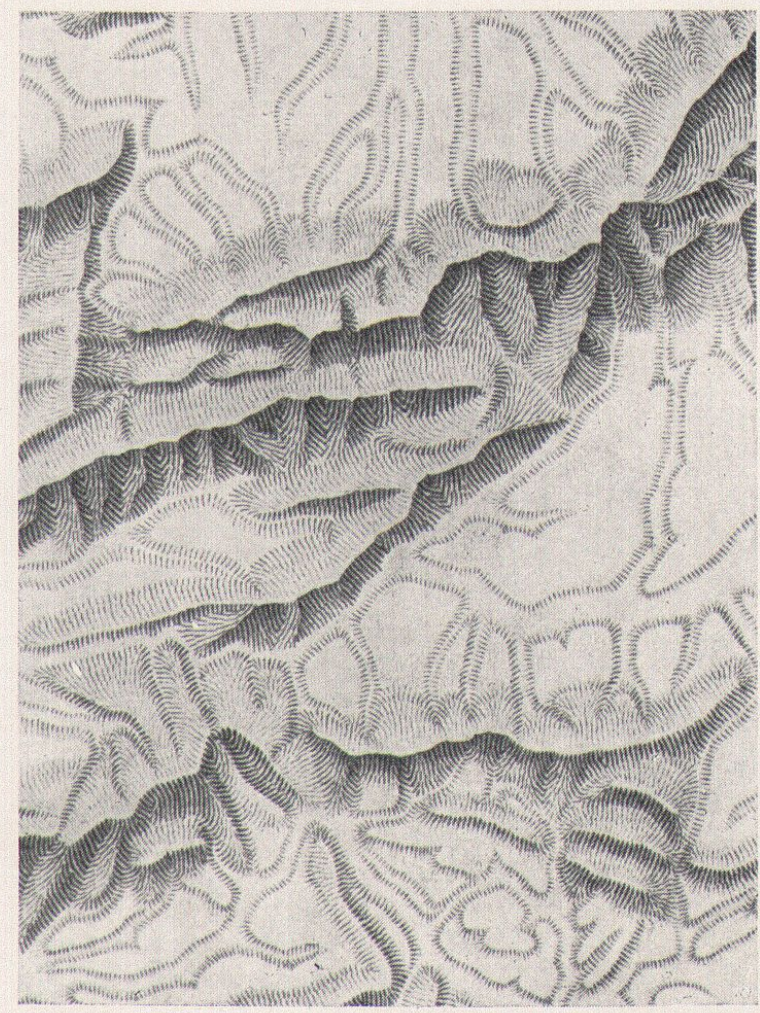

Abb. 4. Dasselbe Gebiet nach nebenstehendem Entwurf durch Steingravur in Schraffen umgesetzt. 


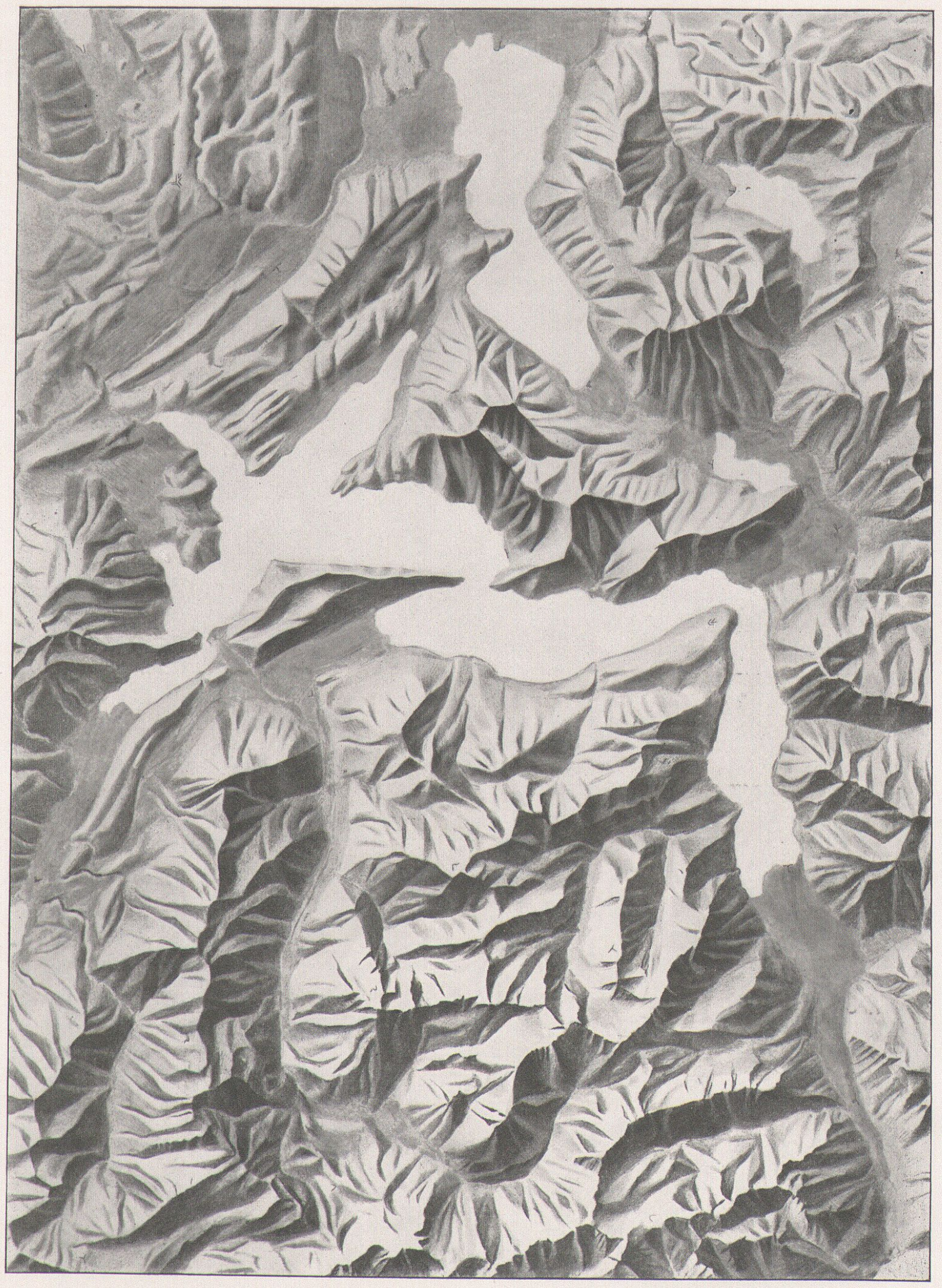

Abb. 5. Reliefvorlage für die Karte der Zentralschweiz 1:200000, (Mittelschulatlas 1948, Seite 1). Die Abbildung ist auf die Hälfte des Originals reduziert. 


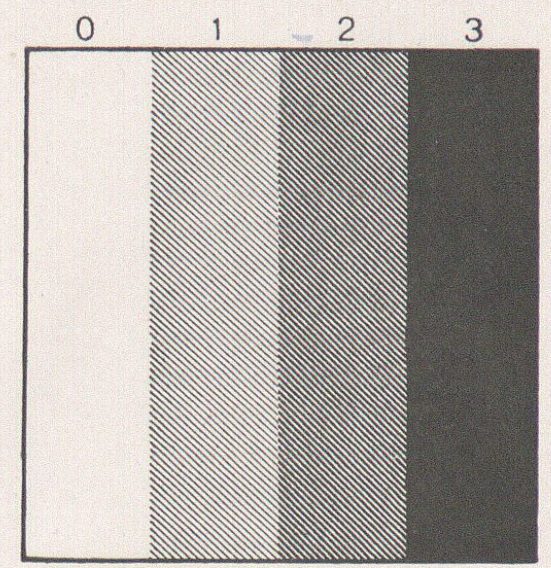

Fig. 1: Hellblau

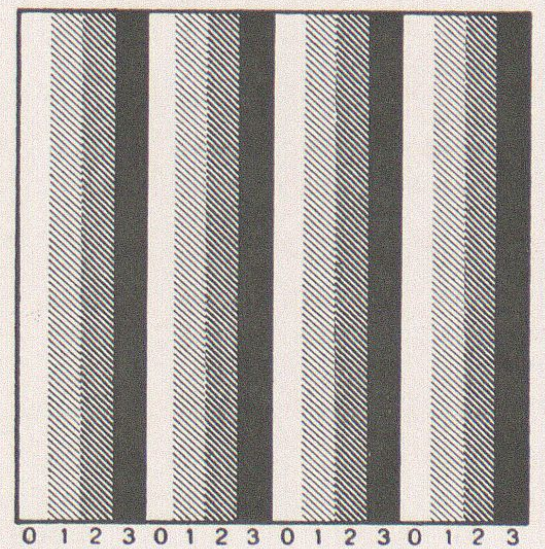

Fig. 4: Hellrol

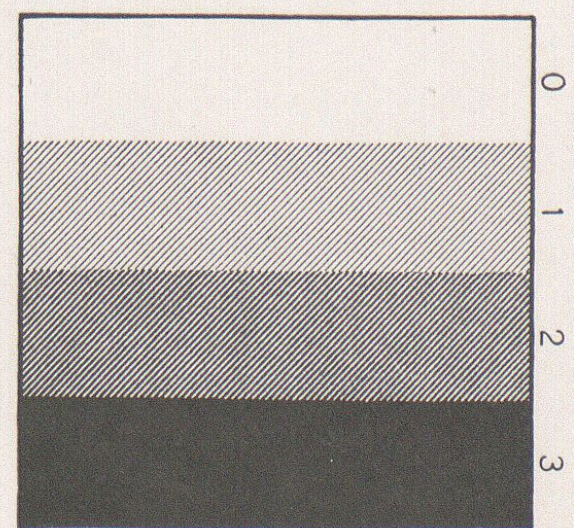

Fig. 2: Gelb

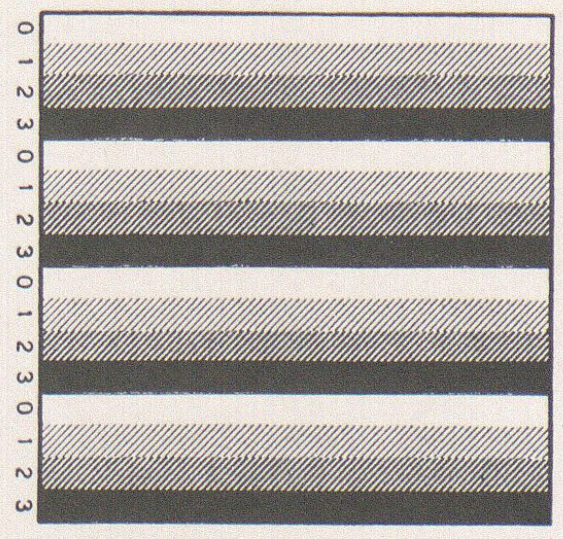

Fig. 5: Braun

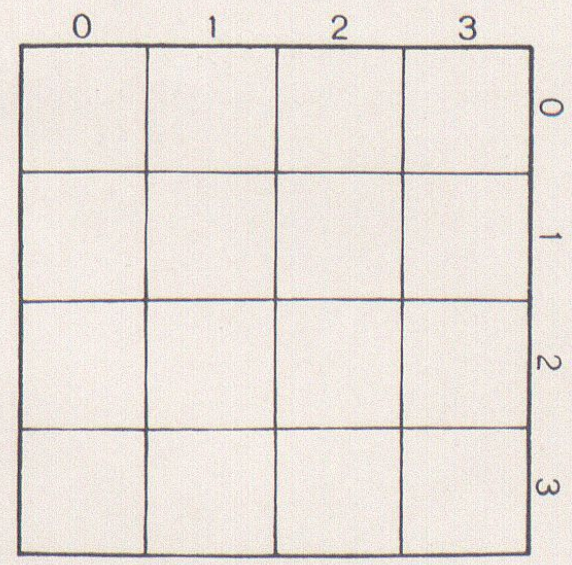

Fig. 3 : Hellblau u. Gelb kombiniert

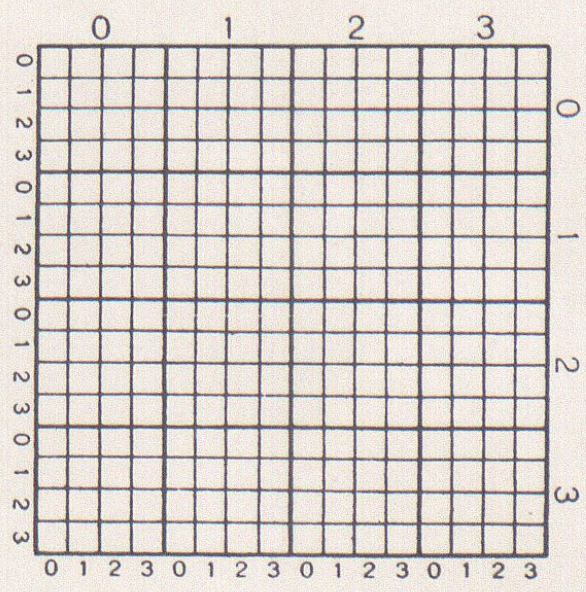

Fig. 6: Alle 4 Farben kombiniert

Fig. 1-6. Aufbau eines Blattes des Farbatlasses. 


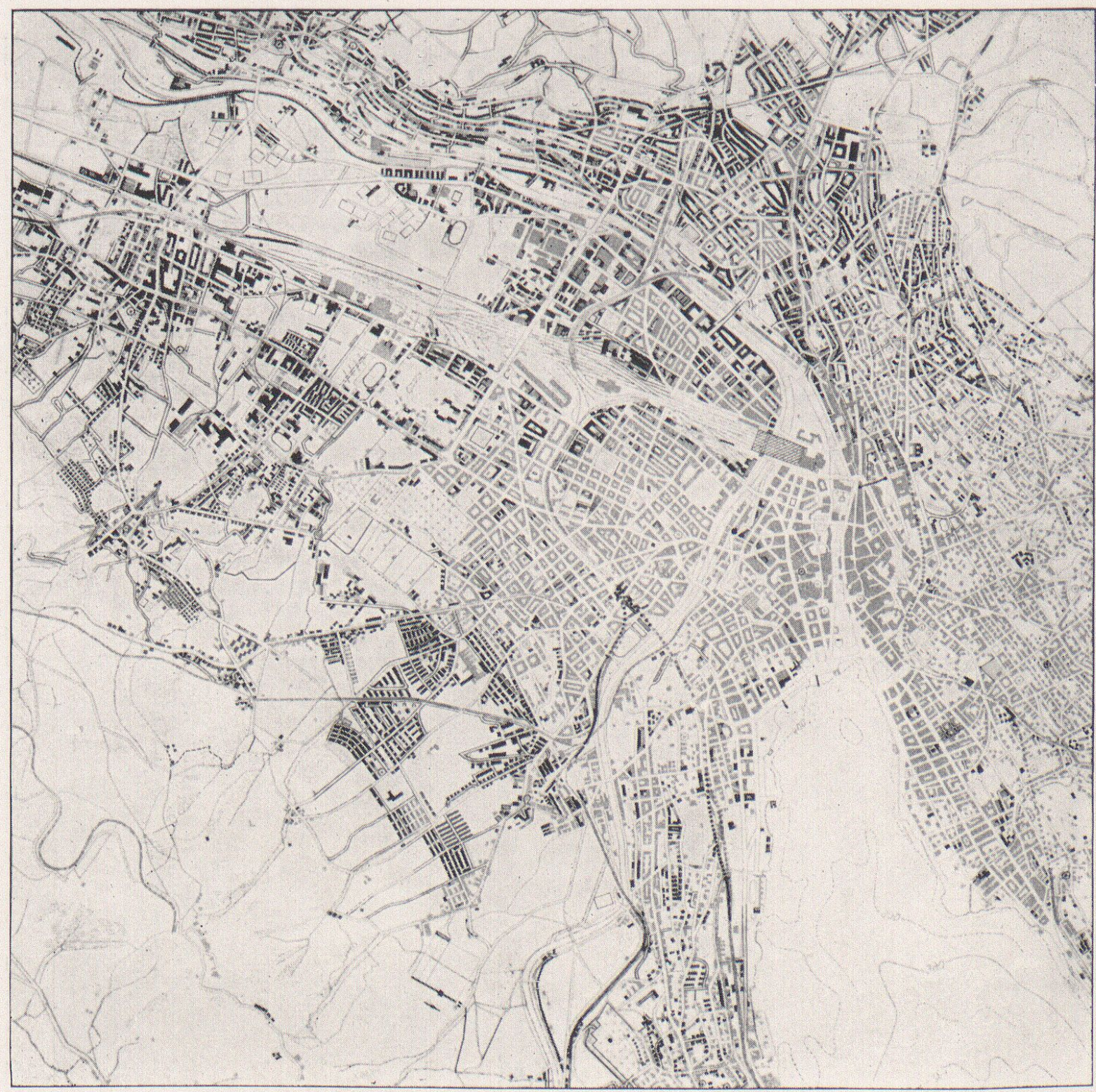

Abb. 6. Zürich. 1:50000. Teilstück. Nachführungsvorlage für die Karte auf Seite 17 des Mittelschulatlasses 1948.

Graue Bildteile $=$ Kartenbild der vorletzten Atlasausgabe (1942).

Schwarze Bildteile $=$ Nachführungen für die Jubiläumsausgabe 1948: neue Gebäude und Straßen und zeichnerische Anpassungen. 
Fettzeichnung mit Lithographietusche für volle Farbtöne und zusätzliche lineare Elemente, wie Grenzbänder usw.

Fettzeichnung mit der Kreide für Reliefschatten und auslaufende Farbtöne.

Rastereindrucke für gleichmäßig aufgehellte Farbflächen.

Photolithographie für die Felszeichnungen der Relief karten und für die Schattentöne der neuen Karte der Zentralschweiz.

Schriftsatz und -umdruck für Karten- und Legendentitel.

Umdruck für die von der Eidgenössischen Landestopographie zur Verfügung gestellten Beispiele amtlicher Kartenwerke (S. 2, 3 und 4 der Ausgabe 1948).

Heute werden Kartenbeschriftungen aus Ersparnisgründen oft durch Buchdrucksatz, lagerichtiges Montieren und nachfolgendes Übertragen auf die Steine gebracht. Für die Karten des Mittelschulatlasses hielten wir an der manuellen Steingravur fest. Sie ist wohl zeitraubender, wird aber in der Schärfe und Schönheit der Schriftformen und im guten Koordinieren von Schrift und Bild durch kein anderes Verfahren erreicht.

Nach Erstellung der Originalplatten werden auf Handpressen Probeabzüge gedruckt. $\mathrm{Da}$ Originalentwürfe und Druckplatten etappenweise entstehen, zeigt sich in den meisten Fällen erstmals in diesen Probeabzügen das fertige Kartenbild. Hier erst können Fehler, Unvollkommenheiten, mangelhaftes Koordinieren der Elemente usw. festgestellt und die Druckfarben endgültig aufeinander abgestimmt werden. Trotz sorgfältigen Abstimmens können aber später in den Auflagedrucken unbeabsichtigte Kraftverschiebungen der Farben eintreten, da $z$. B. Rasterschraffuren in den Handpressen oft magerer "ausdrucken» als beim Auflagedruck. Die Zahl der Probedruck-Korrekturen geht für einen Atlas von mehr als 100 Kartenseiten in die Tausende. Da das Erstellen fertiger Probedrucke umständlich und zeitraubend ist, mußten wir uns für den Mittelschulatlas in der Regel mit einmaligen Probedrucken begnügen, selbst auf die Gefahr hin, daß der eine oder andere Fehler auf den Druckplatten stehenblieb.

Jeder Druckbogen des Mittelschulatlasses enthielt auf Vor- und Rückseite je 4, also insgesamt 8 Atlasseiten. Die 144 Kartenseiten der Ausgabe 1948 beanspruchten somit 18 Bogen. Die meisten derselben erforderten 10 Druckfarben, diejenigen mit Reliefkarten sogar deren 12 bis 13 .

\section{EINIGE WERDEGÄNGE}

Der technische Arbeitsgang, das Entwerfen der Originalzeichnungen und deren Übertragen auf Druckplatten erfolgte nicht nach einem einheitlichen Schema. Je nach den verfügbaren Quellen, nach Gattungen und Maßstäben der zu erstellenden Karten empfahlen sich verschiedene Wege. Zwei derselben seien im folgenden stichwortartig skizziert:

Erstes Beispiel: Reliefkarten schweizerischer Landschaften im Maßstab 1:100000. Bearbeitungsgrundlagen: Amtliche schweizerische Kartenblätter 1:50000.

Arbeitsgang:

1. Lineares dreifarbiges Pausen der für die neue kleinere Karte notwendigen Elemente (Gradnetz, Situation, Gewässernetz, Höhenkurven, Felskanten und -konturen) auf transparente Folien. Hiebei erstmalige Stoffauswahl und lineare Vereinfachung.

2. Photoreduktion dieses transparenten Blattes von 1:50000 in zirka 1:80000 und Erstellen von Blaudrucken auf maßhaltige Aluminiumfolien.

3. Farbig gegliederte Reinzeichnung des neuen linearen und generalisierten Kartenbildes auf einer dieser Aluminiumfolien. Die Felszeichnung entsteht auf einer separaten Aluminiumfolie (Abb. 2). 
4. Photographische Reduktion der linearen Reinzeichnung aus 1:80000 in den Kartenmaßstab 1:100000 und photographische Kopie auf einen Lithographiestein.

5. Klátschdrucke von der Steinkopie auf drei Steine. Auf diesen Gravur der Linien, Signaturen usw., und zwar in Stein Nr. 1 nur das Situationsbild, in Stein Nr. 2 das Gewässetnetz und in Stein Nr. 3 die braunen Höhenkurven. Die Felszeichnung wird nicht graviert, sondern auf photographischem Wege von der Originalzeichnung auf den Stein Nr. 1 übertragen und so mit der Situation zusammengebracht.

6. Erstellen von Probeabzügen in 3 Farben.

7. In den einen dieser Probeabzüge wird mittels Aquarellfarben das farbige Reliefbild gemalt, in einen zweiten Abzug werden die Waldflächen, in einen dritten der Schriftentwurf eingetragen.

8. Manuelle chromolithographische Übertragung des Farbtonbildes auf die erforderlichen weiteren Druckplatten (je eine Platte für Blau, Gelb, Rosa und für einen ersten helleren, graueren und einen zweiten kräftigeren, violetteren Schattenton). Analoge Übertragung des grünen Waldtones unter Verwendung eines feinen Punktrasters.

9. Kopie der Schriftvorlage auf einen weiteren Stein und manueller Stich der Beschriftung.

10. Erstellen von Probeabzügen (Zusammendruck aller Elemente).

11. Korrigieren der Probedrucke und Bereinigung der Originalplatten.

12. Montieren und Umdrucken der einzelnen Elemente ab den Originalsteinen auf die Maschinenplatten (Druckplatten für den Auflagedruck).

13. Erstellen der Auflagedrucke.

Eine Variation dieses Werdeganges wurde bei Erstellung der neuen Reliefkarte der Zentralschweiz eingeführt:

Die Reliefvorlage wurde hier nicht bunt, sondern in Grautönen (mit Tusche und Bleistift) in 11/2facher Vergrößerung und auf Grund eines hellblauen Kurven- und Gewässerbildes auf eine Aluminiumfolie gezeichnet (Abb.5) und dann photolithographisch auf zwei Schattenplatten übertragen. Die Separation in einen leichteren und in einen stärkeren Schattenton erfolgte durch kräftigeres bzw. spitzeres Kopieren. Die Blau-, Gelb- und Rosatöne wurden nach einer zusätzlichen Farbvorlage durch Handlithographie erstellt.

Zweites Beispiel: Allgemeine Länderkarten (z. B. Pyrenäenhalbinsel 1:4000000). Bearbeitungsgrundlagen: zahlreiche Teilgebietskarten größeren Maßstabes, Statistiken der Ortseinwohnerzahlen, geographische Literatur.

1. Konstruktion eines sehr feinmaschigen Gradnetzes auf einer Aluminiumfolie, und zwar im Maßstab der gewünschten neuen Karte.

2. Generalisierte Übertragung der Fluß- und Küstenlinien, der ozeanischen Tiefenlinien, der erforderlichen Ortssignaturen, Bahn- und Grenzlinien usw. in dieses Netz. Ortszeichen und andere Signaturen nach einem besonderen Schlüssel.

3. Photokopie dieses linearen Bildes auf eine Druckplatte. Anschließend auf dem einen Stein manuelle Gravur der Situationszeichnung (dunkelbraune lineare Elemente), auf einem zweiten Stein Stich der roten Bahnlinien.

4. Erstellen einiger Zusammendrucke.

5. In einen Zusammendruck wird mit spitzem Bleistift eine graue, tonige Vorlage für die Gebirgszeichnung erstellt (Abb. 3).

6. Photokopie dieser Vorlage auf einen Stein und Umsetzen der tonigen Flächen mittels Steingravur in Schraffenstriche (Abb. 4).

7. Nochmals Zusammendrucke aller bisherigen Elemente. 
8. In einen solchen Zusammendruck werden in stark differenzierten Farben und unter Anpassung an die generalisierten Geländeformen die Höhenfarbstufen eingetragen, in einen zweiten Zusammendruck die Schriftvorlage entworfen.

9. Übertragung der Höhen- und Tiefenfarbschichten durch Handlithographie, z. T. mit Hilfe von Rastern, auf je einen Stein für Blau, Gelb, Braun, Rosa und eventuell ein zweites Blau und Rot.

10. Gravur der Beschriftung in einen weiteren Stein.

11. Erstellen von Probeabzügen (Zusammendruck aller Elemente).

12. Korrigieren der Probedrucke und darnach Bereinigung der Originalplatten.

13. Montieren und Umdrucken dex Originallithographien auf die Druckplatten für die Maschine.

14. Erstellen der Auflagedrucke.

Auch hier ist eine Variation zu erwähnen:

$\mathrm{Da}$ uns anläßlich der Atlasumformung 1945-1948 genügend eingeübte Terraingraveure fehlten, wurden die Gebirgsschummer photographisch auf doppelten Maßstab vergrößert, auf hellgrauen Photokopien solcher Vergrößerungen die Gebirgsschraffen mit Feder und schwarzer Tusche gezeichnet, und diese dann wieder photographisch reduziert und auf die Terrainplatte übertragen.

\section{DRUCKFARBEN UND IHRE KOMBINATIONEN}

Bei der Erstellung eines Atlasses können die Druckfarben nicht jeder einzelnen Karte angepaßt werden, vielmehr sind sie im vornherein für das gesamte Werk festzulegen. Mit einem gewissen Minimum an Grundfarben muß ein Maximum an inhaltlichen Differenzierungen und Nüancen erreicht werden. Ausdruckskraft und Schönheit der einzelnen Karten wie auch des Atlasses im gesamten sind sehr weitgehend von der glücklichen Wahl der Farben und ihrer Kombinationen abhängig.

Wir unterscheiden zwei Gruppen von Druckfarben, die starken und die schwachen.

Die starken Farben dienen vor allem zum Druck von Linien, Signaturen und Schriften. In flächenhafter Ausbreitung sollen sie nur ausnahmsweise und nur für kleine Areale Verwendung finden. Solche Farben des Mittelschulatlasses waren:

1. Dunkelbraun oder sogenanntes Situationsbraun für Rahmen, Netze, Situationslinien inklusive Gewässernetz und Küsten der meisten Karten, Siedelungen, Signaturen, Felszeichnung, Farbkonturen usw. Die Situation bildet gleichsam das feste Gerippe für alle übrigen Farben.

2. Starkes Blau oder sogenanntes Flußblau für das Gewässernetz der Reliefkarten, ferner für Signaturen, Spezialeintragungen, tiefste ozeanische Stufen usw.

3. Starkes Rot oder sogenanntes Eisenbahnrot für die Bahnlinien, für Signaturen, höchste Landstufen usw.

4. Starkes Grün oder sogenanntes Grenzgrün für politische Grenzbänder, für Landdepressionen, für Signaturen, Waldraster usw.

5. Mittelstarkes Rotbraun (gebrannte Siena) für die Höhenkurven der Reliefkarten.

6. Mittelstarkes Graubraun für die Gebirgsschraffen.

7. Schwarz für Beschriftung, Signaturen usw.

Die schwachen Farben des Atlasses dienen vor allem der Flächentönung und nur ausnahmsweise auch für Linien und Signaturen, da sie in linearer Form im allgemeinen zu wenig hervortreten. Die Wahl fiel hier auf folgende Farben: 
8. Gelb: Basiston für die Festlandflächen der meisten Karten, ferner für sich allein oder in Mischungen für Töne aller Art. Ein vermittelnder Gelbton, der sich unter den übrigen Farben durchzieht, erhöht das harmonische Zusammenspiel der übrigen Farben.

9. Bla u für Seen, Ozeane und viele andere Flächen. In Gelbmischungen vor allem für die tiefsten Festlandstufen allgemeiner Karten und hypsometrische Töne der Relief karte.

10. Hellrot oder Rosa für Höhentöne der Relief- und Länderkarten, ferner für Spezialkarten.

11. Hellbraun für Höhentöne der allgemeinen Länderkarten, für Füllungen von Gebäudeblöcken in Städtekarten (New York usw.), ferner für Spezialkarten.

12. Graublau als leichter Schattenton der Reliefkarten (Erster Schummer).

13. Blauviolett als kräftigerer Schattenton der Reliefkarten (Zweiter Schummer).

Die meisten Druckbogen enthalten nur einen Teil dieser Farben. So kommt z. B. Farbe Nr. 5 (Gebrannte Siena) nur in einzelnen amtlichen Kartenbeispielen und in den Reliefkarten vor. Die Schummertöne Nr. 12 und 13 bleiben auf die letzteren beschränkt, Farbe Nr. 6 auf Druckbogen mit allgemeinen Länderkarten usw. Die meisten Druckbogen enthalten 10 Farben. Für vereinzelte Karten aber kamen nur 3 oder 4 Farben zur Verwendung (z. B. für die Seiten 2 und 3).

Jede Druckfarbe kann entweder als Vollton oder aber als Rasterton gedruckt werden. Raster kommen nur für Flächen in Frage. Sie zerlegen die Volltöne in äußerst feine Punkte oder Schraffuren, wodurch Aufhellungen entstehen. Ferner lassen sich zwei oder mehr Farben zu Farbmischungen kombinieren. Aus Gelb und Blau entsteht Grün usw. Nehmen wir für jede Farbe, so wie dies bei der Erstellung des Mittelschulatlasses der Fall war, einen feineren und einen gröberen Raster an, bezeichnen wir ferner die farblose weiße Papierfläche auch als Farbton, so liefert uns jede Druckfarbe vier veŕschiedene Töne, nämlich

$$
\begin{array}{lr}
\text { den Papierton (ohne Farbe) } & =\text { Stufe } 0 \\
\text { den ersten (hellen) Raster } & =\text { Stufe } 1 \\
\text { den zweiten (kräftigeren) Raster } & =\text { Stufe } 2 \\
\text { den Vollton } & =\text { Stufe } 3 .
\end{array}
$$

Alle möglichen Kombinationen von 2 Farben $\mathrm{zu}$ je 4 Abstufungen ergeben

$$
\begin{aligned}
& 4 \times 4=16 \text { Töne, } \\
& \text { diejenigen von } 3 \text { Farben } 4 \times 4 \times 4=64 \text { Töne, } \\
& \text { diejenigen von } 4 \text { Farben } 4 \times 4 \times 4 \times 4=256 \text { Töne. }
\end{aligned}
$$

Mit 5 Farben ergeben sich 1024 Töne, mit 6 Farben 4096 Töne usw.

Theoretisch lassen sich somit einige wenige Grundfarben zu außerordentlich vielen Tonvariationen kombinieren.

Praktisch sind jedoch die Kombinationsmöglichkeiten beschränkt. Viele der entstehenden Mischungen unterscheiden sich zu wenig yoneinander, oder sie werden durch die stärkste Komponente erschlagen. Schwarz und Situationsbraun eignen sich überhaupt nicht für Flächentonmischungen. Kombinationen von mehr als 4 Druckfarben werden vermieden, weil sie zu schmutzigen Tönen führen und die Papierfläche mit Farbe übersättigen, so daß die letzten Drucke nicht mehr voll aufgenommen werden, und vor allem aber auch, weil farbenreiche Kombinationen lithographisch unnötige Mehrarbeit verursachen.

Damit sind die verwendbaren Mischungen stark eingėschränkt. Am besten eignen sich Kombinationen von nur 2 oder 3 Farben zu je 4 Helligkeitsabstufungen (Papierton, erster Raster, zweiter Raster, Vollton). 
Liegt ein farbiger Kartenentwurf vor, so ist festzustellen, welche Farb- und Rasterkombinationen auf einfachste Art, d. h. mit einem Minimum von Druckfarben, zu den gewünschten Farbtonnüancen führen. Das Ergebnis dieser Untersuchungen ist dem Kartolithographen auf eindeutige Art mitzuteilen. Nur so besteht einige Gewähr dafür, daß dann das zusammengedruckte Schlußergebnis wirklich der Vorlage oder den Wünschen des Autors entspricht.

$\mathrm{Zu}$ diesem Zwecke entwickelte ich eine sehr einfache und praktisch leicht anwendbare Hilfe in der Form farbiger Tafeln. Dieser Farbenatlas und seine Anwendung seien im folgenden erläutert:

Ich ging von der oben begründeten Voraussetzung aus, daf höchstens 4 verschiedene Farben miteinander kombiniert werden sollen. Unwahrscheinliche oder seltene Kombinationen und solche, die zu toten oder schmutzigen Mischungen geführt hätten, waren auszuschalten. Als geeignete Viererkombinationen erwiesen sich u.a. die folgenden:

1. Gelb - Hellblau - Hellrot - Höhenbraun (also alle hellen Flächenfarben, für farbige Höhenschichten usw.).

2. Gelb - Hellblau - Hellrot - Dunkelblau (für Blauabstufungen, Niederschlagskarten usw.).

3. Gelb - Hellblau - Dunkelblau - Grün (für Landdepressionen, ozeanische Tiefenstufen usw.).

4. Gelb - Hellrot - Höhenbraun - Dunkelrot (für Braun-Rot-Mischungen, farbige Höhenstufen usw.).

5. Gelb - Hellblau - Hellrot - Dunkelrot (für Volksdichtekarten usw.).

6. Hellblau - Hellrot - Dunkelblau - Dunkelrot (für starke Violettmischungen).

Es wurden zwei verschiedene Hilfsdruckplatten erstellt, und zwar in der durch Fig. 1 und 4 veranschaulichten Form.

Mit Platte I (Fig. 1) werden mehrere Gelbabzüge erstellt. Nun wird dieselbe Platte um $90^{\circ}$ gedreht (Fig. 2) und mit ihr Hellblau auf die Gelbabzüge gedruckt. Dadurch entstehen $4 \times 4=16$ Quadratfelder (Fig. 3), die 16 verschiedene Farben (inklusive Papierton) enthalten. Auf diese Blätter wird mit Hilfe der Platte II (Fig. 4) Hellrot aufgedruckt. Schließlich wird auch die Platte II um $90^{\circ}$ gedreht (Fig. 5) und mit ihr auf dieselben Papierbogen Höhenbraun gedruckt. Das Ergebnis (Fig. 6) ist ein Quadratgitter mit $16 \times 16=256$ verschiedenen Farbtönen (inklusive Papierton). So entstehen alle überhaupt möglichen Raster- und Volltonvariationen jeder einzelnen Farbe und von 2 oder 3 oder 4 Farben zusammen. Keine Variation fehlt, und keine erscheint mehr als einmal.

Diese Drucke entsprechen der ersten der obigen sechs Farbkombinationen (Gelb Hellblau - Hellrot - Höhenbraun). Jede Helligkeitsstufe ein und derselben Druckfarbe ist darin durch eine Nummer $0-3$ bezeichnet $(0=$ Papierton, $1=$ heller Raster, 2 = starker Raster, 3 = Vollton).

Auf gleiche Weise erstellt man Farbdrucke der fünf anderen Farbkombinationen.

Zusammen bilden sie den gewünschten Farbatlas. Jedes Blatt ist darin in mehreren identischen Exemplaren vertreten.

Aus diesem. Farbatlas lassen sich nun geeignet erscheinende Farbmüsterchen herausschneiden und zu Farbskalen zusammenstellen. Erweist sich eine solche Zusammenstellung als unschön, unharmonisch oder unstetig und unterscheiden sich einzelne Töne zu wenig voneinander, so lassen sie sich durch geeignetere ersetzen.

Ist die Skala endgültig festgelegt, so wird sie dem Kartolithographen mitsamt der Kartenvorlage übergeben, und zwar in der Form des folgenden Beispieles: 
Legende und Farbrezept für Landhöhen und Meerestiefen (Atlas S. 134-135)

\begin{tabular}{|c|c|c|c|c|c|c|}
\hline \multirow{3}{*}{$\begin{array}{l}+4000 m \\
+2000 m\end{array}$} & - & gelb 2 & braun 3 & hellrot 3 & - & - \\
\hline & - & gelb 2 & braun 3 & hellrot 2 & - & - \\
\hline & - & gelb 2 & braun 3 & - & - & - \\
\hline \multirow{2}{*}{$\begin{array}{l}+1000 m \\
++500 m\end{array}$} & - & gelb 2 & braun 1 & - & - & - \\
\hline & - & gelb 2 & - & - & - & - \\
\hline$+200 m$ & hellblau 2 & gelb 2 & - & - & - & 一 \\
\hline $\begin{array}{c}0 m \\
\text { Dearessionen }\end{array}$ & hellblau 2 & gelb 2 & - & 一 & - & grün 1 \\
\hline
\end{tabular}

\begin{tabular}{|c|c|c|c|c|c|c|c|}
\hline \multirow{3}{*}{$-200 \mathrm{~m}$} & & hellblau 1 & - & - & - & - & - \\
\cline { 2 - 8 }$-2000 \mathrm{~m}$ & & hellblau 2 & - & - & - & - & - \\
\cline { 2 - 8 }$-4000 \mathrm{~m}$ & & hellblau 3 & - & - & - & - & - \\
\cline { 2 - 8 }$-8000 \mathrm{~m}$ & & hellblau 3 & - & - & - & dunkelblau 2 & - \\
\cline { 2 - 8 }$-8000 \mathrm{~m}$ & & hellblau 3 & - & - & - & dunkelblau 3 & - \\
\cline { 2 - 8 } & & hellblau 3 & - & - & - & dunkelblau 3 & grün 3 \\
\hline
\end{tabular}

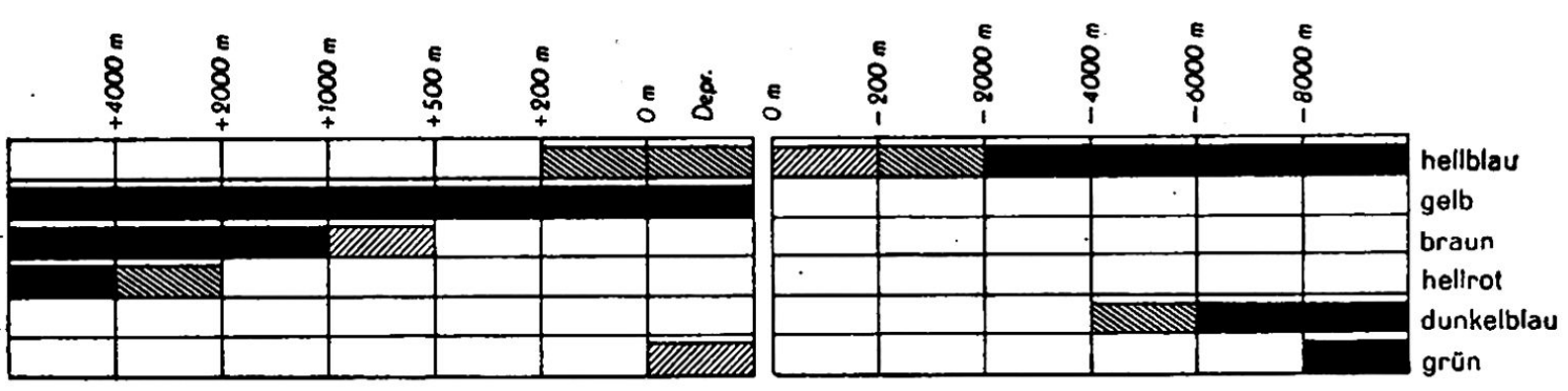

Fig. 7. Farbprofil für Landhöhen und Meerestiefen. Das Gelb ist hier, in Abweichung obenstehender Tabelle, als Vollton eingesetzt. In den Karten kommen, je nach Druckbogeninhalt, beide Lösungen vor.

Auf diese Art wird die Arbeit des Kartolithographen erleichtert. Aus der Tabelle erkennt er auf den ersten Blick, welche verschiedenen Flächen er mit einem bestimmten Raster einer bestimmten Farbe zu belegen hat. Vor allem aber besteht Sicherheit, daß die Farben der gedruckten Karten (abgesehen von Nüancen des Farbabstimmens) den Wünschen des Redaktors entsprechen.

Dieses Vorgehen hat viel zur Klarheit und Schönheit der Karten des Mittelschulatlasses und auch zur Vereinfachung und Verbilligung seiner lithographischen Erstellung beigetragen.

Im Gegensatz zu den Ostwaldschen Farbtafeln ist der hier beschriebene Weg unmittelbar den praktischen Bedürfnissen der Kartenreproduktion angepaßt. Er garantiert das genaue Einhalten einer Vielheit von Farbnüancen mit einem Minimum von Druckplatten und ist viel rationeller als das bisherige Vorgehen beim Druck geologischer Spezialkarten, wo fast für jeden Farbton eine eigene Druckplatte verwendet wird; so daß zu ihrem Druck oft über 30 Platten erforderlich sind! 


\section{a) Dachziegelartiger Farbaufbau}

Selbst bei sorgfältigstem Druck muß mit gewissen ungewollten minimalen Verschiebungen einzelner Farben, mit sogenannten Passerschwierigkeiten, gerechnet werden. Wechseln längs ein und derselben Linie zwei oder mehr Farben bzw. Farbraster, so entstehen störende Farbüberlappungen oder aber Farbklaffen. Dieses Úbel . läßt sich ausschalten, wenn dafür gesorgt wird, daß sich die Farb- oder Rastertöne im Farbprofil dachziegelartig überdecken. Es ist dies nicht überall, aber doch in vielen Fällen möglich. Dàs Farbrezept für Landhöhen und Meerestiefen (Tabelle und Fig. 7) zeigt ein Beispiel. Bei jeder Stufengrenze ändert stets nur eine einzige Farbe bzw. ein einziger Raster, während sich die übrigen Farbkomponenten unverändert weiterziehen. Nur an der Wasserkante (beim Úbergang vom Meer zum Festland) treten gleichzeitig zwei neue Farben (Blau und Gelb) auf. Doch sind hier allfällige kleine Verschiebungen infolge der dunkelbraunen Uferlinie weniger leicht sichtbar.

Ein solcher dachziegelartiger Aufbau ist nicht nur eine Sicherung gegen Passerunstimmigkeiten, er erhöht zugleich Harmonie und Stetigkeit der Farbleitern.

Dieser Aufbau wird durch die oben dargelegte Verwendung eines Farbatlasses sehr erleichtert.

\section{b) Rasterdrehungen}

Werden zwei verschiedene Raster (Linienschraffuren) aufeinandergedruckt, so können bei ungeschicktem Vorgehen unliebsame Streifenmusterungen, sogenannte Moirés, entstehen. Dies ist stets der Fall, wenn die Strichrichtungen beider Raster nahezu parallel laufen oder auch bei genau parallelen, jedoch nicht genau gleichabständigen Strichlagen. Da, wo sich Striche oder Strichstücke beider Raster genau oder nahezu decken, entstehen andere Töne als $\mathrm{da}$, wo die einen in die Intervalle der andern fallen. Um dies zu vermeiden, wird dafür gesorgt, daß die Striche des einen Rasters mit denjenigen des andern stets einen genügend großen, spitzen Winkel bilden. Rechtwinkligkeit ist zu vermeiden, da sie unangenehme, grobe Gitterwirkungen ergibt.

Auf ähnliche Art können auch bei Überlagerung von drei oder mehr verschiedenen Rastern Musterungen entstehen oder aber bei geschickter Drehung der einen gegen die andern vermieden werden.

Ein Beispiel ungewollter Rastermusterung zeigt die Erdkarte «Luftdruck und Winde im Juli» der Mittelschulatlas-Ausgaben vor 1932. Man beachte dort die GrauBlau-Bänderungen in Nordamerika, Grönland usw. - In den neueren Atlasausgaben wurden solche, dem Kartographen längst bekannte Störungen durch geeignete Rasterdrehungen vermieden:

\section{c) Kombinierte Gravur oder Lithographie verschiedenfarbiger Elemente}

In manchen Karten, besonders oft in solchen wirtschaftsgeographischer Art, stehen viele verschiedenfarbige Signaturen dicht beisammen. Werden sie getrennt voneinander auf verschiedene Druckplatten lithographiert oder graviert, weiß also die linke Hand nicht, was die rechte tut, so sind störende Aufeinanderlagerungen nicht zu vermeiden. Bei der jüngsten Atlasumformung wurden daher zunächst alle solchen verschiedenfarbigen Eintragungen zusammen auf eine einzige Druckplatte gebracht. Auf diese Art konnten sie lagemäßig gut koordiniert werden. Dann druckte man dieses koordinierte Bild auf die verschiedenen Farbplatten um und löschte in jeder derselben das Nichtgewünschte. So wurden gegenseitige Störungen auf ein Minimum herabgedrückt. 


\section{d) Farbkonturen}

Ähnlich war das Verfahren zur Koordinierung von Farbflächen. Sämtliche Konturen aller Farbflächen wurden zunächst auf ein und dieselbe Druckplatte gebracht und dann von dieser auf die endgültigen Druckplatten gedruckt. So konnte die Lithographie der einzelnen Farbtöne auf den Druckplatten genau lagerich'ig vorgenommen werden.

In manchen Fällen empfahl es sich, die Konturen der Farben als feine Situationslinien - stehenzulassen. Man betont auf diese Art die Farbgrenzen und erleichtert dem Kartenleser das Unterscheiden ähnlicher Töne. Bei überlasteten Karten und da, wo der dargestellte Inhalt in der Natur nicht schroff, sondern stetig-kontinuierlich hinübergleitet, empfahl es sich aber manchmal, die Konturen nachträglich zu löschen.

e) Schriftabelle

Der Mittelschulatlas enthält nach Art und Größe eine Vielheit von Schriften. Verschiedene Art der Schrift deutet stets auf verschiedenartige Dinge hin, verschiedene Schriftgröße und verschiedene Stärke der Schriftzüge hingegen auf Unterschiede in der Größe, Bedeutung oder Wichtigkeit einer Sache.

Um auch in den Beschriftungen für das gesamte Kartenwerk Einheitlichkeit zu erreichen und zur Erleichterung des Zusammenspiels von Redaktor und Schriftgraveuren, wurde zu Beginn der Arbeiten ein Schriftmusterblatt graviert. Dieses enthielt alle vorkommenden Schrifttypen, Schriftgrößen, Schriftstärken, insgesamt 756 eindeutig bezeichnete Variationen.

\section{DER UMDRUCK}

Der Druck großer Auflagen erfolgt nicht von den Originalsteinen, sondern mit Hilfe umgedruckter Platten. Auf diese Art schützt man die ersteren vor Abnützung und vor eventuellem Bruch.

Nach Bereinigung der Originalplatten werden ihre Fettbilder durch Umdrucken auf die Auflagedruckplatten übertragen. Schärfe und Maßhaltigkeit solcher Umdrucke sind für die Schlußergebnisse von großer Bedeutung. Die Originalsteine entsprechen meist einzelnen Karten oder Atlasseiten, die umgedruckten Steine jedoch den Druckbogen. Das Zusammenfügen der Karten zu Druckbogen erfolgt also erst durch das Umdrucken.

\section{DER AUFLAGEDRUCK}

Die Auflagedrucke des Mittelschulatlasses erfolgten bis zum Jahre 1928 auf lithographischen Flachdruckschnellpressen, seither jedoch auf Offsetpressen. Diese letzteren arbeiten bedeutend rascher. Sie liefern schönere Karten; denn es kommen matte Papiere zur Verwendung, und die Druckfarben weisen nicht den Fettglanz des Flachdruckes auf. Da aber die Farben mittels Gummizylinder von den Druckplatten auf die Papierbogen übertragen werden, ist zur Vermeidung von Passerungenauigkeiten große Vorsicht erforderlich. Die Größe der Druckbogen wurde daher mit dem Wechsel 'der Presse von 8 auf 4 Atlasseiten herabgesetzt.

Die Farbreihenfolge ist für das Schlußergebnis nicht gleichgültig. Für den Atlasdruck hat sich folgende Reihenfolge bewährt: Situationsbraun - Flußblau — Geländeschraffenfarbe - Gelb - Hellblau - Höhenbraun - Hellrot - Dunkelrot - Grün Schwarz. Diese Reihenfolge entspricht im allgemeinen dem inhaltlichen Aufbau von den linearen Elementen über die hellen Basisflächen zu den zusätzlichen dunkeln Flächen. Die Schrift wird zuletzt schwarz eingedruckt, damit sie klar lesbar auf den übrigen Farben sitzt. Überdies ist es auf diese Art möglich, erst alle Farben für die deutschen, französischen und italienischen Auflagen gemeinsam zu drucken und dann für jede Ausgabeform die ihr entsprechende Beschriftung beizufügen. 
Die Jubiläumsausgabe 1948 wurde in 21000 Exemplaren gedruckt. Ihre Karten belegten, wie oben bemerkt, 18 vor- und rückseitig bedruckte Bogen. Jeder Bogen enthielt auf jeder Papierseite im Mittel etwa 10 Farben, wat somit zwanzigmal durch die Presse zu führen. Dies erforderte im ganzen $20 \times 18 \times 21000=7560000$ Drucke. Dazu kommen zirka 600,Bogen Druckzuschuß, also weitere $20 \times 600=12000$ Drucke. Vor Druckbeginn mußte jeder Papierbogen satiniert werden, lief also einmal leer durch die Maschine. Dies ergab für die ganze Auflage $21000 \times 18=378000$ (farblose) Drucke. Die Gesamtzahl der Drucke betrug somit. 7950000 oder rund 8 Millionen. Eine Presse leistete pro Tag, neben dem Einrichten der Platten und dem Abstimmen der Farben, etwa 9000 Drucke. Somit erforderte der Druck annähernd 900 Arbeitstage einer Maschine oder etwa 2700 Arbeitstage eines einzelnen Mannes (an einer Offsetpresse sind mit Umdrucker, Plattenschleifer usw. durchschnittlich mindestens drei Mann beschäftigt). Der Druck erfolgte vom April 1946 bis Juli 1948, wobei eine Presse ununterbrochen und eine zweite mit Unterbrüchen im Betrieb war. Pro Bogen betrug die Druckdauer zirka 8 Wochen.

Ist nun die gesamte Auflage einer Karte, z. B. derjenigen von China, gedruckt und zeigt sich darin später irgendeine Mutation oder ein Irrtum, so stellt sich dem Redaktor die Frage, ob die Berichtigung auf einer noch nicht gedruckten Karte desselben Gebietes, z. B. auf der politischen Asienkarte, berücksichtigt werden soll. Gegen die Berücksichtigung spricht der Wunsch nach inhaltlicher Übereinstimmung der Karten, dafür aber das stärkere Argument möglichster Richtigkeit oder Fehlerausschaltung. Fehler, die sich erst im Laufe des Druckes zeigten, wurden auf den noch nicht gedruckten Karten korrigiert, selbst auf die Gefahr hin, daß sich der eine oder andere Atlasbenützer dann an gewissen Inkonsequenzen stoße.

Das gesamte Druckplattenmaterial besteht, wie wir gesehen haben, aus Originalplatten und Umdruckplatten.' Da ein Teil der Auflage deutsche, ein zweiter Teil französische und ein kleiner Rest italienische Beschriftung besitzt, so waren alle Schriftplatten in dreifacher Ausführung erforderlich. Das gesamte Plattenlager besteht heute aus zirka 1400 Originalsteinen und 50 Zinkplatten (für Waldtöne und andere Zusatzelemente). Das Gewicht dieser Platten beträgt 44 Tonnen.

Die erforderliche Papiermenge umfaßt mit Einschluß der stets mitzurechnenden Ausschußexemplare zirka 380000 Bogen mit einem Totalgewicht von 18 Tonnen. Es kam hiebei zähes, hadernhaltiges Offsetpapier der Papierfabrik Biberist zur Verwendung.

Würde sich der einzelne Papierbogen zwischen erstem und letztem Farbaufdruck in den Dimensionen auch nur um Bruchteile eines Millimeters verändern, so hätte dies verheerende Störungen im Zusammenpassen der Inhaltselemente zur Folge. Die Papiere mußten daher während der ganzen Dauer des Druckes sehr sorgfältig gelagert und vor geringsten Temperatur- und Feuchtigkeitsschwankungen geschützt werden.

Auch Farbvariationen, ungenaues Einpassen der Druckplatten in die Presse usw. hätten empfindlichste Störungen des Schlußergebnisses zur Folge.

So stellen Karten infolge der außerordentlichen Dichte und Feingliedrigkeit ihres Inhaltes ganz besonders hohe Anforderungen an die Reproduktionstechnik.

Redaktor, technischer Leiter der Reproduktion und Drucker atmen erst auf, wenn nach Jahren des Bangens alle Bogen die Pressen passiert haben; sie schätzen sich glücklich, mit einem blauen Auge davonzukommen.

\section{NACHFÜHRUNG UND KORREKTUR DER KARTEN}

Karten sind nie fehlerfrei; denn sie stützen sich auf vielerlei Quellen, die ihrerseits stets auch Fehler aufweisen. Selbst wenn der Redaktor über eine Riesenorganisation zur Erfassung aller wichtigeren Mutationen der gesamten Erdoberfläche verfügte, ließen sich nie alle Zweifel beheben. Úber viele Dinge, Namen, Statistiken, Forschungs- 
ergebnisse, bestehen selbst unter Lokal- und Spezialkennern Meinungsverschiedenheiten. Überdies werden durch unvermeidliche Generalisierungen Entstellungen in die Karte getragen. Die Lösung einer mathematischen Aufgabe ist richtig oder falsch. Karten aber sind gut oder schlecht, d. h. mehr oder weniger fehlerfrei, mehr oder weniger formtreu, klar und anschaulich. Kein Redaktor kennt und sieht und erfaßt alles. Ein Atlass ist nie fertig. Längst bevor eine neue Auflage den Weg in die Schule findet, füllt sich die Kartothek des Redaktors bereits wieder mit Nachtrags- und Fehlernotizen für eine zukünftige Ausgabe.

Die Welt steht nicht still. Selbst wenn sie keine politischen Eruptionen erlitte, stünde ihr Bild nicht fest. Des Menschen Gedächtnis ist kurz; Karten aber bewahren die Erinnerung an frühere Zustände. Alte Blätter zeigen, daß Gewässer, Siedelungen, Verkehrsnetz und Bodenbedeckung des schweizerischen Mittellandes in wenigen Jahrzehnten völlig umgeformt worden sind. Ähnlich war es anderswo. Je größer der Maßstab einer Karte, je reicher und differenzierter ihr Inhalt, um so rascher und umfangreicher die Mutationen.

Der Schweizerische Mittelschulatlas wurde seit seiner erstmaligen Herausgabe ungefähr alle fünf Jahre nachgeführt und neu gedruckt. Abgesehen von Programmänderungen, von neu eingefügten Karten, waren für jede neue Auflage Tausende von Mutationen nachzutragen. Art, Menge und Erhebung der Nachführungen sind je nach Kartengattung sehr verschieden. Die größte Anzahl weisen naturgemäß die Detailkarten schweizerischer Städte auf. So waren für die jüngste Ausgabe im halbseitigen Kärtchen von Zürich mehrere hundert neue Gebäudeblöcke nachzutragen (Abb. 6). Geringer ist die Zahl der Mutationen in Übersichtskarten kleiner Maßstäbe, da sich hier nur sehr einschneidende Änderungen bemerkbar machen. Anderseits aber sind sie infolge der Weiträumigkeit und großen Entfernungen der Gebiete viel schwerer festzustellen und nachzuprüfen. Die Nachführung von Detailkarten naher Gebiete verursacht daher vor allem dem Zeichner und Kartenlithographen viel Arbeit, diejenige der Úbersichtskarten entfernter Räume jedoch dem Redaktor. Sehr zahlreich sind in den Übersichtskarten stets die Größenänderungen von Ortssignaturen, die Nachträge neuer Bahnlinien und - als Folge geopolitischer Verschiebungen - die Änderungen von Städtenamen. Solche Mutationen dürfen nicht auf den ersten Anhieb, z. B. auf Grund einer Zeitungsmeldung, berücksichtigt werden, sondern erst, wenn sichere Quellen vorliegen und die Gewähr einer gewissen Konstanz der Änderung besteht. So hinkt wohl jeder Atlas in einigen Eintragungen den Tatsachen um Jahre nach.

Auch der Inhalt der Spezialkarten steht nicht fest. Hier sind es zum geringsten Teil tatsächliche .Veränderungen, sondern Fortschritte der Forschung, die zu Mutationen und Neuzeichnungen führen.

Die Durchsicht der Karten erfolgt nach drei wesensverschiedenen Richtungen:

Einmal wird die Aufmerksamkeit auf Positions- und Formfehler von Signaturen, Namen usw. konzentriert. Eine zweite Durchsicht macht Jagd auf rein graphische Versehen, auf mangelhafte Gravur, auf ungenügendes Zusammenspiel der verschiedenen Elemente usw. Größere Probedrucke mit feinmaschiger Gliederung enthalten oft, trotz sorgfältiger lithographischer Ausführung, Hunderte solcher Fehler. Eine dritte Durchsicht geht aufs Ganze; man beurteilt die Bildwirkung, die Farben usw. und kontrolliert, ob Wichtiges gegenüber Unwesentlichem genügend hervortritt, ob störende Úberlastungen auszumerzen sind usw.

Mutationen und Nachträge späterer Auflagen weichen in der Art ihrer Generalisierung vom ursprünglichen Charakter einer Karte oft etwas ab. Dies gilt auch für neu hinzugefügte Schriften. Damit geht eine gewisse Einheitlichkeit verloren. Lithographische Druckplatten leiden durch wiederholtes Herausschleifen und Neueintragen von Zeichnungsteilen. Durch mehrfaches Umdrucken können Striche und Raster an Schärfe und Qualität einbüßen. Bei späteren Auflagen werden auch die Druckfarben 
leider nicht immer mit derselben Sorgfalt abgewogen wie beim erstmaligen Drucken. So gibt es viele Beispiele von Karten, deren spätere Auflagen wesentlich hinter der ersten Ausgabe zurückstehen. Trotz steten Kampfes gegen solchen Zerfall kommt früher oder später der Zeitpunkt, da sich Neuerstellungen empfehlen. Nicht nur inhaltliche und methodische Neuerungen drängen dazu, sondern auch die hier genannten Erscheinungen.

\section{RÜCKBLICK UND AUSBLICK}

Es wäre verlockend, nun die einzelnen Karten und Kartengruppen der Jubiläumsausgabe auch inhaltlich zu erläutern, ähnlich, wie dies Prof. Dr. EmIr Letsch für die Ausgabe 1932 in verdienstvoller Weise besorgt hatte (Lit. Nr. 27). Solche Kommentare würden ein Lehrbuch der Geographie füllen. Es konnte sich nicht darum handeln, hier ein solches zu geben. Jeder Geographielehrer wird leicht in der Lage sein, den Entdeckerpfad des Schülers zu ebnen und den Karten die erforderlichen Ergänzungen und Erläuterungen beizufügen.

Nicht überflüssig erscheinen mir jedoch einige Bemerkungen über zukünftige Entwicklungen des Atlasses.

Kein Atlas ist vollkommen. Auch der Mittelschulatlas in seiner neuen Gestalt ist es nicht. Kein Atlas ist von langer Dauer; denn das Weltbild ändert sich in rasendem Lauf. Ziele und Methoden des Unterrichtes, kartographische Darstellungsformen und die Technik der Reproduktion wandeln sich und drängen zu Umgestaltungen. Würde ein Atlas sich selbst überlassen, nicht mehr gehegt und gepflegt und kritiklos neu gedruckt, so ginge er in kurzer Zeit zugrunde. Die Erfahrungen der letzten Jahrzehnte lehren, daß für den Mittelschulatlas mit höchstens etwa sechsjährigen Nachführungsperioden gerechnet werden darf.

Seit seiner ersten Herausgabe im Jahre 1910 erfuhr der Atlas dreimal grundlegende Umformungen. Sie drängten sich auf, weil die ältesten Ausgaben zu wenig Spezialkarten europäischer Teilgebiete und der Erdteile, vor allem zu wenig wirtschaftsgeographische Karten enthielten, weil die Ausführung der ursprünglichen Karten nicht befriedigte und weil das politische Weltbild wiederholte Veränderungen erfuhr.

Obwohl die Berechtigung dieser Atlasumformungen in ihren wesentlichen Teilen feststeht, scheint es mir, daß da und dort etwas leichtfertig am kostbaren Werk herumgeschneidert worden ist. Mehrmals wurden Änderungen des Inhaltsplanes vorgenommen, die später wieder rückgängig gemacht werden mußten. So wurden einige Reliefkarten schweizerischer Landschaften, die geologische Alpenländerkarte, die Karten von Rußland, Palästina und Westindien, einige Himmelsdarstellungen usw. gestrichen und später in ähnlicher Form wieder aufgenommen. Noch wechselvoller waren die Schicksale der geologischen Europakarte und der Erdübersicht der Verkehrssprachen. Sie wurden aufgenommen, weggelassen, wieder eingefügt und ein zweitesmal gestrichen. Die Departementskarte von Frankreich wurde vergrößert und später wieder verkleinert. Mit der politischen Karte von Afrika ging es umgekehrt.

Solches Hin und Her war in keiner Weise durch Änderungen der Lehrziele bedingt. Ich bin der Letzte, der sich notwendigen Erneuerungen widersetzen wollte. Doch dürfen die Nachteile von Umformungen auch nicht übersehen werden. Sie führen im Schulgebrauch zu schweren Unbequemlichkeiten, da in manchen Klassen ältere und neuere Ausgaben nebeneinander Verwendung finden. Sie verursachen große Kosten, die nur durch Staatsbeiträge oder Preiserhöhungen gedeckt werden können. Eine qualitative. Verbesserung vorhandener Karten wird erschwert, wenn Geldmittel, Ärbeitszeit und Hilfskräfte allzusehr durch Neuerstellungen beansprucht werden. Es fällt nicht schwer, in einer Kommission die Aufnahme dieser oder jener neuen Karte zu beschließen. Viel schwieriger ist es, nachher die erforderlichen Geldmittel zu beschaffen und eine gute kartographische Ausführung zu erreichen. 
Aus all diesen Gründen wird man sich jede erneute Umformung des Inhaltsplanes zweimal überlegen müssen. Es scheint mir, daß der Aufbau des Atlasses, wie ihin die Jubiläumsausgabe zeigt, in den Hauptzügen nun für längere Zeit stabil bleiben dürfte. $\mathrm{Zu}$ dieser Ansicht führen mich folgende Feststellungen und Überlegungen:

Man kann zwei grundsätzlich verschiedene Arten von Schulbüchern unterscheiden, die Lehrgänge und die Stoffsammlungen. Auf sprachlichem Gebiet zählen zu ersteren in der Regel die Grammatikbücher, zu letzteren die Sammlungen von Lesestücken. Ein guter Lehrgang enthält nichts Überflüssiges und läßt nichts Wesentliches vermissen; er ist einer bestimmten Schulstufe angepaßt und führt Lehrer und Schüler einen streng vorgezeichneten Weg. Gute Stoffsammlungen hingegen bieten eine gewisse Fülle des Besten zu freier Wahl. In manchen Fällen werden beide nebeneinander benötigt. Der Inhalt der Geographie ist so außerordentlich reich und vielgestaltig, daß er durch die Schule stets nur in enger Auswahl zu vermitteln ist. Diese Auswahl ist an der Mittelschule weitgehend dem Fachlehrer überlassen. Ein Lehrbuch der Geographie kann versuchen, einen eigentlichen Lehrgang vorzuzeichnen; doch liegt es in der Natur der Sache, daß hier Charakter und Stoffauswahl stets betont individuell sind. Es ist daher verständlich, daß eine solche "Eselsleiter», selbst wenn sie noch so gut gefügt ist, von tüchtigen Fachlehrern meist abgelehnt wird. Mehr Anklang finden geographische Stoffsammlungen in Form gutgewählter Lesestücke.

Eine notwendige Basis für jeden Geographieunterricht ist hingegen der Atlas. Er vermittelt nicht Geographie an sich; er bietet nur deren kartographische Untermauerung; er kann daher auch niemals einen Lehrgang geben wollen. Er ist seinem ganzen Wesen nàch Stoffsammlung. Als solche ist er stets einerseits zu arm und anderseits zu reich. Es wäre völlig verkehrt, den Schüler jede Karte des A.tlasses vollinhaltlich ausschöpfen zu lassen. Man wird als länderkundlichen Stoff das einemal Frankreich, ein anderes Mal Italien besonders eingehend behandeln. Niemals aber kann der Atlas für jedes zu besprechende Gebiet alle wünschbaren Karten enthalten. Stets wird der Lehrer weitere Karten, statistische Darstellungen, Diagramme, Ansichtsbilder, Profile usw. beiziehen müssen. Zudem hat der Atlas mehreren verschiedenartigen und ungleich mit Geographiestunden ausgestatteten Mittelschultypen zu dienen. Unter solchen Umständen erfüllt er seinen Zweck am besten durch eine gewisse Ausgeglichenheit des Inhaltes, durch zentrifugale Stoff- und Maßstababstufung und durch angemessene Berücksichtigung topographischer, physiogeographischer und anthropogeographischer Elemente.

In diesem Sinne ist die Jubiläumsausgabe des Mittelschulatlasses systematischer, konsequenter, abgewogener als die früheren Ausgaben. Sie wird allen wichtigeren Erdräumen und geographischen Erscheinungen gerecht. Daher meine oben geäußerte Ansicht, der Inhaltsplan erheische in nächster Zeit und im großen ganzen keine weiteren grundlegenden Umformungen. Im einzelnen freilich wird man da und dort Schlacken entfernen und Anpassungen vornehmen müssen.

Eine solche Schlacke ist das Beispiel der Dufourkarte auf Seite 3 des Atlasses, und zwar nicht, weil die amtliche Karte 1:100000 an und für sich schlecht wäre, sondern weil sie im Rahmen des Atlasses nicht befriedigend gedruckt werden kann. Man wird Siegfried- und Dufourkarte durch Beispiele der neuen staatlichen Kartenwerke ersetzen, sobald die entsprechenden Gebiete vorliegen. Diese neuen Kartenbeispiele lassen sich ohne Nachteile auf einer Atlasseite vereinigen. Damit würde der erforderliche Raum gewonnen, um die ausgeschiedene Reliefkarte der Berninagruppe und des Oberengadins wieder einzufügen. Sie zeigt das schönste Hochtal der Welt und eine einzigartige $\mathrm{Pa}$ - und Seenlandschaft. Es war dieses Blatt, das Prof. Dr. E. BRENNECKE zu begeisterten und geistvollen Betrachtungen über die Kartographie als wissenschaftliche Kunst hingerissen hat ${ }^{6}$. Gute Karten gelingen selten. Man darf daher einmal Erreichtes nicht leichthin wegwerfen.

${ }^{0}$ Im oben zitierten Vortrag. 
Ein zweites Postulat wird sich in der Kartengruppe Mitteleuropa stellen. Wir verzichteten für die Jubiläumsausgabe auf ein politisches Kärtchen von Deutschland, da die Verhältnisse der letzten Jahre völlig unabgeklärt waren. Auf die Dauer aber wird man eine halbseitige Darstellung der Ländergliederung Deutschlands nicht entbehren wollen. Der erforderliche Raum wird sich durch Streichungen auf den anschließenden Seiten 48 und 49 gewinnen lassen, da dort die eine der beiden ähnlichen Karstlandschaften genügen dürfte.

Gewisse maßstäbliche Inkonsequenzen zeigen die Karte von China und Japan 1:10000000 und die große, doppelseitige Wirtschaftskarte 1:30000000 von Asien. Erstere weicht im Maßstab von denjenigen der übrigen asiatischen Teilgebietskarten ab. Auf deren Maßstab 1:15000000 reduziert, ließe sie sich mit Einschluß der bisher fehlenden Philippinen auf $11 / 2$ Seiten unterbringen. Letztere aber könnte ohne inhaltliche Einbuße auf den Maßstab 1:40000000 oder 1:45000000 der übrigen Erdteilwirtschaftskarten reduziert werden. So ließen sich in den freiwerdenden Räumen Nebenkärtchen (Jerusalem, Peking, Tokio, Fudschijama, Mount Everest usw.) unterbringen; denn trotz großer Seitenzahl fehlen bisher Detailkärtchen aus dem asiatischen Raume.

Gelegentlich wurde angeregt, den Karten statistische Darstellungen, Blockdiagramme, Profile, ja sogar Landschaftsphotographien usw. beizufügen. Hievor muß mit Entschiedenheit gewarnt werden. Es wäre sinnlos, irgendwo als Lückenbüßer ein Diagramm oder ein Ansichtsbild einzuschalten. Wenn schon, so wären sie überall und in systematischer Auswahl zu bieten. Dies aber würde den Rahmen des Ganzen sprengen. Zudem sind statistische Zahlenwerte viel weniger stabil als Karten. Eine bescheidene Menge von Ansichtsbildern dürfte niemanden befriedigen; sie bliebe stets hinter den großen geographischen Bilderwerken zurück. Ein Hauptargument gegen solche Zugaben liegt in Verschiedenheiten reproduktionstechnischer Art. Es wäre falsch, den Atlas mit Dingen zu belasten, die rationeller durch einfarbigen Buch- oder Tiefdruck wiederzugeben sind und die auch seinem einheitlichen graphischen Stil wenig förderlich wären. Wenn schon solche Zusatzdarstellungen, dann erstrebe man sie als Anhang zum Atlas oder noch besser separat in Buchform.

Viel wesentlicher als die eine oder andere Änderung des Inhaltsplanes erscheinen mir für die nächsten zehn oder zwanzig Jahre Verbesserungen und Erneuerungen der geographischen Inhalte und der graphischen Formen bisheriger Karten. Besonders nach letzterer Richtung stehen bedeutende Fortschritte im Bereich der Möglichkeiten. In den vorangehenden Abschnitten wurden für zahlreiche Karten Verbesserungsvorschläge zur Sprache gebracht. Wir wcllen sie hier nicht wiederholen und auch vereinzelte weitere Möglichkeiten übergehen.

Grundlegende Neuerungen für die allgemeinen Länder- und Erdteilkarten wären Reliefschattierungen an Stelle der Gebirgsschraffen und blaue Gewässerlinien statt der schwarzbraunen. Hand in Hand damit ginge eine entsprechende Anpassung der Höhenfarben. Durch solche Änderungen könnten die Karten an Klarheit, Anschaulichkeit und Schönheit außerordentlich gewinnen. Zuvor aber sind Form und Erstellung von Relief karten kleiner und kleinster Maßstäbe näher abzuklären.

Weitere Entwicklungsmöglichkeiten zeichnen sich heute schon auf reproduktionstechnischem Gebiete ab. Es wird früher oder später notwendig werden, die schwer nachführbaren Lithographiesteine durch geeignetere Bildträger zu ersetzen und die Übertragung von Originalen auf Druckplatten rationeller und besser zu gestalten.

Der Schweizerische Mittelschulatlas erfreute sich stets des besonderen Interesses von Lehrern, Schülern und weiteren Kartenfreunden. Auch die Behörden des Bundes und der Kantone brachten ihm jederzeit größtes Wohlwollen entgegen. Möge dies so bleiben; denn solch freundlicher Einstellung entspringt die Kraft zu weiterer Entwicklung. Sorgen wir dafür, daß er auch in Zukunft seiner schönen Aufgabe gerecht werde und für schweizerisches Schaffen Ehre einlege. 


\section{VERZEICHNIS DER WICHTIGSTEN QUELLEN FÜR DIE ATLASUMARBEITUNG 1928-1932}

(Außer den auf Seite 300 genannten oder von einzelnen Mitarbeitern benützten Werken)

Hand- und Spezialatlanten:

ANDREES allgemeiner Handatlas. 8. Auflage. Bielefeld 1922.

Atlante internazionale del Touring Club Italiano. Milano 1928.

Baratta, M., und Visintrn, L.: Grande Atlante Geografico. Instituto Geografico de Agostini. Novarra 1927.

FreYrAGs Weltatlas. Wien 1927.

FriederichSen, M.: Methodischer Atlas zur Länderkunde von Europa. Hannover und Leipzig 1914 bis 1919.

MEYERS Geographischer Handatlas. Leipzig 1928. .

PhirIPs' Mercantile Marine Atlas. London.

Philips' New Commercial Atlas over the World. London.

PhIrIPs' New Imperial Atlas. London.

StIELERs Handatlas. Hundertjahrausgabe. Gotha 1925.

Vivien de Saint Martin et Schrader: Atlas universel de Géographie. Paris.

Schulatlanten:

HAACK, H.: Oberstufenatlas. Gotha 1913.

NiermeYer, J. F.: Bos' Schoolatlas der Gheele Aarde. Groningen-Den Haag 1922.

Slanar, H.: Atlas für Hauptschulen, Mittelschulen usw. Wien 1927.

SYDOW-WAGNER: Methodischer Schulatlas. 19. Auflage, umgearbeitet von H. HAACK und H. LAUTENSACH. Gotha 1931.

Spezialkarten:

Beyschlag, F., und Schriel, W.: Kleine geologische Karte von Europa. Berlin 1924.

Frer, R.: Karte der diluvialen Gletscher der Schweizer Alpen. Beiträge zur geologischen Karte der Schweiz. Neue Folge. Lieferung XLI. Spezialkarte Nr. 74. Bern 1912.

Maurer, J., und Lugeon, J.: Niederschlagskarte der Schweiz (in Frür, J.: Geographie der Schweiz, I. Band. St. Gallen 1930).

Bureau international de l'Union postale universelle: Carte des lignes postales aériennes. Berne 1931.

Allgemeine Karten:

Amtliche Karten verschiedener Staaten.

Stadt- und Hafenpläne.

Internationale Weltkarte $1: 1000000$.

Europe, Asia and North Africa $1: 4000000$. War Office, London.

Geographische Werke:

Abensour: Nouvelle Atlas Larousse. Paris 1924.

BusChaN, G.: Illustrierte Völkerkunde. Stuttgart 1909.

FrüH, J.: Geographie der Schweiz, I. Band. St. Gallen 1930.

GerbING, W.: Das Erdbild der Gegenwart. Leipzig 1926 und 1927.

HettNer, A.: Grundzüge der Länderkunde. Leipzig und Berlin 1923.

LAUTENSACH, H.: Allgemeine Geographie zur Einfuihrung in die Länderkunde. Gotha 1926.

Paravicini, E.: Die Bodennutzungssysteme der Schweiz. Gotha 1928.

Petermanns Geographische Mitteilungen aus Justus Perthes' Geographischer Anstalt. Gotha. Jahrgänge 1928-1931.

Philippson, A.: Europa. 2. Auflage. Leipzig 1906.

Philippson, A.: Grundzüge der allgemeinen Geographie. 1. Auflage. Leipzig.

SAPPER, K.: Allgemeine Wirtschafts- und Verkehrsgeographie. Leipzig und Berlin 1930.

SEYduItz, E. v.: Geographie. Hundertjahrausgabe. Breslau 1931.

Tabellenwerke und Jahrbücher:

Gothaer Jahrbuch für Diplomatie und Statistik. Gotha. Jahrgänge 1928-1931.

HüBNERs Geographisch-statistische Tabellen aller Länder der Erde. Wien. Ausgaben 1929-1931.

Schweizerisches Postlexikon. Bern.

Statistisches Jahrbuch der Schweiz, herausgegeben vom Eidgenössischen Statistischen Amt. Bern. Jahrgänge 1928-1931.

The World, Almanac and book of facts. New York 1929. 


\section{VERZEICHNIS DER WICHTIGSTEN QUELLEN FÜR DIE ATLASUMARBEITUNG 1945-1948}

(Außer den oben genannten oder von einzelnen Mitarbeitern benützten Quellen)

\section{Atlanten:}

Atlante fisico economico d'Italia di Giotto Dainelli. Consociazione Turistica Italiana. Milano 1939. . Atlas de France, publié par le Comité national de Géographie. Paris 1931 à 1945.

Atlas des deutschen Lebensraumes in Mitteleuropa. Im Auftrag der Preußischen Akademie der Wissenschaften herausgegeben von Norbert Krebs. Leipzig 1937.

Atlas of Finland, published by the Geographical Society of Finland. Helsinki 1925-1928.

DEBES, E.: Neuester großer Handatlas. Neu bearbeitet von Dr. HANS FisCHER. Berlin und Leipzig 1935. Grand Atlas soviétique de l'Univers. Editeur: Institut scientifique pour les publications du Grand Atlas soviétique de l'Univers. Moscou 1934.

\section{Einzelkarten:}

Amtliche Karten verschiedener Staaten.

Burky, CH.: Carte ethnique et linguistique de l'Europe centrale. Lausanne 1937.

CArol, H.: Wirtschaftsgeographische Karte der Schweiz 1 : 300000 . Bern 1946.

Carte administrative de l'Union des RSS. $1: 16000000$. Edition du Trust Fédéral Cartographique. Moscou.

Eidgenössisches Statistisches Amt: Industriekarten der Schweiz. Bern 1943.

Europe, Asia and North Africa $1: 4000000$. War Office. London.

Internationale Weltkarte $1: 1000000$.

FREY, H.: Die Industrien der Schweiz 1 : 300000. Bern 1943.

Map of India and Burma. Cartographic Section for the National Geographic Magazine. Washington 1946.

Geographische und andere Werke:

Allix, A., et Leysitz: Géographie générale. Paris 1934.

Mrchel et Wrest: La Terre I et II. Fribourg (Suisse) 1936.

Philippson, A.: Grundzüge der allgemeinen Geographie. 2. Auflage. Leipzig 1933.

Schubart, A.: Praktische Orkankunde. Berlin 1934.

Willet, H. C.: Descriptive Meteorology. New York 1944.

LEYDEN, F.: Die Volksdichte in Belgien, Luxemburg und den Niederlanden.

Petermanns Mitteilungen. Ergänzungsheft Nr. 204. Gotha 1929.

Friedensverträge 1946 für Finnland, Ungarn, Rumänien, Bulgarien und Italien.

Statut für das Territorium Triest.

Zeitschrifteriaufsätze :

Newham, E. V.: Hurricanes and tropical revolving storms. Geophysical memoirs No. 19. London 1922. Visher, S. S.: Storms of the world, Economic Geographie. Vol. 20. Nr. 4. 1944.

Zeitschriften und Jahrbücher:

Almanach de Gotha. Annuaire généalogique diplomatique et statistique. Justus Perthes. Gotha.

Annuaire statistique de la Société des Nations. Genève.

World affairs, a map review of current events. Published by Serial Maps. 38, William IV Street, London. 


\section{LITERATURVERZEICHNIS}

1 Anhang zum Reglement über die eidgenössischen Maturitätsprüfungen (vom 20. Januar 1925).

2 BeCKer, F.: Die Kunst in der Kartographie. Geographische Zeitschrift, Bd. 16, Heft 9. Leipzig 1910.

3 Burchard; A.: Der neue Sydow-Wagner, Geographischer Anzeiger, herausgegeben von H. Haack, 31. Jahrgang, 1931.

4 DäNIKER, A. U.: Geobotanische Karten. Festschrift Vermessung, Grundbuch, Karte (Schweizerische Landesausstellung in Zürich 1939). Verlag des Schweizerischen Geometervereins. Zürich 1941.

5 Deutsche Biographie, Bd. 25 (über Justus Perthes) und Bd. 36 (über Stieler).

6 Die "Kartographia Winterthur», vormals Topographische Anstalt Winterthur, J. Schlumpf. Winterthur 1906.

7 Die Schweiz im Spiegel der Landesausstellung, Bd. I. Zürich 1939.

8 ECKERT, M.: Die Kartenwissenschaft, Forschungen und Grundlagen zu einer Kartographie als Wissenschaft, 2 Bände. Berlin und Leipzig 1921 und 1925.

9 Eckert, M.: Kartographie, ihre Aufgaben und Bedeutung für die Kultur der Gegenwart. Berlin 1939.

10 GeIsLER, W.: Politik und Sprachenkarten. Zeitschrift für Geopolitik. 1926.

11 Geisler, W.: Absolute und relative Methode? Probleme der Bevölkerungs- und Wirtschaftsgeographie. Kartographische Mitteilungen 1930.

12 Gsten, H.: Die Darstellung der Bevölkerungsverhältnisse auf Karten. Geographischer Anzeiger 1934.

13 HaAck, H.: Unterstufenatlas, Oberstufenatlas (Prospekt mit Einführungstext). J. Perthes. Gotha 1913.

14 HeLd, L.: Kartograph R. Leuzinger. Jahrbuch des Schweizer Alpenclub 1895/1896.

15 Hetriner, A.: Eigenschaften und Methoden der kartographischen Darstellung. Geographische Zeitschrift, Bd. XVI, 1910.

16 Hetrner, A.: Die Geographie, ihre Geschichte, ihr Wesen und ihre Methoden. Breslau 1927.

17 IмноF, Ed.: Neuer Schweizerischer Volksschulatlas. Ein Geleit- und Einführungswort. Zürich (Art. Institut Orell Füßli) 1924.

18 IмноF, Ed.: Die Relief karte. Jahrheft 1924 der Ostschweizerischen Geographischen Commerziellen Gesellschaft. St. Gallen 1925.

19 Iмноғ, ED.: Begleitworte zum Schweizerischen Sekundarschulatlas. Jahrbuch 1935 der Sekundarlehrerkonferenz der Ostschweiz. Zürich 1935.

20 IмноF, Ed.: Das Siedlungsbild in der Karte. Mitteilungen der Geographisch-Ethnographischen Gesellschaft Zürich, Bd. XXXVII. Zürich 1937.

21 Imнof, Ed.: Prof. Dr. August Äppli, Nekrolog. Mitteilungen der Geographisch-Ethnographischen Gesellschaft Zürich, Bd. XXXVIII. Zürich 1938.

22 IмноF, ED.: Einige Bemerkungen zur Lehre der Kartenzeichnung. Die Reliefkarte. Festschrift Vermessung, Grundbuch, Karte (Schweizerische Landesausstellung in Zürich 1939). Verlag des Schweizerischen Geometervereins. Zürich 1941.

23 Kantonales Gymnasium Zürich. Programm und Lehrplan 1935. Neudruck 1940. Zürich.

24 KüNZEL, W.: Die Methode der räumlichen Gruppenbildung am Beispiel einer neuen Volksdichtekarte vom Freistaat Sachsen. Mitteilungen des Vereins der Geographen an der Universität Leipzig. X/XI. 1932.

25 LAUtensach, H.: Einige Erläuterungen zur Europakarte der Verteilung der Bevölkerung 1928 (Probekarte aus Sydow-Wagners Methodischem Schulatlas, 19. Auflage). Geographischer Anzeiger, herausgegeben von $\mathrm{H}$. Haack. 31. Jahrgang. 1930.

26 LEYDEN, F.: Die Darstellung der Volksdichte auf Karten. Geographischer Anzeiger, herausgegeben von H. Haack. 31. Jahrgang. 1930.

27 LETsCH, E.: Begleitworte zur 6. Auflage (1932) des Schweizerischen Mittelschulatlasses. Basel 1934.

28 Margerie, E. DE: L'Atlas scolaire suisse. Bulletin de la Section de Géographie du Comité des Travaux historiques et scientifiques, tome LVII. Paris 1942.

29 Paravicini, E.: Wilh. Osbahrs Karte zur Wirtschaftsgeographie der Welt und die Prinzipien der kartographischen Darstellung der Weltwirtschaft. Schweiz. Handelswissenschaftliche Zeitschrift 1926.

30 Peucker, K.: Studien am Atlante Scolastico per la Geografia Fisica e Politica di Giuseppe Pennesi. Mitteilungen der kaiserlich-königlichen Geographischen Gesellschaft in Wien. 1899-1900.

31 PREUSS, W.: Zur Darstellung von Bevölkerungsverteilung und Volksdichte. Mitteilungen des Vereins der Geographen an der Universität Leipzig. 1936.

32 PREuss, W.: Úber Bevölkerungskarten: Darstellung von Verteilung, Dichte, Entwicklung und Bewegung. Allgemeine Vermessungsnachrichten. Berlin 1937.

33 Rebsamen, H.: Zukunftsaufgaben des Geographieunterrichts unserer Mittelschulen. Geographica Helvetica, Band I. Bern 1946.

34 Sснül., W.: Úber hypsometrische Karten. Jahresbericht der Geographischen Gesellschaft von Bern. Bd. XXXVIII, 1927/1928. Bern 1929.

35 TRUNK, H.: Die Anschaulichkeit des geographischen Unterrichtes. 4. Auflage. Wien 1902.

36 Windisch, H.: Schule der Farbenphotographie. Harzburg 1939.

37 BenrmanN, W.: Statische und dynamische Kartographie. Jahrbuch der Kartographie, herausgegeben von der Deutschen Kartographischen Gesellschaft. 1. Band. Leipzig 1941. 


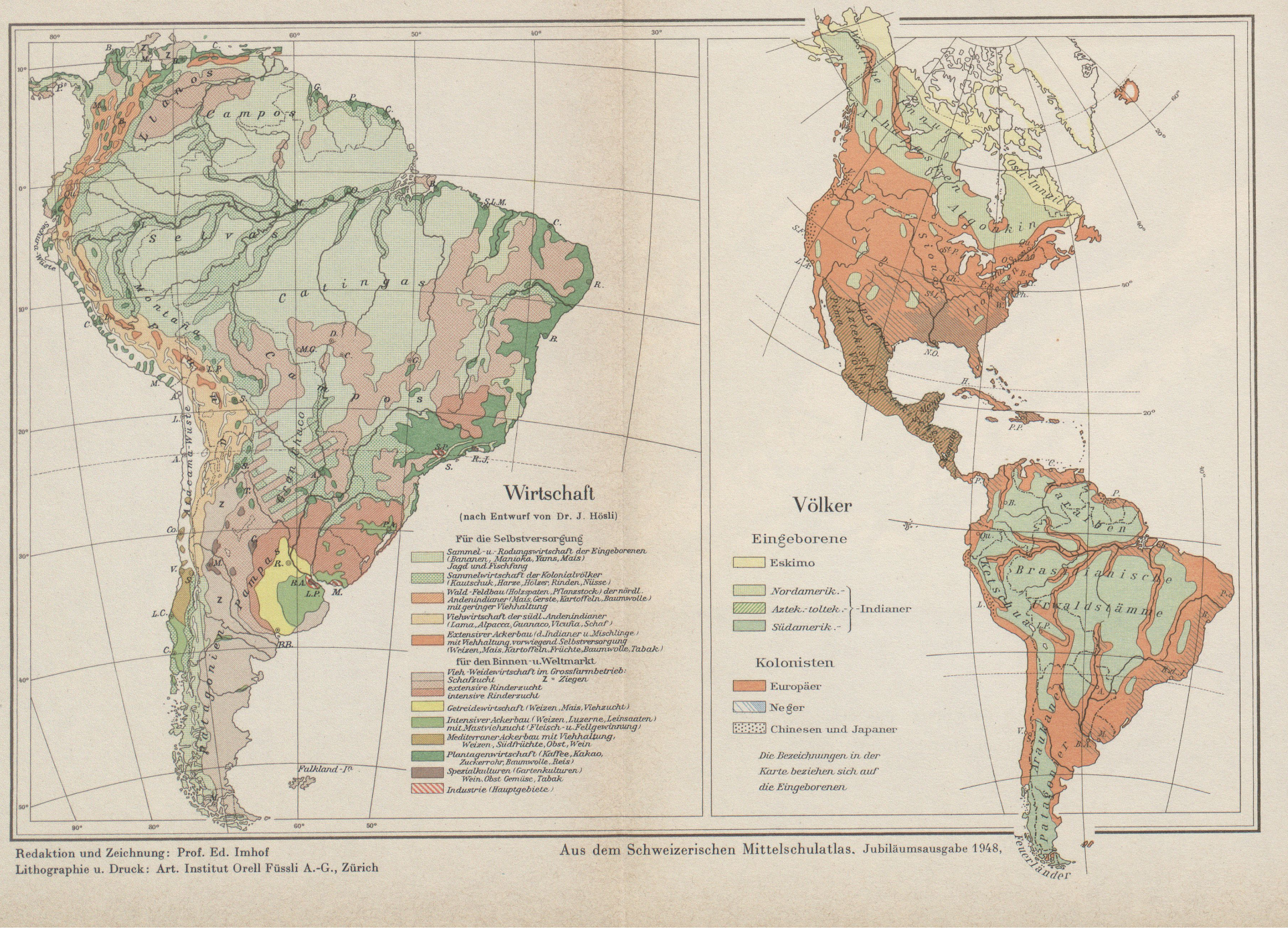




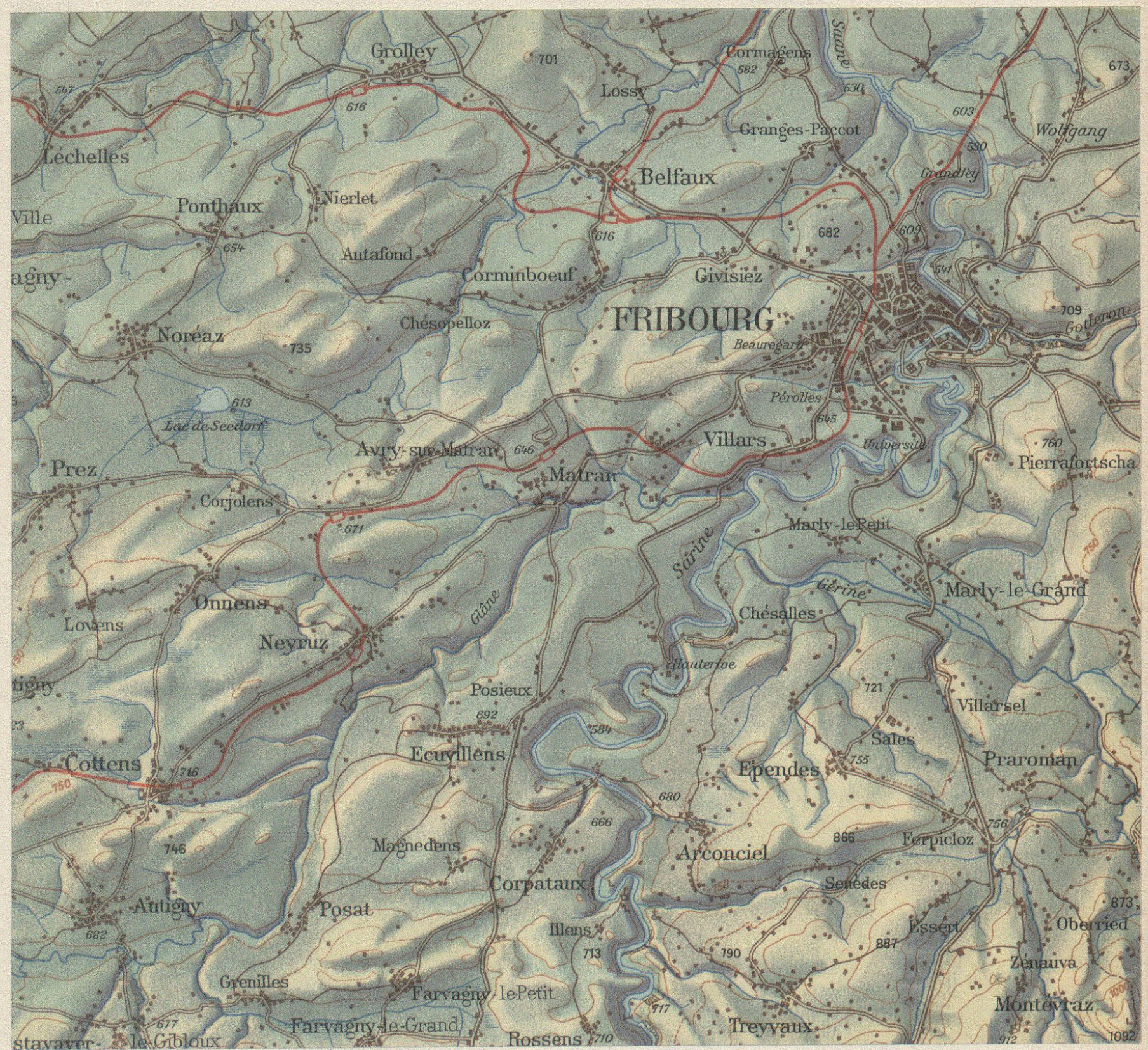

Beispiel einer Reliefkarte aus dem

Schweizerischen Mittelschulatlas

Entwurf: Prof. Ed. Imhof

Ausführung: Art. Institut Orell Füßli A.G. Zürich 


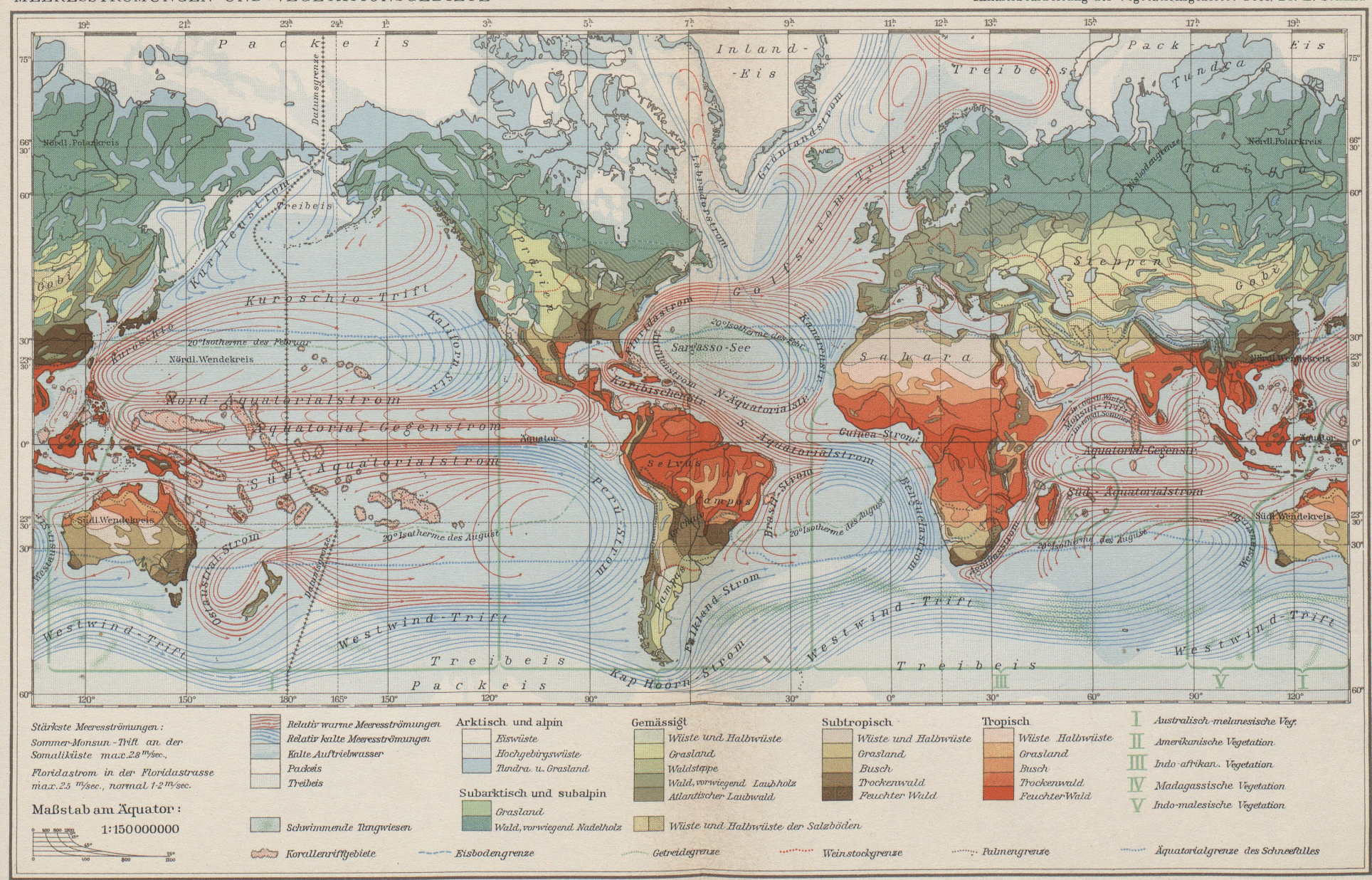




\section{INHALTSVERZEICHNIS}

Einleitung .

I. Teil: Inhaltliche Entwicklung

A. Vorläufer . . . . . . . . . . . . . . . . . . . . . . . . 295

B. Die erste Ausgabe des Mittelschulatlasses . . . . . . . . . . . . . . . . . . . . . . . 298

C. Die Entwicklungen von 1910 bis 1928 . . . . . . . . . . . . . . . . . . . . . . . 301

D. Die Umarbeitung 1928-1932 . . . . . . . . . . . . . . . . . . . . . . . . . . . . . 306

1. Arbeitsorganisation und Mitarbeiter . . . . . . . . . . . . . . 306

2. Wegleitende Postulate . . . . . . . . . . . . . . . . . . . . . . . . . . . . . . 307

3. Die wesentlichsten Änderungen des Inhaltsplanes . . . . . . . . . . . . . . . . 308

4. Änderungen und Nachführungen der Karten . . . . . . . . . . . . . . . . . . . . . . 311

5. Gesamtausmaß der Atlasumformung . . . . . . . . . . . . . . . . . . . . . . 312

6. Beurteilung . . . . . . . . . . . . . . . . . . . . . . . 312

E. Die Ausgaben 1936 und 1942 . . . . . . . . . . . . . . . . . . . . . . . . . . 313

F. Die Umformung 1945-1948 und die Jubiläumsausgabe 1948 . . . . . . . . . . . . . 314

1. Arbeitsorganisation und Mitarbeiter . . . . . . . . . . . . . . . . . . . . . . 314

2. Die wesentlichsten Inhaltsänderungen . . . . . . . . . . . . . . . . . . . . . 315

3. Gesamtausmaß der Atlasumformung . . . . . . . . . . . . . . . . . . . 320

4. Zeitbedingte Schwierigkeiten . . . . . . . . . . . . . . . . . . . . . . . . . 321

G. Beziehungen zu den neueren Volks- und Sekundarschulatlanten. . . . . . . . . . . . 322

II. Teil: Form und Erstellung des Mittelschulatlasses und seiner Karten . . . 325

Vorbemerkungen . . . . . . . . . . . . . . . . 325

A. Dispositionsfragen . . . . . . . . . . . . . . . . . . . . . . 325

1. Buch- und Kartenformate . . . . . . . . . . . . . . . . . . . . . . . 325

2. Wahl der Karten und ihrer Maßstäbe . . . . . . . . . . . . . . . . . . . . . 326

3. Kartenreihenfolge . . . . . . . . . . . . . . . . . . . . . . . . . . . . . . . . . 328

4. Allgemeine graphische Dispositionen . . . . . . . . . . . . . . . . . . . . . . 329

B. Kartographische Gestaltung . . . . . . . . . . . . . . . . . . . . . . . . . . . 331

1. Allgemeines über die Beziehungen zwischen Entwurf und Reproduktion, Koordinierung der Elemente und Generalisierung . . . . . . . . . . . . . . . . . . 331

2. Reliefkarten schweizerischer Landschaften . . . . . . . . . . . . . . . . . . . . 332

3. Geländedarstellung allgemeiner Karten ausländischer Gebiete . . . . . . . . . . . 335 a) Gebirgsschraffen; b) Farbige Höhenschichten; c) Zusammenspiel von Geländeschraffen und Höhenfarben; d) Ozeanische Tiefenstufen; e) Trennung von Land und Wasser

4. Situationszeichnung der allgemeinen Karten . . . . . . . . . . . . . . . . . . 337

5. Spezialkarten . . . . . . . . . . . . . . . . . . . . . . . . . . . . . . . . . . . . . 339

Niederschlagskarten; Karten der Temperaturen; Erdkarte der Wärmeschwankung; Volksdichtekarten; Sprachen-, Völker- und Religionskarten; politische Karten; geologische und tektonische Karten; Vegetationskarten; wirtschaftsgeographische Karten; geschichtliche Karten

6. Die Kartenbeschriftung . . . . . . . . . . . . . . . . . . . . . . . . . . . 350

7. Über künstlerisches Gestalten $\ldots$

C. Die Reproduktion der Karten . . . . . . . . . . . . . . . . . . . . . . . . 356

1. Druckplattenerstellung . . . . . . . . . . . . . . . . . . 356

2. Einige Werdegänge . . . . . . . . . . . . . . . . . . . . . . . . . . . . . . . . . . . 357

3. Druckfarben und ihre Kombinationen . . . . . . . . . . . . . . . . . . . . . 359

4. Einige weitere technische Hilfen . . . . . . . . . . . . . . . . . . . . . 363

5. Der Umdruck . . . . . . . . . . . . . . . . . . . . . . . . . . . . . . . . . . . . . 364

6. Der Auflagedruck . . . . . . . . . . . . . . . . . . . . . 364

D. Nachführung und Korrektur der Karten . . . . . . . . . . . . . . . . . 365

Rückblick und Ausblick . . . . . . . . . . . . . . . . . . . . . . . . . . . . . . . . 367

Verzeichnis der Quellen für die Atlasumarbeitung 1928-1932 . . . . . . . . . . . . . . . 370

Verzeichnis der Quellen für die Atlasumarbeitung 1945-1948 . . . . . . . . . . . . . . . 371

Literaturverzeichnis . . . . . . . . . . . . . . . . . 372 


\section{L'ATLAS SĊOLAIRE SUISSE POUR L'ENSEIGNEMENT SECONDAIRE}

Il y a 50 ans, en été 1898 , la conférence des chefs des Départements cantonaux de l'Instruction publique décidait de faire parâtre, dans les trois langues nationales, un Atlas scolaire suisse pour l'enseignement secondaire. L'Atlas parut, pour la première fois, en 1910 et fut, depuis, plusieurs fois réédité. Une édition, dite du jubilé, augmentée et améliorée, vient, récemment, de sortir de presse.

La première partie de l'article ci-dessus traite des modifications apportées successivement au contenu de l'Atlas. Ses prédécesseurs furent les atlas de Keller (1843), Zirgler (1851), WerrstenN (1872) et de SChlumpF-Götzinger (1902). C'étaient des entreprises privées qui, par suite de l'exiguité de leurs débouchés, ne pourvaient soutenir la concurrence des atlas étrangers.

Les plus anciens, atlas scolaires, y compris ceux de l'étranger, ne contenaient que des cartes générales n'indiquant; par leurs teintes, que les divisions politiques. Ce n'est qu'à la fin du siècle dernier que les atlas furent enrichis de cartes détaillées de régions importantes et caractéristiques et par de nombreuses cartes spéciales de géographie physique et humaine. A la fin du siècle passé l'excellent atlas allemand de C. Dirercke était d'un usage général dans les écoles secondaires de Suisse allemande. Mais c'était contraire à notre intérêt national.

En 1898, le prof. Dr Auguste Aeppli, maître de géographie à l'Ecole cantonale de Zurich, prit l'initiative de mettre un terme à ce fâcheux état de choses. Mais une intervention officielle était nécessaire. Le Département de l'Instruction publique du canton de Zurich présenta les propositions d'Aeppli à la Conférence des chefs de départements de l'Instruction publique, récemment constituée. Celle-ci décida d'éditer et de financer un atlas scolaire suisse pour l'enseignement secondaire.

Une commission de pédagogues et de géographes mit sur pied un plan bien conçu et bien équilibré. La rédaction fut confiée au prof. Aug. Aepplr. Mais l'exécution cartographique, par "Kartographia Winterthur" ne donna pas toute satisfaction.

Une première transformation eut lieu en 1920 à 1924. On ajouta de nombreuses cartes économiques, quelques cartes furent rénovées, etc. Mais le nouveau contenu et, avant tout, l'exécution graphique ne satisfirent pas complètement et provoquèrent, au sein de l'Association des maîtres de géographie, des critiques très vives. L'établissement de Winterthur fut liquidé en 1924 et repris par l'Institut Art. Orell Füssli à Zurich auquel la reproduction de l'atlas pour l'enseignement secondaire fut également confiée. En 1928 parut pour la première fois à Zurich une édition, d'ailleurs sans changements.

La deuxième transformation fut effectuée de 1928 à 1932. Une nouvelle commission de rédaction revisa le plan de l'ouvrage. L'établissement des cartes originales et la rédaction furent confiés au Prof. Ed. Imнor (E.P.F., Zurich), la lithographie et l'impression à l'Institut Art. Orell Füssli. Ces dispositions sont restées les mêmes. L'atlas paru en 1932 contient 260 cartes nouvelles ou redessinées, représentant 100 pages d'atlas. Les autres cartes furent aussi remaniées, de sorte que plus des trois quarts de l'ouvrage furent renouvelés. On choisit, en particulier d'autres specimens de cartes de relief de paysages suisses caractéristiques et l'on augmenta le nombre des cartes spéciales de pays européens et de parties de la terre. L'atlas fut, ainsi, mieux adapté aux exigences de l'enseignement moderne de la géographie. La présentation des cartes fut sensiblement améliorée de sorte qu'E. De Margerre (Paris) put dire "L'Atlas scolaire est le plus remarquable qui ait encòre été publié jusqu'à ce jour, non pas seulement en Suisse, mais aussi bien dans le reste de l'Europe et du monde».

Une troisième transformation eut lieu de 1945 à 1948. Les bouleversements politiques de la deuxième guerre mondiale la rendaient nécessaire. Une série de cartes spéciales de pays européens et d'outre-mer furent modifiées, les échelles trop petites de beaucoup de cartes agrandies, de nouvelles cartes régionales de Russie, de l'Asie du Sud-Ouiest et du Sud, des Indes occidentales revisées ou rénovées. Sur 266 cartes, 91 furent refaites, toutes les autres complètement revues. A remarquer, particulièrement, les nouvelles cartes économiques (par J. HösLr), de la végétation (E. ScHMID), la nouvelle carte géologique des pays alpins (J. Cadisch et K. Arbenz jun.), etc. Les noms de tous les collaborateurs et les sources consultées figurent sous des rubriques spéciales.

La seconde partie de l'article ci-dessus est consacrée à la forme et à l'établissement de l'atlas et de ses cartes.

Dans un premier chapitre sur la disposition générale, on traite du format du volume et des cartes, du choix des cartes et de leurs échelles, de leur ordre et des dispositions graphiques générales.

Un second chapitre, plus étendu, est consacré aux problèmes cartographiques.: On y traite des relations entre le plan et sa reproduction, la coordination des éléments géographiques et graphiques de la carte, de la généralisation cartographique. Puis on discute de la construction des cartes représentant le relief des types de paysages de la Suisse et des cartes de pays à plus petite échelle. Les paragraphes sur les cartes spéciales donnent, pour la première fois dans la littérature cartographique, des directives sur leur structure graphique. Des remarques suivent sur les principes règlant l'écriture des noms et l'aspect artistique des cartes.

Un troisième chapitre s'occupe de la reproduction des cartes. On y donne, entre autres, des indications nouvelles sur l'emploi des teintes et couleurs.

Dans une dernière partie figurent les adjonctions et.corrections apportées aux cartes.

L'épilog u e contient quelques suggestions de l'auteur sur despossibilités de développements ultérieurs. 


\section{L'ATLANTE SVIZZERO.PER LE SCUOLE MEDIE}

Cinquant'anni or sono, nell'estate del 1898 , la Conferenza dei Direttori cantonali della Pubblica Educazione decise la pubblicazione di un atlante svizzero per le scuole medie redatto in lingua tedesca, francese e italiana. Alla prima edizione, apparsa nel 1910, seguirono molte altre e recentemente è uscita l'edizione del cinquantennio ampliata e migliorata.

Nella prima parte del presente scritto viene esposta l'evoluzione del contenuto sostanziale dell'atlante. I suoi predecessori furono gli atlanti di KeLLER (1843), ZIEGLER (1851), WeTTSTEIN (1872) e di SCHLUMPF-GöTZINGER (1902), editi da istituzioni private, che non poterono rivaleggiare con i concorrenti esteri aventi un campo di smercio molto più vasto. Gli atlanti scolastici più vecchi, sia svizzeri, sia esteri, contenevano soltanto carte generali di paesi e di continenti con una semplice divisione politica. Appena più tardi vennero aggiunte carte generali fisiche; verso la fine del secolo scorso gli atlanti furono arricchiti con cartine rappresentanti in dettaglio parti caratteristiche di paesi e con cartine speciali fisiche e antropogeografiche. All'inizio del nostro secolo, nelle scuole medie della Svizzera tedesca era generalmente in uso il ricco atlante germanico di C. DIERCKE: ma ciò era evidentemente in netta contraddizione con gli interessi nazionali.

Nel 1918 l'insegnante di geografia del Liceo cantonale di Zurigo, Prof. Dr. August Aeppli, si fece promotore di un'iniziativa tendente ad evitare questa situazione poco desiderabile nel campo dell'insegnamento. Ma una soluzione radicale sarebbe soltanto stata possibile con un appoggio delle autorità. La direzione del Dipartimento della Pubblica Educazione del Canton Zurigo fece sua l'iniziativa di AEPpli proponendola all'appena costituita Conferenza dei Direttori cantonali della Pubblica Educazione, che decise la pubblicazione e il finanziamento di un atlante svizzero per le scuole medie.

Una commissione di eminenti pedagoghi e geografi compilò in modo organico e razionale il piano di ordinamento del contenuto e la redazione fu affidata al Prof. Dr. A. AEppli. Meno soddisfacente fu invece l'attuazione cartografica della casa editrice "Kartographia Winterthur».

Nella prima revisione del 1920-1924 vennero aggiunte numerose cartine di carattere economico e sostituite alcune già esistenti. $\mathrm{Ma}$ il nuovo contenuto e l'insufficiente attuazione grafica non soddisfarono; fecero anzi nascere energiche critiche in seno all'Associazione svizzera degli insegnanti di geografica.

L'incapacità della direzione condusse al fallimento l'istituto cartografico di Winterthur nel 1924 che venne assorbito dall'Istituto Art. Orell Füsssli di Zurigo. E con ciò anche la riproduzione dell'atlante per le scuole medie passò al nuovo Istituto. Nel 1928 apparve la prima edizione stampata a Zurigo, ma il contenuto rimaneva quello delle edizioni precedenti.

La seconda revisione ebbe luogo nel periodo 1928-1932. Una nuova commissione redazionale revisò il piano del contenuto; la redazione e il disegno delle carte originali furono affidati al Prof. ED. Imноr (Scuola Politecnica Federale di Zurigo); la litografia e la stampa all'Istitu to Art. Orell Füssli: quest'ordine rimase invariato fino ad oggigiorno. L'atlante apparso nel 1932 conteneva 260 carte nuove o ridisegnate occupanti nel loro insieme 100 pagine: anche le ulteriori carte furono rielaborate così che più dei tre quarti dell'opera risultarono rinnovati. Fra l'altro la nuova scelta delle carte di rilievo dei paesaggi svizzeri e l'arricchimento delle carte speciali dei paesi e dei continenti condusse ad un maggiore adeguamento dell'atlante ai programmi scolastici vigenti; il miglioramento fu tale che E. DE MArgerie (Parigi) potè esprimere una illimitata lode definendo l'opera quale "L'atlas scolaire le plus remarquable qui ait encore été produit jusqu'à ce jour, non pas seulement en Suisse, mais aussi bien dans le reste de l'Europe et du monde».

Nel periodo 1945 a 1948 si passò ad una terza revisione, resa necessaria dagli sconvolgimenti politici della seconda guerra mondiale. In questa occasione la serie delle carte speciali dei paesi europei e dei continenti venne rielaborata in un modo più sistematico: scale troppo ridotte furono ingrandite; nuove carte regionali della Russia, dell'Asia meridionale e sud-occidentale, dell'India occidentale e molte altre carte vennero introdotte o rifatte, cosi che su di un totale di 290 carte 91 furono disegnate a nuovo e tutte le altre subirono una profonda revisione. Particolare attenzione meritano le nuove carte economiche (compilate da J. HösLI), quelle della vegetazione (E. SchmiD) e la nuova carta geologica della regione alpina (J. Cadisch e K. ARBENZ jun.). Tutti i collaboratori e le opere consultate sono elencati in particolari paragrafi. Nella seconda parte del lavoro vengono discusse la forma e la preparazione dell'atlante e delle sue carte.

Nel primo capitolo dedicato alla disposizione sono esposti alcuni criteri seguiti (il formato del libro e delle carte, la scelta delle carte e delle loro scale, la successione delle carte e le disposizioni grafiche generali). Il secondo vasto ca pi tolo è dedicato alla conformazione cartografica. Vengono trattati i seguenti argomenti: relazione tra disegno originale e riproduzione, coordinazione degli elementi geografici e grafici, la generalizzazione delle carte. Viene inoltre discussa la struttura delle carte di rilievo dei paesaggi svizzeri e di quelle dei paesi riprodotte in scale piccole e attirata l'attenzione sui numerosi rinnovamenti. Nei paragrafi riservati alle carte speciali appaiono per la prima volta nella letteratura cartografica principi stilistici inerenti alla rappresentazione grafica. Seguono osservazioni sui principi seguiti nella scrittura e nell'attuazione artistica delle carte.

Un terzo capitolo si occupa della tecnica della riprodazione e del metodo applicato nella combinazione dei colori. $\mathrm{Da}$ ultimo un corto capitolo ricorda il lavoro di correzione delle carte. E concludendo l'autore esprime la sua idea sull'e voluzione futura dell'atlante. 